\title{
West Virginia
}

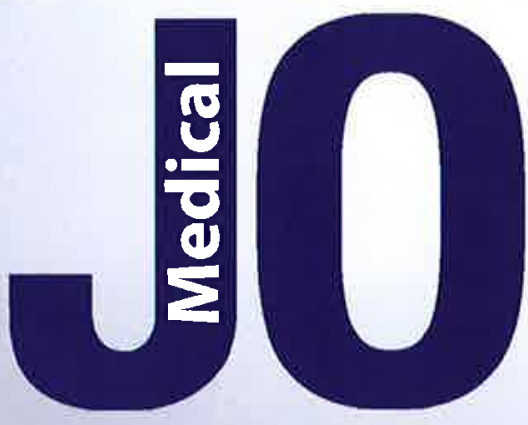

Ist Quarter

2019)

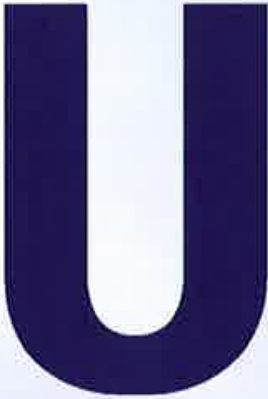

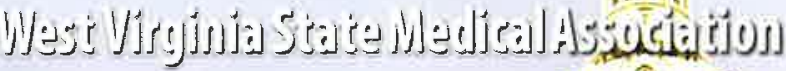

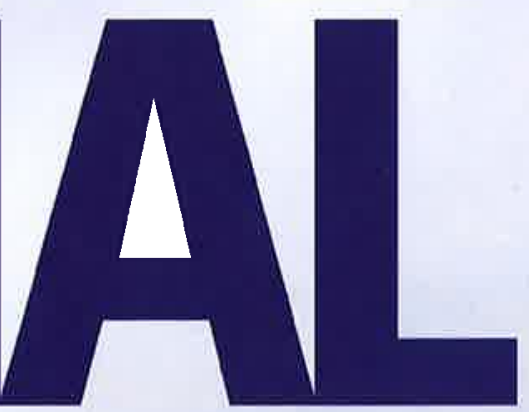

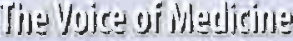
in West Virginifio

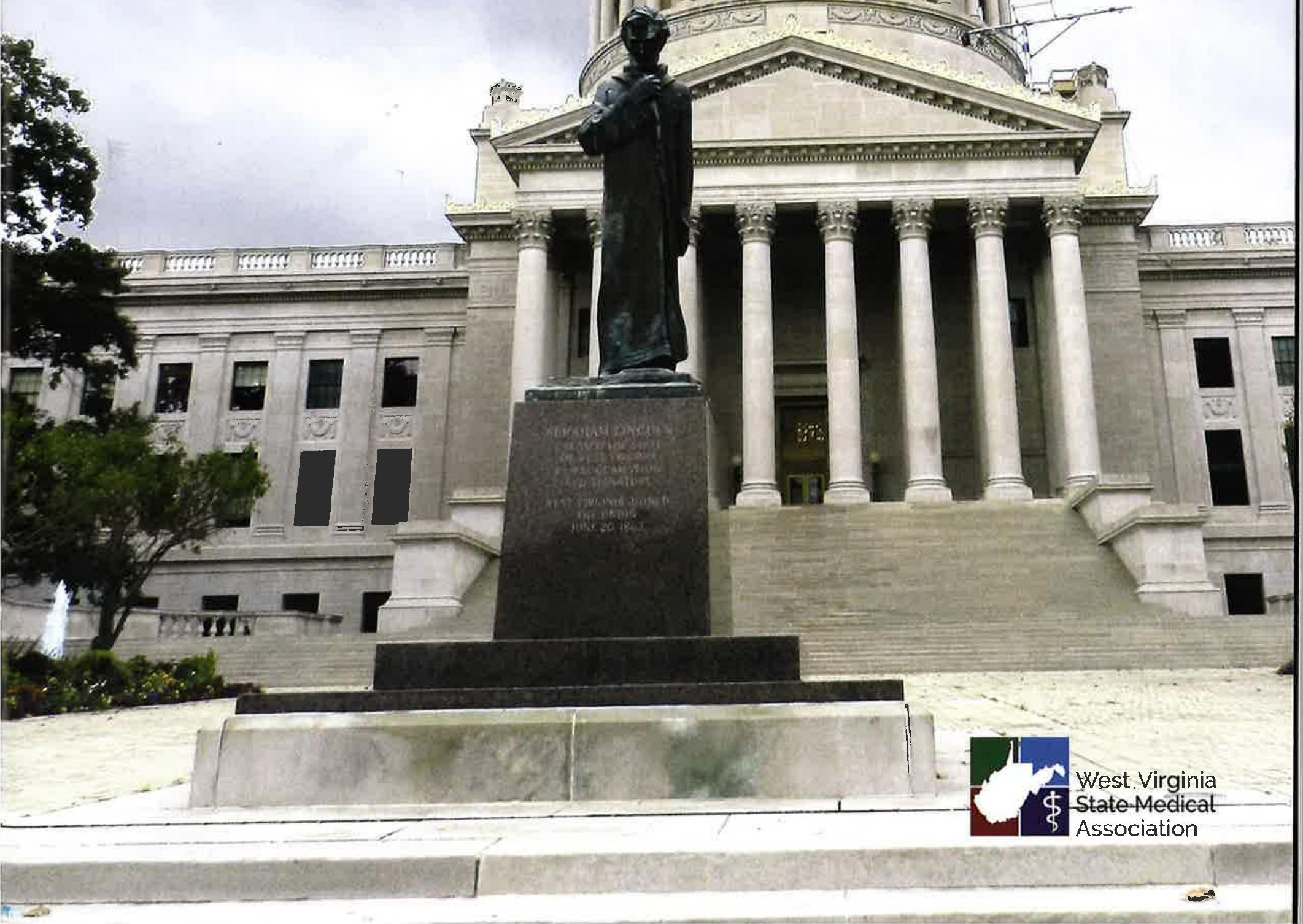




\section{WEST}

Free Statewide Prescription Assistance Program

West Virginia Rx Card can provide savings to your patients of up to $75 \%$ on prescription drugs at over 68,000 retail pharmacies.

You can help by encouraging your patients to print a free West Virginia Rx Card at: www.westvirginiarxcard.com

$$
\begin{aligned}
& \text { Customize the West Virginia } \\
& R \times \text { Card for your practice!) }
\end{aligned}
$$

\section{Pharmacy $\mid$ Prescription
Coupon}

Coupon MBR ID: Enter Year \& Time RXGRP: WVRX RxBIN: 610709

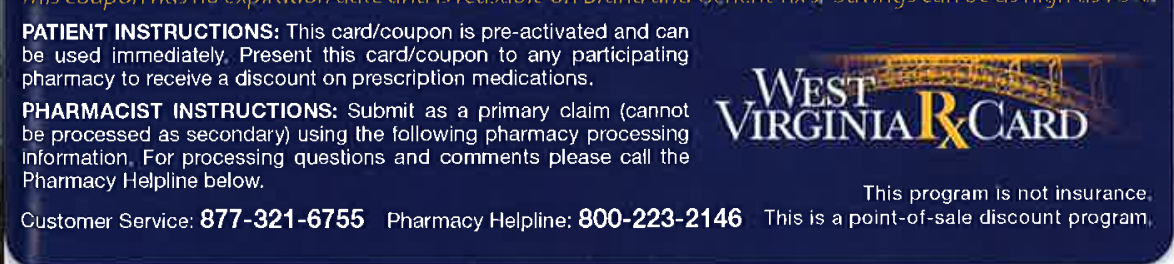

Now, in her third year of medical school, Class President Preeya Shah, is bridging her passions for patient care, science \& problem-solving with the opportunity to educate, diagnose and treat those in need.

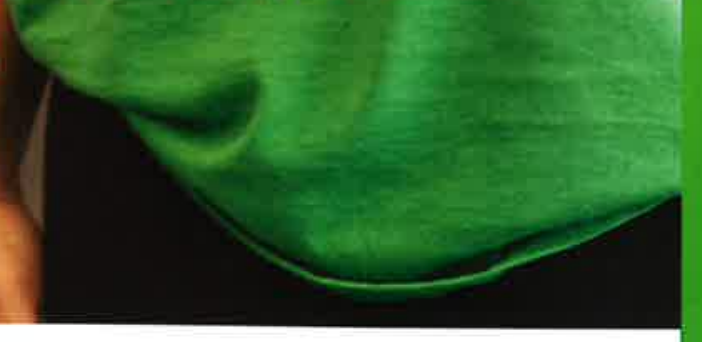

\section{jcesom.marshall.edu}

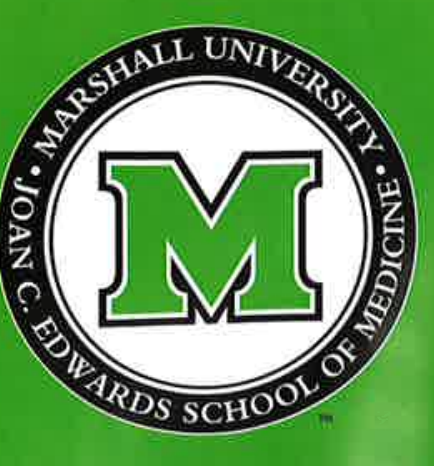

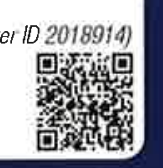
Dr. John Doe Family Health Cente

\section{Program Highlights:}

$\checkmark$ Free to all patients.

$\checkmark$ Cards are pre-activated, no sign-up forms needed.

$\checkmark$ Discounts on brand and generic medications.

$\checkmark$ Helps patients that have high deductible plans or are uninsured.

$\checkmark$ Reduces patient callbacks.

$\checkmark$ Enhances physicians ability to treat patients with drugs that may not otherwise be affordable.

Compliments of:

\section{West Virginia}

West Virginia

Association
For more information or to order your free personalized West Virginia Rx Card please contact:

Stacy Miller - smiller@westvirginiarxcard.com - 888-808-0099 


\begin{tabular}{|c|c|c|}
\hline $\begin{array}{l}\text { Hassana Barazi, MD, MBA, CCD } \\
\text { Assistant Profiessor, Radiology } \\
\text { West Virginia University School of Medicine } \\
\text { Morgantown, WV }\end{array}$ & $\begin{array}{l}\text { Sidney C. Lerfald, MD } \\
\text { Clinical Professsor of Psychiatry } \\
\text { West Virginia University School of Medicine } \\
\text { Charleston Campus, Charleston, WV }\end{array}$ & $\begin{array}{l}\text { Robert Shapiro, MD, FACOG, FPMRS } \\
\text { Assoc. Proff \& Residency Prog. Dir., Dept. of OB/GYN } \\
\text { West Virginia University School of Medicine } \\
\text { Morgantown, WV }\end{array}$ \\
\hline $\begin{array}{l}\text { Sven T. Berg, MD, MPH, FAP, CPE } \\
\text { CEO, ualiy Ingights, Inc. } \\
\text { Charleston, WV }\end{array}$ & $\begin{array}{l}\text { John Magruder, MD } \\
\text { Asst. Prof., J.W Ruby Memorial Hospital, WVU } \\
\text { Medicine Children's Pediatric Neurology Clinic, POC } \\
\text { Molraantown WW }\end{array}$ & $\begin{array}{l}\text { David Shimm, MD } \\
\text { Carl Larson Cancer Center } \\
\text { Beckley WW }\end{array}$ \\
\hline $\begin{array}{l}\text { Peter Chirco, MD } \\
\text { Diagnostic Radiologist } \\
\text { Huntington, WV }\end{array}$ & $\begin{array}{l}\text { Paul IJ McCarthy, MD } \\
\text { Dir., Cardilovascular Critical Care \& Asst. Profo. of } \\
\text { Medicine, WWU Heart \& Vascular Institute } \\
\text { Morgantown, WW }\end{array}$ & 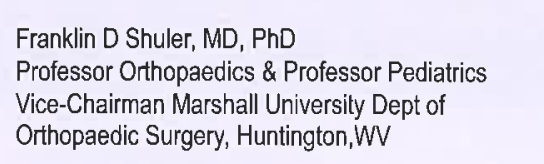 \\
\hline $\begin{array}{l}\text { Medical Director, Northwood Health System } \\
\text { Wheeling, WW }\end{array}$ & Kelly Melvin, MD, MEd & $\begin{array}{l}\text { Ralph Smith, MD } \\
\text { Dounhiptist }\end{array}$ \\
\hline $\begin{array}{l}\text { James Felsen, MD, MPH, FACPM } \\
\text { Public Cealth Specialist, Retired } \\
\text { Great Cacapon, WV }\end{array}$ & $\begin{array}{l}\text { Deppt. of PSychiatry and Behavairara Medicine } \\
\text { Joan C.Edwards School of Aedicice } \\
\text { Marshall University, Huntington, WV }\end{array}$ & $\begin{array}{l}\text { Psychiatrist } \\
\text { Charleston, WV } \\
\text { Shafic A. Sraj, MD }\end{array}$ \\
\hline $\begin{array}{l}\text { P. Bradley Hall, M.D., DABAM, DFASAM } \\
\text { Execuive ENedica Director, WMMPHP } \\
\text { Vice-President, WSSMA }\end{array}$ & $\begin{array}{l}\text { Bobby L. Miller, MD } \\
\text { Professor, Medicine-Pediatrics } \\
\text { Joan C. EEwards School of Medicine } \\
\text { Marshall University, Huntington, WW }\end{array}$ & $\begin{array}{l}\text { Asst. Profi, Orthopaedics, Orthopaedic Surgeon } \\
\text { West Virinia University School of Medicine } \\
\text { Morgantown, WV }\end{array}$ \\
\hline Mount Clare, WV & $\begin{array}{l}\text { Shirley M. Neitch, MD, FACP, AGSF } \\
\text { Maier Professor \& Chief, Section of Geriatrics }\end{array}$ & $\begin{array}{l}\text { W. Andy Stewart, MD } \\
\text { Plastic \& Reconstructive Surgery } \\
\text { Charleston, WV }\end{array}$ \\
\hline 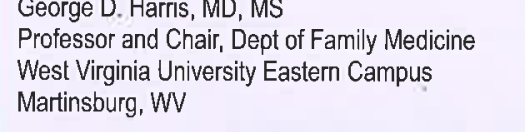 & $\begin{array}{l}\text { Joan C. Edwards School of Medicine } \\
\text { Marshall University, Huntington, WW }\end{array}$ & $\begin{array}{l}\text { Michael L. Sttely, MD } \\
\text { Associate Professor, OB/GYN, University of Otago }\end{array}$ \\
\hline $\begin{array}{l}\text { Thomas F. Hogan, MD } \\
\text { Professsor Department of Medicine } \\
\text { WUU Cancer Institute }\end{array}$ & $\begin{array}{l}\text { Profiessor of Medical Education and Pediatrics } \\
\text { West Virginia University School of Medicine } \\
\text { Morgantown, WW }\end{array}$ & $\begin{array}{l}\text { Dunedin, New Zealand } \\
\text { Errington C Thompson, MD, FACS, FCCM } \\
\text { Director of Trauma Services }\end{array}$ \\
\hline Morgantown, WV & $\begin{array}{l}\text { Louis C. Palmer, MD } \\
\text { Dermatologist, Retired } \\
\text { Bridgeport, WV }\end{array}$ & $\begin{array}{l}\text { Joan C. Edwards School of Medicine } \\
\text { Marshall Universily, Huntington, WW }\end{array}$ \\
\hline $\begin{array}{l}\text { Asst. Profi, General Internal Medicine, Geriatrics } \\
\text { Joan C. Edwards SShood of Melidice } \\
\text { Marshall University, Huntinglon, WW }\end{array}$ & $\begin{array}{l}\text { Stephen M. P.eranyy, MD } \\
\text { Professor \& Chair Dept. of Family \& }\end{array}$ & $\begin{array}{l}\text { Richard M. Vaglienti, MD, MBA } \\
\text { Director Pain Mecicie } \\
\text { Assoc. Professor Anesthesiology \& Psychiatry }\end{array}$ \\
\hline $\begin{array}{l}\text { Collin C. John, MD } \\
\text { Associat Professor, Assistant Program Director - } \\
\text { Internal MedicinelPediatrics Proge }\end{array}$ & $\begin{array}{l}\text { Community Heatth } \\
\text { Joan C.Edduards chool of Medicine } \\
\text { Marshall Universily, Huntington, WV }\end{array}$ & $\begin{array}{l}\text { WVU School of Medicine, Morgantown, WV } \\
\text { John Vargo, MD }\end{array}$ \\
\hline $\begin{array}{l}\text { West Viriginia University school of Medicine } \\
\text { Morgantown, WV }\end{array}$ & $\begin{array}{l}\text { JonDavid Pollock, MD } \\
\text { Division of Radiation nocology } \\
\text { The Schiffler Cancer Center }\end{array}$ & 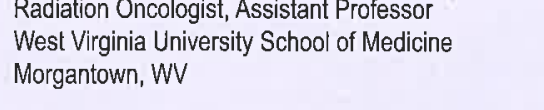 \\
\hline $\begin{array}{l}\text { Steven J Jubelire, MD } \\
\text { Clinical Prof. of Medicine, Hematology/Oncology }\end{array}$ & Wheeling, WV & David B Walson, MD, FAAN, FAHS \\
\hline $\begin{array}{l}\text { David Lee Cancer Center } \\
\text { Charleston, West Virginia }\end{array}$ & $\begin{array}{l}\text { Richard C. Rashid, MD } \\
\text { Oophalmologit, Private Practice } \\
\text { Charlston, WV }\end{array}$ & 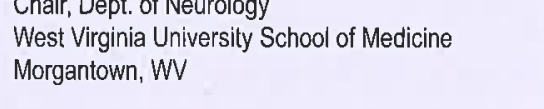 \\
\hline 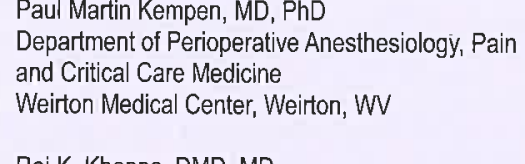 & $\begin{array}{l}\text { Michael Russell, MD } \\
\text { Asst. Irofifssor Dept. of Anesthesilogy } \\
\text { West Virginu University School of Medicine } \\
\text { Morgantlown, WV }\end{array}$ & $\begin{array}{l}\text { Paulette S. Wehner, MD } \\
\text { Professor, Dept. of Cardiology } \\
\text { Joan C. EEwards School of Medicice } \\
\text { Marshall University, Huntington, WV }\end{array}$ \\
\hline 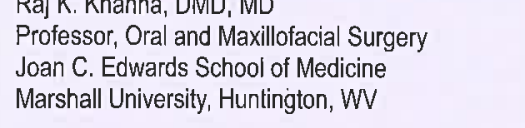 & $\begin{array}{l}\text { Charles P. Schade, MD, MPH } \\
\text { Consultant Medical Epidemiologist } \\
\text { Charleston, WV }\end{array}$ & $\begin{array}{l}\text { Sherri A. Young, DO, FAAFP } \\
\text { WVSMA, President-elect } \\
\text { Pinch, WW }\end{array}$ \\
\hline $\begin{array}{l}\text { Roberto E. Kusminsky, MD, FACS, MPH } \\
\text { Professsor, Chairperson, Dept of Surgery } \\
\text { West Virginia University School of Medicine } \\
\text { Charleston Campus, Charleston, WV }\end{array}$ & $\begin{array}{l}\text { Joseph I. Shapiro, MD } \\
\text { Vice Presicent and Dean } \\
\text { Joan C. Edwards chool of Medicine } \\
\text { Marshall University, Huntington, WV }\end{array}$ & $\begin{array}{l}\text { Stanley Zaslau, MD, MBA, FACS } \\
\text { Professor and Chairman, Dept. of Urology } \\
\text { West Virginia University School of Medicine } \\
\text { Morgantown, WV }\end{array}$ \\
\hline
\end{tabular}

\begin{tabular}{llll}
\hline Editor & Managing Editor & Executive Director & Associate Editor Emeritus \\
F. Thomas Sporck, MD, FACS & Angela L. Brown & Danny F. Scalise II, MBA, MPH, CPH & Douglas L. Jones, MD, FACP, FACE \\
Retired, Charleston, WV & & Retired, Levisbourg, WV
\end{tabular}
Douglas L. Jones, MD, FACP, F
Retired, Lewisburg, WV

contents con

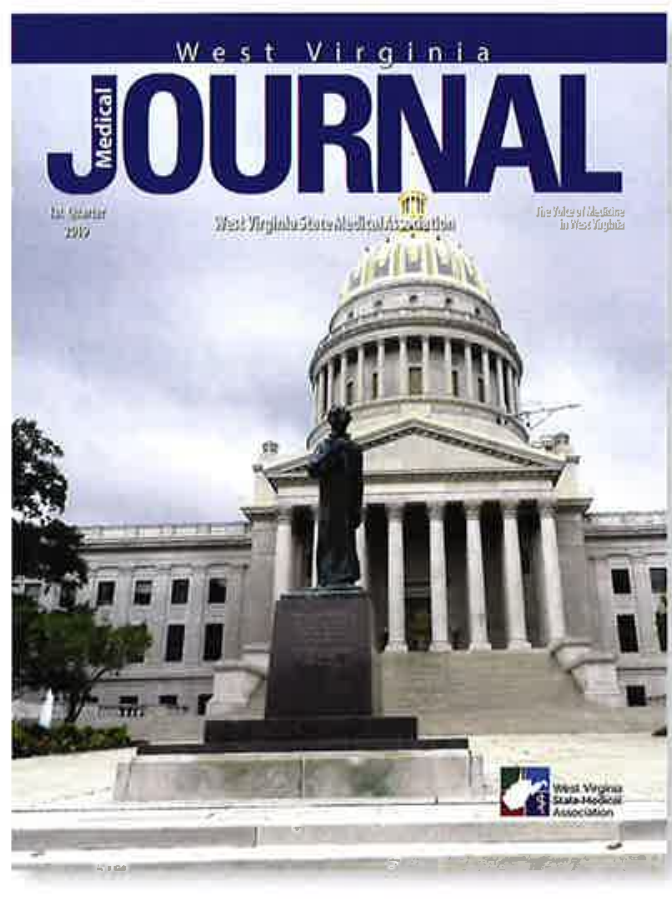

The West Virginia State Capitol south entrance featuring the "lincoln Wak s a Midnight"state

\section{Features}

President's Message

A Checklist for Physician Advocacy

2018-19 Education \& Training Schedule

Congratulations - Danny F. Scalise

AMA Interim Meeting Report

WV Mutual Insurance - Chairman's Corne

Member News - Rahul Gupta, MD

Health Law Corner

General News - HPV Vaccine Update

Marshall University Joan C. Edwards

School of Medicine News

The West Virginia Medical Journal (WVMJ) is published by the WVSMA for its members. If you wish to contribute an editorial, tor at 304-925-0342, ext. 200 or angie@wvsma.org.
to

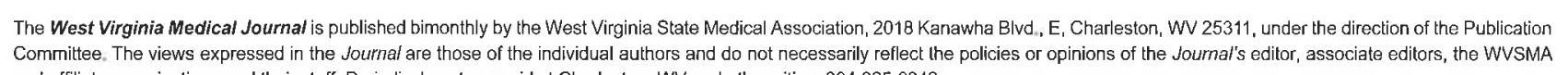




\section{President's Message}

Coy A. Flowers, MD, FACOG
WVSMA President, 2018-2019

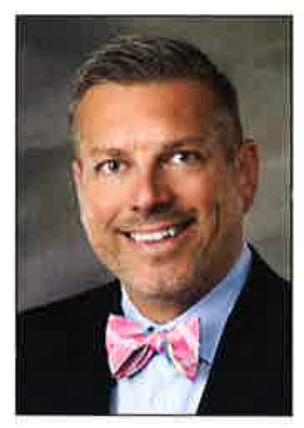

Dear Colleagues,

In November, I was honored to be part of our WVSMA's AMA Delegation at the Interim meeting t National Harbor. Literally, from sun up to sun down, 1 and others were completely immersed in the intricacies of health care policy. In elementary school, I sure knew the dangers of misplaced modifiers and dangling participles; however, I had no earthly idea that adjectives, commas, and the ordering of phrases could mean so much to the health of a nation. But, they do. And, I also learned hat those words mean nothing without advocates, standing firm behind them and educating elected officials and the public alike on why those words, grouped together into evidence-based polices, Ittimately lead to a healthier country.

Over these next few months, our WVSMA Legislative Team - our Legislative Committee, Lobbyists, and Government Affairs staff - will be in constant contact with our membership to discuss in detail our goals for the coming legislative session in Charleston. Key to the success of any of these efforts is YOU - the Physician Advocate - as

\section{Advocacy noun} ad-vo'ca'cy | l'ad-və-kə-sē

Definition of advocacy: the act or process of supporting a cause or proposal : the act or process of advocating something // He was known for his advocacy of health care rights.

you hold a power stronger than most any other individual or organization in our state. Physicians are warriors on the front lines of public health and witness the impact of government's actions - and inactions - on patients' lives.

Recently, the American Medical Association (AMA), American College of Physicians (ACP), American Academy of Family Physicians (AAFP), American College of Obstetricians \& Gynecologists (ACOG), American Psychiatric Association (APA), and American Academy of Pediatricians (AAP) released national joint statements calling for our "government to act on the public health epidemic of gun violence" and for "stronger state and federal gun laws that protect children, including a ban on assault weapons, as well as stronger backgroun checks, solutions addressing firearm trafficking, and encouraging safe firearm storage." In response, the National Rifle Association (NRA) told America's physicians to "stay in our lane" and to speak out only on those issues we might actually know something about.

Then, doctors revolted all across this country. From their workplaces in emergency rooms, clinics, and even morgues, physicians told their patient's stories, detaliling thousands of horrific and gruesome stories of how they take care of the countless numbers of gun violence victims every single day. Until now, organized medicine, like our WVSMA has done the yeomen's work for our health care advocacy efforts. Now, and for the immediate future, we must be discussing how individual physicians can step into roles as activists on issues related not only to gun violence, but also health care, obesity, poverty and mental health. For the impending 60-day 2019

legislative session, WVSMA will advocate for a continued emphasis on solving the opioid crisis, correcting inefficiencies and eliminating burdens in the prior authorization process, and working toward much stronger anti-smoking and tobacco
(17R) $\mathrm{NRA}$

Someone should tell self-important anti-gun doctors to stay in pushing for gun control. Most upsetting, however, the medical
community seems to have consulted NO ONE but nraila.orglarticles:20181 O 3,416 2:43 PM- Nor 7,201

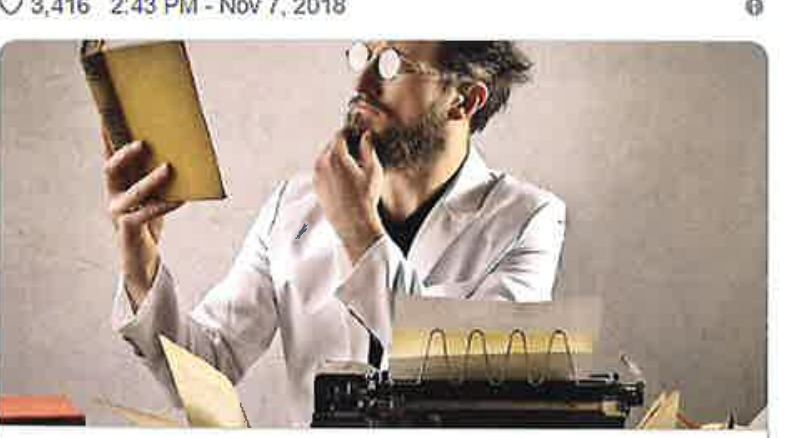
theirlane. Half of the articles in Annals of Internal Medicine are

marianne haughey

Replying to @NFA I trauma bay as I have cared for victims of gun violence for the past 25 years. THAT must be MY lane. COME INTO MY LANE. Tell one mother her child is dead with me, then we can talk. \#5top GunViolence \#toomanydead @Jacobi_EM@SBH_EM_Res

$2: 16$ AM - 9 Nov 2018

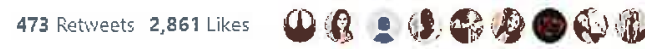

The Story Behind The Worst Measles Outbreak In The European Union

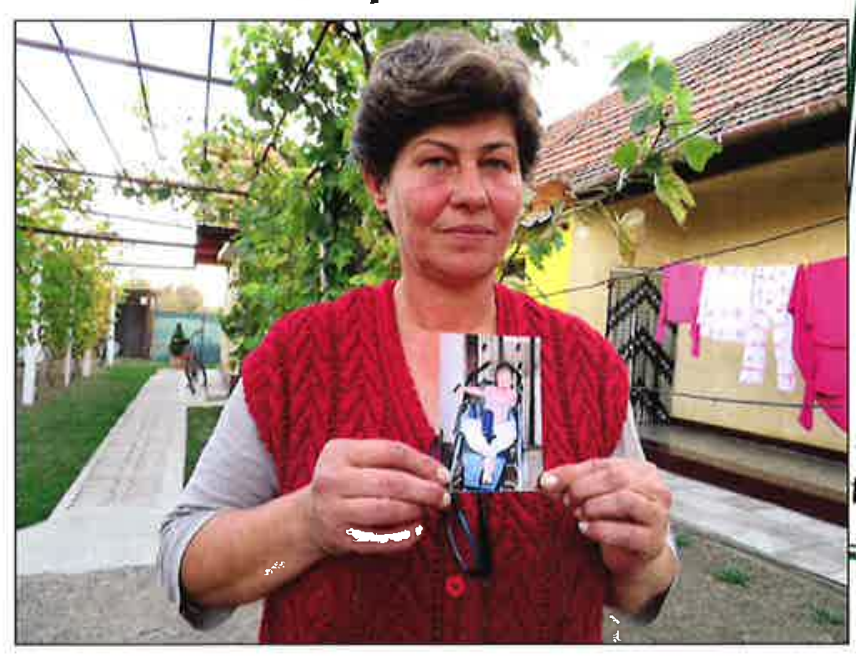

Global Spike in Measles a 'Serious Concern'

Nov. 30, 2018 --

2017, as many counties cases surged in breaks due to gaps in saw severe outage, according to vaccination coverHealth Organization data from the World Since 2000, more (WHO) and the CDC have been saved than 21 million lives zations, but cas through measles immunicreased by more reported since 2016 in report says.

The resu

ous concern, with of measles is of sericurring across regith extended outbreaks occountries that had ans, and particularly in to achieving, measlieved, or were close Swaminathan, $M D$ es elimination," Soumya rector general for proge WHO's deputy diment. Unless mograms, says in a statemore children, "We is done to vaccinate rogress in protecting losing decades of unities against this children and comely preventable diserastating, but en-

use regulations and policies. Today, however, our collective medical community - all of us who care for patients - are faced with a real and serious challenge to our core mission: protecting the public health.

Recent national headlines reflect outbreaks of vaccine-preventable diseases: measles outbreaks in New York and New Jersey and a chickenpox outbreak in North Carolina. These outbreaks have been fueled by vaccine-refusal, supported by nonmedical exemptions to school immunization requirements. In West Virginia, we do not see such headlines as ou school immunization policies protect our children from vaccine-preventable diseases. Nevertheless, despite the success of our rigorous and effective school immunization requirements that protect our students and communities from vaccinepreventable diseases, legislation is frequently introduced that would allow nonmedical exemptions to school immunization requirements and, subsequently, reduce vaccination rates.

Perennially. WVSMA has fought these threats to the overall health of West Virginia and has prevailed to maintain the policies necessary to keep our people well, but you can be certain that groups who oppose vaccines have already drafted legislation for the 2019 legislative session that would allow nonmedical exemptions to immunization requirements. Their efforts are not waning which is exactly why physicians and other medical providers across this state need to speak out. YOUR VOICE - the perspective from a HEALTH EXPERT - is necessary to inform legislators, particularly newly elected 
senators and delegates, about the strength and necessity of our school immunization our current laws.

As your President, I always want to lead by example. Over the last few days, I contacted my newly elected officials from Greenbrier County to discuss this issue. I told them that West Virginia has one of the most effective school immunization requirements in the nation, which protects our school-age children and communities from vaccine-preventable diseases, and our statutes do not allow any nonmedical (personal belief, philosophical, or religious) exempflons. As a result of our school immunization requirements, our kinderganten and adolescent inmunizalion rates have isen to among the highest in the nation and reach Healthy People 2020 goals. Speaking as a physician in their community who cares for their constituents, I asked each of them to always maintain West Virgina's inmunization requich without nonmedical exemplions. See here what each of them said. There are 134 members of he WV Ieglstaluro, and we need each and every one on the record supporting our current WV vaccination program. That's exactly why, 1, along with the entire WVSMA Lejislative Tean, encourage all of our WVSMA physician and physician assistant members to engage your representatives. No one is more qualified to educate your elected officials on this particular issue of vaccines than YOU. When should you call upon your senators and delegates? NOW! The most effective time lo meet with your legislators is before they head to Charleston for the start of 2019 legislative session on January 9th. While still at home, they have much more time to listen to their constituents' issues and, trust me, they will listen to you and are extremely appreciative for your expert perspective. At times, I have encountered some individua

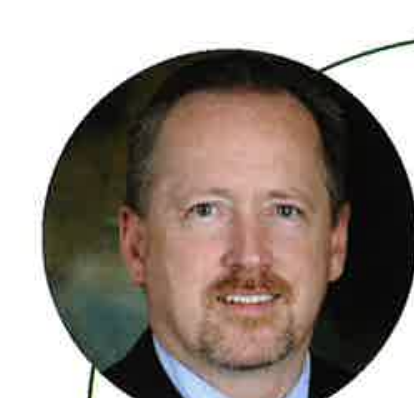

“'As a public school teache lic school teacher for nearly 20 years, student safety is our top priority. This includes the health of all students. West Virginia's ram is among the school vaccination proneed to keep it that way. The recent chickenpox outbreak at a private school in Asheville, North Carolina, highlights the importance of va Delegate Jeff Campbell

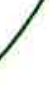

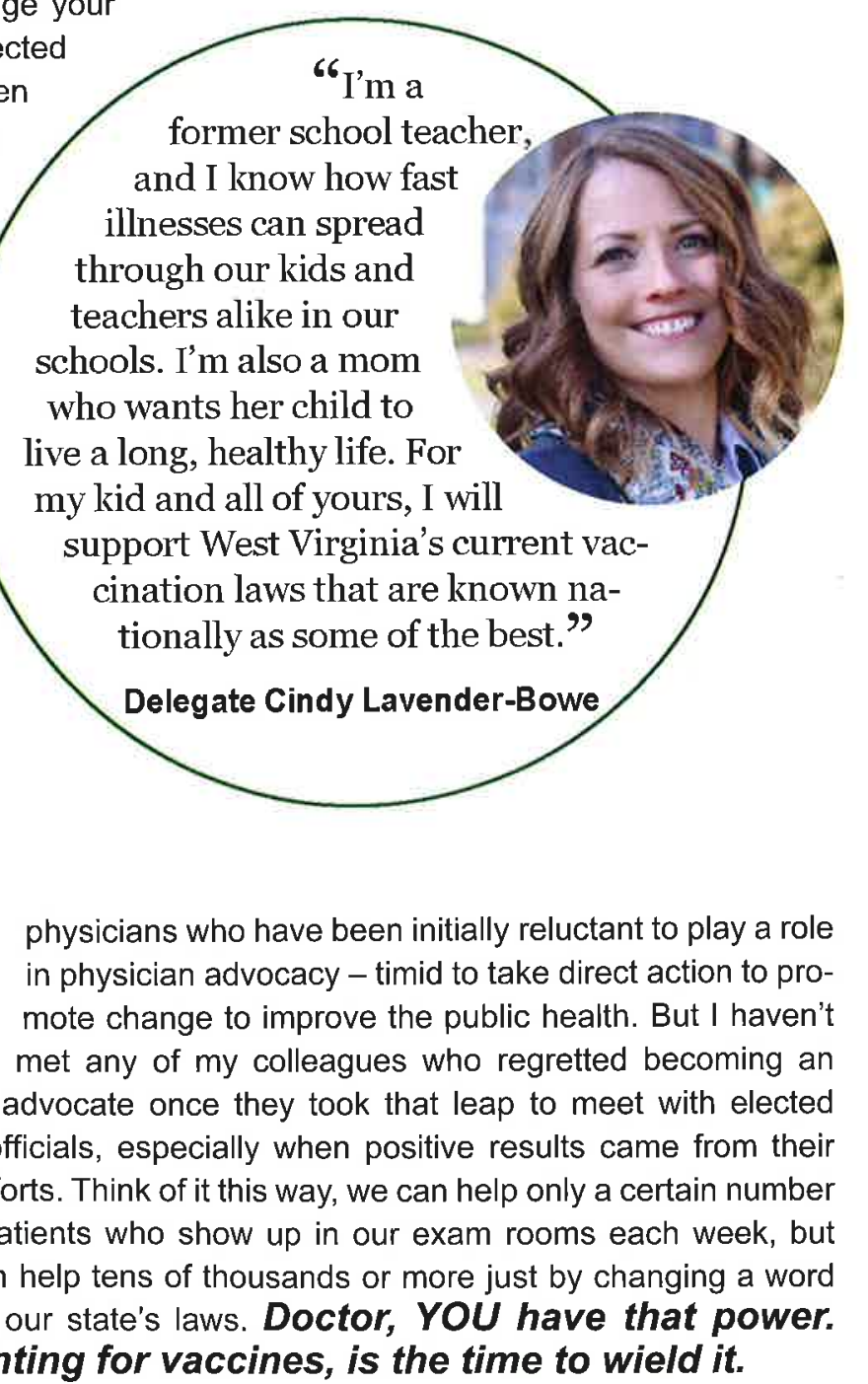
or two in our state's laws. Doctor, YOU have that power. Today, fighting for vaccines, is the time to wield it.

Senator Stephen Baldwin

\section{A Checklist for Physician Advocacy}

Be a WVSMA Member

clate receiving the counsel of medical professionals alongside that of patients when important issues like this me before the legislature."

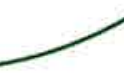

et to know

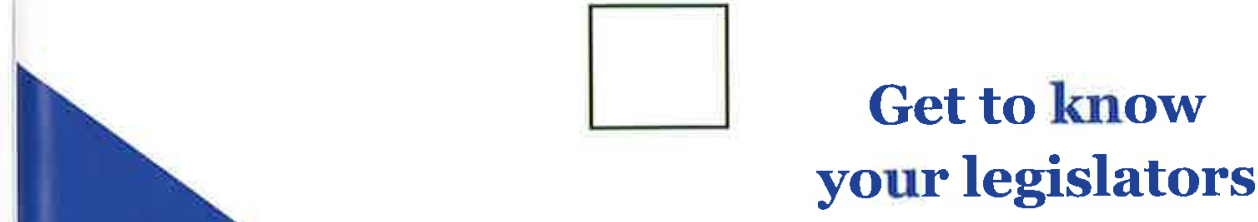

Attend WVSMA

Follow the simple SAVPI
Advocacy Events

Read

"Under the Dome"

(WvSMA e-newsletter)

Donate to WESPAC

Follow Us on Social Media

Join the WVSMA Legislative Committee Contact Danny Scalise
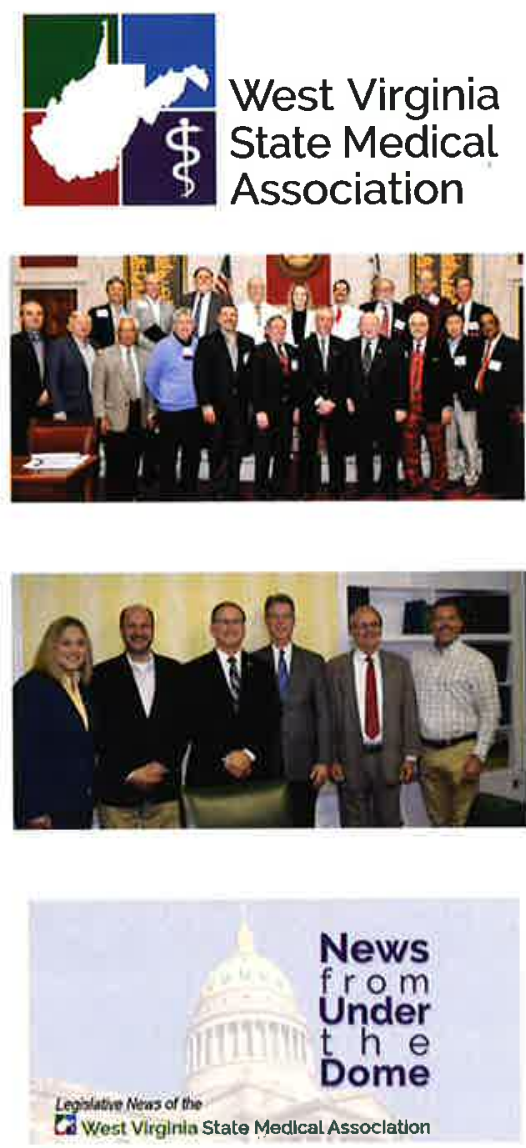

WESPAC

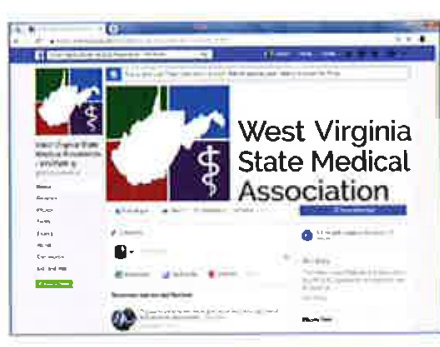

$0^{m}$

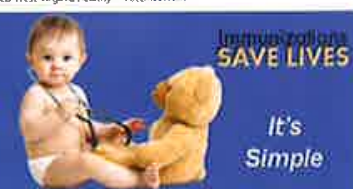




\section{West Virginia State Medical Association} $\&$

Practice Management Institute

\section{8-19 Education \& Training Schedule}

\section{Course Name}

Medicare \& Compliance Changes

CPT Code Update

Certified Medical Office Manager

Medical Front Office Skills Certificate Program

Certified Medical Office Manager-

CMOM (4 days)

Certified Medical Coder-CMC (5 Tuesdays)

E/M Chart Auditing Workshop

Transform the Front Desk Staff

Transform the Front Desk Staff

Medical Office Compliance

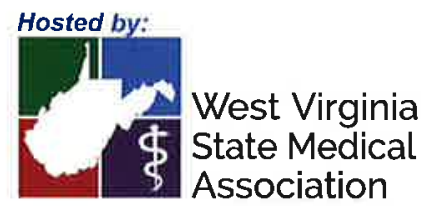

\begin{tabular}{llll} 
Location & Date & Time & Price \\
\hline Charleston, WV & $1 / 4 / 2019$ & $09: 00-12: 00$ & $\$ 199.00$ \\
Charleston, WV & $1 / 4 / 2019$ & $01: 00-04: 00$ & $\$ 199.00$ \\
Charleston, WV & $1 / 10 / 2019$ & $09: 00-04: 00$ & $\$ 999.00$ \\
Charleston, WV & $2 / 6 \& 13 / 2019$ & $09: 00-04: 00$ & $\$ 295.00$ \\
Charleston, WV & $8 / 6-7 / 2019$ & $09: 00-04: 00$ & $\$ 999.00$ \\
& $8 / 13-14 / 2019$ & & \\
Charleston, WV & $9 / 3 / 2019$ & $08: 00-04: 00$ & $\$ 1250.00$ \\
Charleston, WV & $4 / 9 / 2019$ & $09: 00-04: 00$ & $\$ 299.00$ \\
Charleston, WV & $7 / 23 / 2019$ & $09: 00-12: 00$ & $\$ 199.00$ \\
Charleston, WV & $7 / 23 / 2019$ & $01: 00-04: 00$ & $\$ 199.00$ \\
Charleston, WV & $10 / 1 / 2019$ & $09: 00-04: 00$ & $\$ 299.00$
\end{tabular}

Contact: Michael Moore; mmoore@pmimd.com; 800.259.5562 x270

If your practice, group of practices or institution is interested in scheduling any PMI course for 10 o more attendees, please contact Devon Lopez at 304-925-0342, ext. 200 or devon@wvsma.org.
PHYSICIANS NEEDED (OUTPATIENT EXAMS - NO TREATMENT)

Tri-State Occupational Medicine, Inc. (TSOM) is looking for physicians to join their group to perform disability evaluations in their WV offices. Part-time and possible full-time opportunities. No treatment is recommended or performed. No call, no weekends and no emergencies. Physicians working for us have various backgrounds and training. Training and all administrative needs including scheduling, transcription, assisting, and billing are provided. Some travel is required. Must have a current WV medical license. TSOM has an excellent reputation for providing Consultative Evaluations for numerous state disability offices. Contact: Susan Gladys 866-929-8766 / 866-712-5202 (fax)/ susang@tsom.com.

\section{Congratulations Danny Scalise, MBA, MPH, CPH}

West Virginia Executive Young Gun 2019

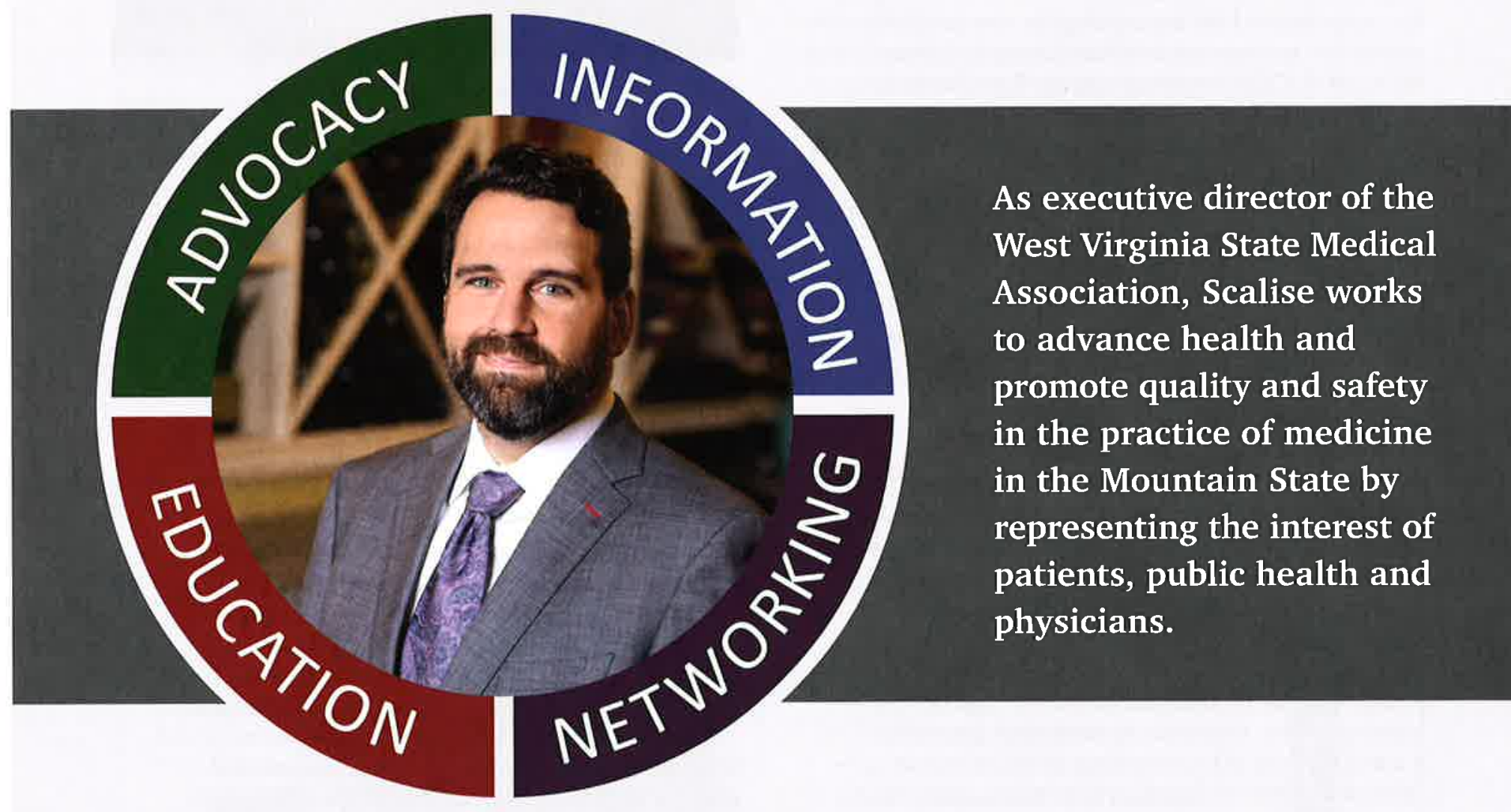

Thank you, Danny, for advocating for a happier, healthier West Virginia. Congratulations on this well-deserved honor from your friends at:

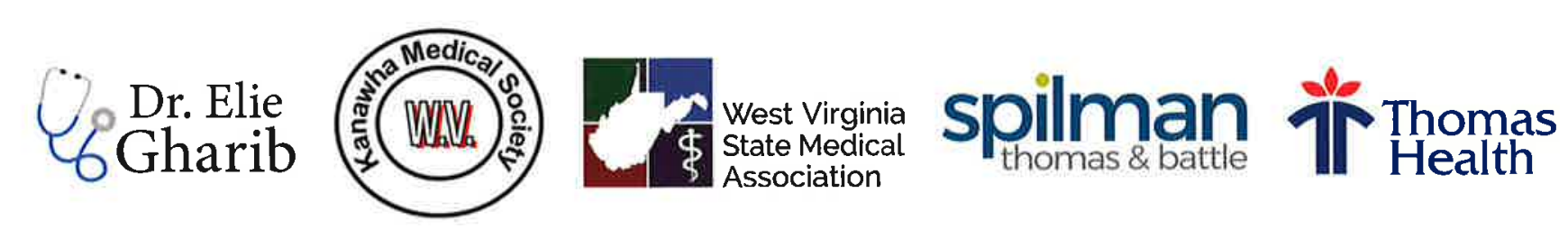


2018 Interim Meeting of the American Medical Association House of Delegates

The 2018 Interim Meeting of the American Medical Association House of Delegates and Convention Center, National Harbor, Maryland and Convention Center, National Harbor, Maryland
on November 10-13, 2018. The West Virginia State Medical Association was represented by Dr. Joseph B. Selby, delegate and chair; Dr. Hoyt Burdick, delegate; $\mathrm{Dr}$. and Dr. Coy Flowers, current president of the Wert Virginia State Medical Association. Dr. Ron Stollings, the newly elected alternate delegate, was unable to attend due to schedule conflicts. Danny F. Scalise II. MBA, MPH, CPH, the West Virginia State Medical Association Executive Director, was in attendance and coordinated the activities of the delegation. The order of business for consideration of reference committee reports included: Reference Committee on Amendments to Constitution and Bylaws.

Reference Committee (B) Legislative Advocacy Reference Committee (C) Medical Education Reference Committee (F) AMA

Governance and Finance

Reference Committee (J) Medical

Service, Praclice and Insurance

Thelth The action

recommended and subsequently adopted by the House

The issue of confronting harassment within

medicine was met head on with an emergency

resolution that reaffirms the AMA's commitment to

equity, fairness and respect for human dignity. The adoption of this resolution by the House prompted a standing ovation from the floor of the House of Delegates. This resolution strengthened measures

adopted at the Annual Meeting in 2017 and 2018. The AMA's zero-tolerance anti-harassment policy applies to employees, and all attendees of our meetings and functions. Multiple reporting options are available including an option to register complaints confidentially an external vendor online or by way of a toll-free hotline. Policy was adopted to urge the Centers for Medicare \& Medicaid Services to assist physician practices seeking to qually for and sustain medical home status

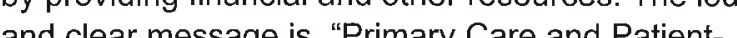
Centered Medical Home (PCMH) are bedrocks of high-quality Patient Contered Care". In addition to the directive to CMS the Council on adical Service encouraged health agencies, health systems and other

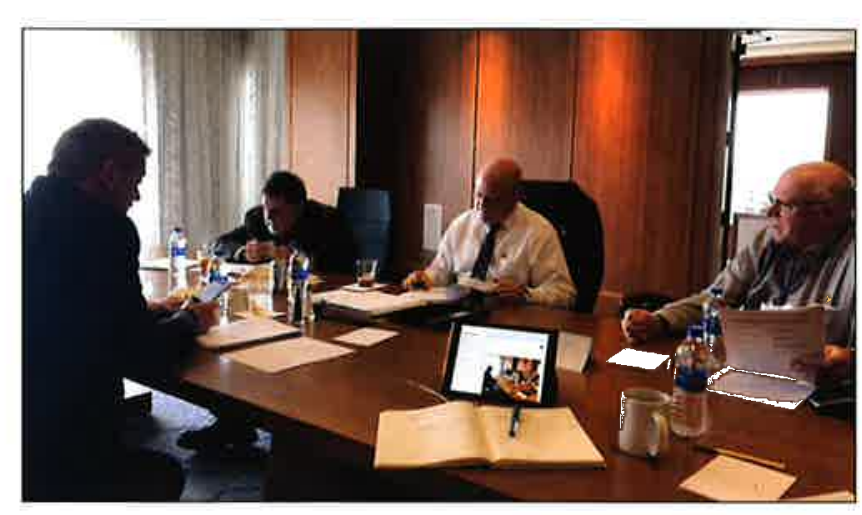

WV Delegation Caucus Meting

stakeholders to assist and support Patient-Centered Medical Home transformation and maintenance. To address the issue of rural health disparities, new policy was adopted to advocate for expansion of broadband and wireless connectivity to all rural areas of the United States. The public health crisis created by "Gun Violence" prompted new AMA policy to seek stronger background-check systens for firearm purchase. Existing policy was amended to support $a$ ban on the manufacturer, importation and sale of the 3-D printed firearms and the production and distribution of 3-D firearm dightal blueprints. AMA policy encourages cheses of prohibitindividuas, as definge by State and Fedral the Nation Criminal Background Check System (NICS). To address the high suicide rate for medica professionals the House of Delegates directed the AMA to request that the Liaison Committee on Medical Education (LCME) and the Accreditation Council for Graduate Medical Education (ACGME) collect data on medical students, residents, and fellow suicides to Identify patterns that could predict such events and ultimately save lives. The AMA House of Delegates sent a strong messag to the FDA pronouncing the urgent public health epidemic of "Vaping. Research has shown the use of e-cigarettes and vaping products is unsafe. In an effort to help stem the popularity of vaping, delegates the use AmA pollcy to "encourage the FDA" to prohibt the use of flavoring agents in tobacco products which AMA advocates against misapplication of the $\mathrm{CDC}$.

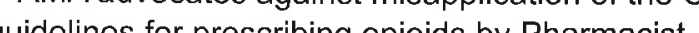
Health Insurers, Pharmacy Benefit Manners, Legislatures, Government, and Private Regulatory
Bodies in ways that prevent or limit patients' medical access to opioid analgesia. The morphine milligram equivalent threshold found in the CDC guidelines are guidelines, not absolute thresholds to signal professional discipline or loss of clinic practice. Finally, I would like to bring to the attention of Report 1 Competency of Senicr Physicians physicians are an essential part of our work force in the United States. Currently $26.6 \%$ of all physicians in the U.S. are 65 or older according to AMA data The Council on Medical Education began work on "Assuring Safe and Effective Care" for Patients by Senior/Late Career Physicians in 2015. Additional work group meetings have occurred in 2016 and 2017. The report presented before the House of Delegates this meeting came with a list of recommendations. There was a great deal of discussion in Reference Committee (C) on this issue. The Committee made deletions to the recommendations and additions, however, the House or Delegates chose to refer Arguments were made that health plans could use competency evaluations to limit participation. Research suggests that the effect of age on an individual physician's competency can be highly variable, and wide variations are found in cognitive performance with aging. Implied in the doctor-patient relationship is an ethical obligation for patient safety. Physicians

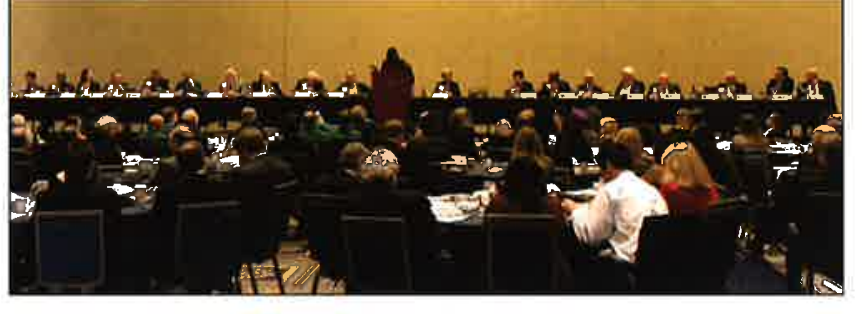

AMA President-Elect and WV native, Patrice Harris, MD speaking during the
Southeastern Delegation breakfast. Dr. Joseph Selby seated on the far right.

should retain the right to modify their practice to allow them to continue to provide safe and effective care. For WVSMA members who are also members of the AMA, you can view the Reference Committee Reports as amended and the action taken by the House of Delegates by going to the AMA websit
(www.ama-assn.org). Click American Medical Association (AMA), then menu, then House of Delegates. Next click Interim Meeting, then Business of the House of Delegates I 2018 and Reports of Reference Committee, Annotated will display. Select the individual Reference Committee to review.

Respectfully Submitted

Joseph B. Selby, MD

West Virginia State Medical Association

Delegate and Chair

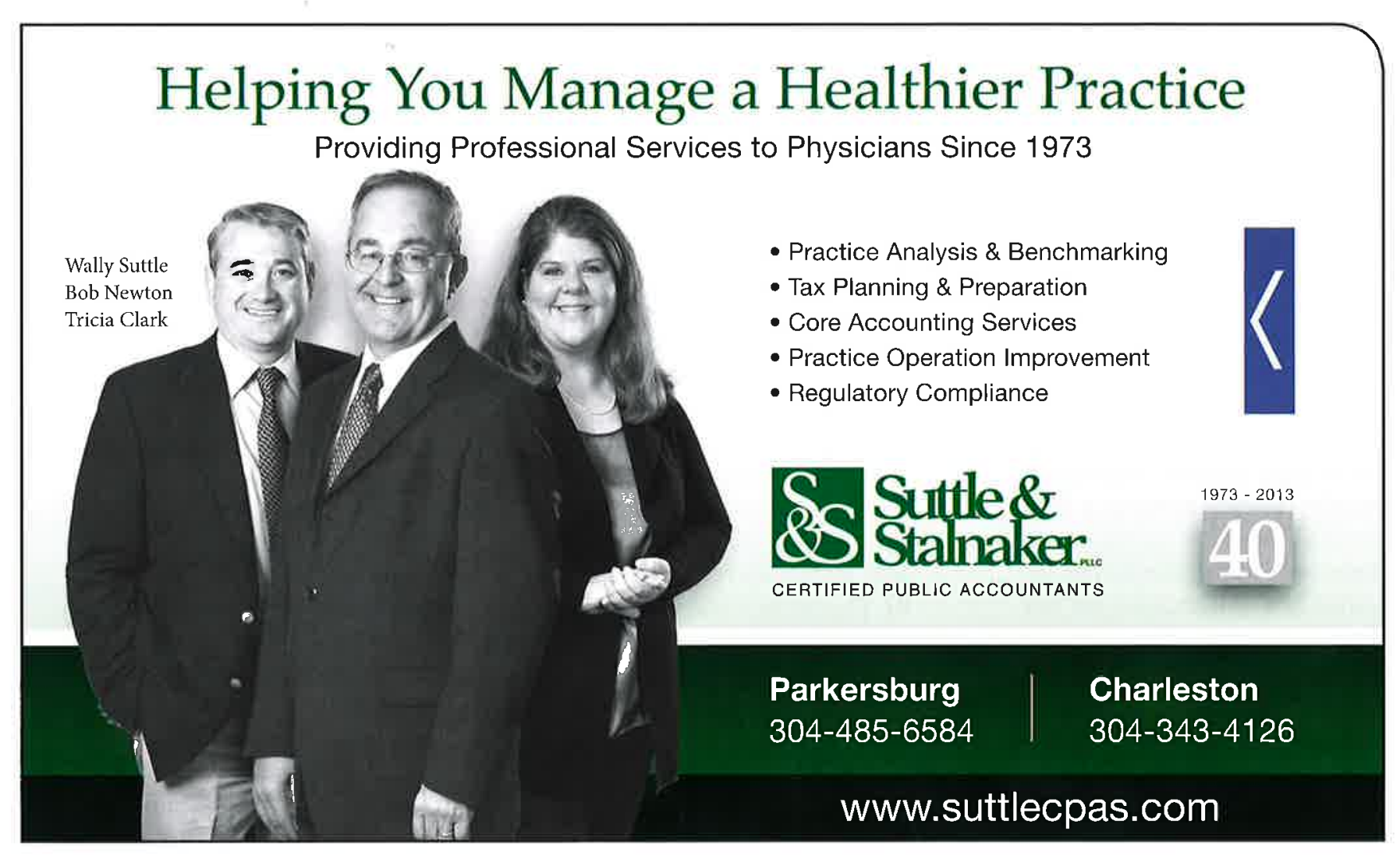


Part I. Infantile Hemangioma: Literature review of current science, classification and management

Jason Sheikh DMD, MD former Fellow Pediatric Maxillofacial Surgery,
CAMC, Charleston, W, now in practic in Port
Saint Lucie, $F$ L

Ciara Brown MD, Resident
Plastic and Reconstructive Surgery Emor Plastic and Reconstructive Surgery, Emory
Universily, Atanta, GA

Paul Kloostra DDS, MD

Attending Surgeon, Department of Surgery, CAMC

Bruce B. Horswell MD,

DDS, MS, FACS
Clinical Profossor of Surgeny, Department of
Surgen, CAMC, Charleston, WW

Corresponding Author: Dr. Bruce B. Horswell, Suite
302830 Pennsylvania Ave., Charleston, WV 25302.
Emali: bruce.horswel|@camco.org.

Grants and Financial

Support: none to declare.

Key Words: Infantile Hemangioma Vascular neoplasms; Propranolol treatment for hemangiomas

Abstract

Infantile hemangioma is the most common benign tumor in

infants. These vascular tumors

are not usually present at birth but

will begin to form within the first

12 weeks after birth, completing

growth by $9-12$ months of age, the

entering into an involutional stage

of several years. Tumors vary from

very small, non-invasive to large

tumors that cause disfigurement and
depending upon location, functional

compromise. Hemangiomas may

not entirely resolve, often times

leaving residual tumor or a lipo-
fibrotic mass with dermal scarring

Treatc mass with dermal scarring.

vreal

limited to oby ine, but not

Iimited to, observation, surgery,

laser therapy. Choice of tres, and

based on size location, and stage

of tumor growth. This review article

of tumor growth. This review article

comprehensive literature review of the current science of the biology of hemangioma formation, classification schemes, and management. Part II the management of these sometimes challenging lesions of childhood. (Part Il will be published in the 2nd Quarter edition of the WVMJ.)

\section{Introduction}

Infantile hemangioma $(\mathrm{IH})$ is the most common congenital tumo and vascular lesion of infancy, Hemangiomas are benign vascula growth followed by slowing or growh followed by slowing or involution. Hemangiomas vary size from small superficiar vary in to disfiguring tumors occupying large tissue areas and organs. These lesions are often mistaken for a lymphatic-venous malformation early in its manifestation, but clinical behavior will soon generally typify which vascular lesion is at hand Due to the possibility of rapid growth and functional impairment in infants, some require early or urgent treatment. Management has included observation pharmacological treatment with a variety of medications and surgical modalities. Currently, the standard of care for mos proliferative or threatening hemangiomas is propranolol. ${ }^{12}$ As these tumors are very common, primary care providers Who care for children will see H. Therefore it is importent to be well-vered in the diagnosis of and current managents these lesions. This paper is in two parts- Part I is a review of the current literature science, and managrent of $\mathrm{IH}$, followed by Part II which is a single institution's experience in Ten managing these vascular neoplasms in the head and neck region utilizing four management arms.

Methods

Articles from English-based last 15 years were accessed through various search engine modalities for current research, classification schemes, and management of vascular lesions and infantile hemangiomas. Review

Can" statemons (Standard or Care "stand also reviewed for pertinent finding and recommendations for treatment. These have ben summarized into the following headings.

Literature Review

\section{Pathogenesis}

Hemangioma is a tumor of the microvasculature characterized by proliferation of immature endothelial cells with angiogenic potential. Itinteang et al. and North et al. suggest a placental embolic origin during the first trimester of pregnancy due to detected presence of glucose transporter protein 1 (GLUT-1) - a marker expressed Embolic placental tissue may be distributed (cellular implantation in vascular-rich tissue beds) in similar fashion to neural crest segmental presentation and IH) with delayed proliferation in the destayed proliferatio Hemangioma formation may also result from pucto or local tissue hypoxia in the developing fetus which in turn result in ischemic drive and increased journals published over the chapters and specialty statement on placental endothelium and $\mathrm{IH}^{3}{ }^{3 \mathrm{~A}}$ cell migration (accounting for fetus from malernal and placenta influence may lead to loss of angiogenic control, accounting for the higher prevalence vascular lesions in premature infants. Increased incidence has also been noted to follow amniocentesis an chorionic villus sampling. ${ }^{3,7}$ Risk factors for IH include low birth weight, prematurity, multiple gestations, female sex (3: predilection), advanced materna age and is more common in Caucasians ${ }^{5.6}$ Most occur in the head and neck region followed Solitary lesions are Soltary lesions are generally found but approximately $20 \%$ of infants Sporadic occurren $\mathrm{f} I \mathrm{H}$ is the norm, however the ore is the reports of familial inheritance 11,12

\section{Classification}

The International Society for the Study of Vascular Anomalies recently updated the classification of vascular anomalies and groupe them into vascular tumors and vascular malformations. Vascular malformations are divided into simple malformations, combined malformations, malformations of major named vessels, and malformations associated with other anomalies based on anatomic presentation. 13,14 The groundwo by Mulliken and co-workers was helpful in developing classification schemes which serve to recognize clinical presentation, behavior and prescribed management for various malformations, including $\mathrm{IH}$. Vascular anomalies have been neoplasms (including hemangiomas) and vascular malformations (representing lymphatic-venous, capillary, arterial and mixed manifestations) of tissue-specific entities. ${ }^{13}$ Vascular tumors grow by cellular hyperplasia whereas malformations develop through defect in tissue morphogenesis. These growth mechanisms are still not fully understood. Vascular malformations are present at birth, display a slow and progressive growth timeline, appear blueviolaceous in hue; they are soft and warm to touch and often extend to and involve the underlying soft tissue or bone. Malformations generally grow with the patient unless stimulated by trauma or inflammatory processes in which case rapid growth may be detected. ${ }^{16}$ Lymphatic and venous malformations usually appear after the first month of life, they are often the same color as the surrounding skin and extend to and involve deeper tissues. Stimulation of osseous tissue may result in overgrowth phenomena of classified broadly into vascular

the involved craniofacial skeleton which is not characteristic of $\mathrm{IH}$. Further classification of $\mathrm{IH}$ is based on clinical presentation and behavior. Hemangiomas are recognized by their levels of activity and grouped into phases termed proliferative, plateau (or involuting) and involutional. Depths of tissue involvement are descriptively classified as superficial, deep and compound or mixed. It is important to distinguish between congenital hemangiomas (CH) and infantile hemangiomas Th) as their behavior will be distinct. Those hemanglomas delected in the or prest or present fully developed at bith immuno-phenotypic markers for H- glucose transporter protein-1 specific marker for end thelial cells is lacking in $\mathrm{CH}^{20.21} \mathrm{Also}$, involution begins earlier in $\mathrm{CH}$ (days to weeks after birth) with frequent uceration, periodic bleeding, and mild anemia.

\section{Clinical Behavior}

Hemangiomas are usually recognized in the first or second week of life. ${ }^{18}$ They develop with an during early infancy, attaining abou $80 \%$ of final size by $4-5$ months of age. Hemangiomas demonstrate slow but persistent growth beyond 6 months with completion of growth at around one year of

\begin{tabular}{|c|c|c|c|c|c|c|c|c|c|c|}
\hline & History & & & & & & $\begin{array}{l}\text { Exam } \\
\text { Findings }\end{array}$ & & & \\
\hline Type of Lesion & $\begin{array}{l}\text { Present } \\
\text { at Birth }\end{array}$ & $\begin{array}{l}\text { Proportional } \\
\text { Growth }\end{array}$ & $\begin{array}{l}\text { Unproportional } \\
\text { Growth }\end{array}$ & $\begin{array}{l}\text { Involution } \\
\text { Phase }\end{array}$ & $\begin{array}{l}\text { Episodes of } \\
\text { Infection }\end{array}$ & $\begin{array}{l}\text { Pulse / } \\
\text { Bruit }\end{array}$ & $\begin{array}{l}\text { Skin } \\
\text { Color }\end{array}$ & $\begin{array}{l}\text { Trans- } \\
\text { illuminate }\end{array}$ & Deflate & Refill \\
\hline Hemangioma & - & - & + & + & $\begin{array}{l}+ \\
\text { Involutional } \\
\text { Phase }\end{array}$ & - & Blue-Red & + & rapid & - \\
\hline Lymphatic & + & + & $\begin{array}{l}+ \\
\text { Episodic }\end{array}$ & - & + & - & No Color & & slow & - \\
\hline Venous & + & + & $\begin{array}{l}+ \\
\text { Episodic }\end{array}$ & - & - & - & Blue & + & slow & - \\
\hline iterial & + & & & - & - & & Blue-red. & & rapid & 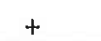 \\
\hline
\end{tabular}




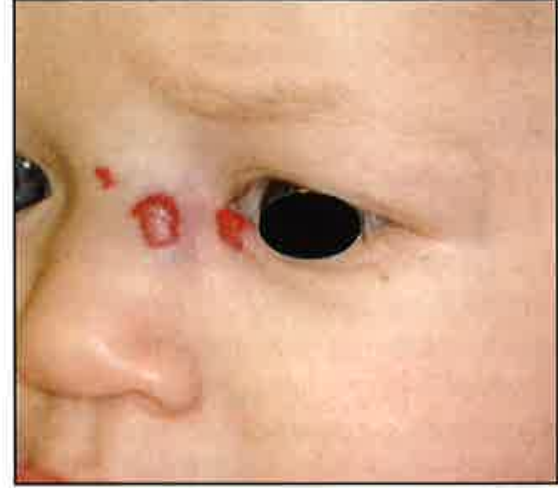

Figure 1. Superficial infantile hemangioma
with extension to deeper structures or to the with extension
conjunctiva.

age. ${ }^{22-25}$ The proliferative phase is characterized by marked endothel proliferation and hypercellularity The plateau phase represents
the cessation of growth and initial the cessation of growth and initi involution of the lesion over the resolve to some degree, and no treatme some degree, and no $20-40 \%$ of patients have a residu tumor or changes in character

or appearance of the associar

or appearance of the associated
soft tissue and skin. 924,25 Furthe soft tissue and skini. ${ }^{924,25}$ Further, adversely affect vision, respiration adversely affect vision, respiratio obstruction) and cardiac status which may require intervention prior to the involutional phase. ${ }^{6}$

\section{Clinical Features}

For reference to a summary of clinical presentation and lesion

behavior for vascular lesions,

including hemangiomas, refer to

Table 1. This guide will help the

clinician distinguish hemangiomas

from similar appearing vascula

malformations, especially

lymphatic-venous lesions.
Superficial IH typically present Superficial IH typically present
as bright red, non-compressible, elevated plaques (Figure 1) which are distinct from the bluish compressible and indistinct

margins of deeper hemangiomas

or lymphatic-venous malformation

(Figure 2). Deep lesions involve

the deep dermis and subcutaneous

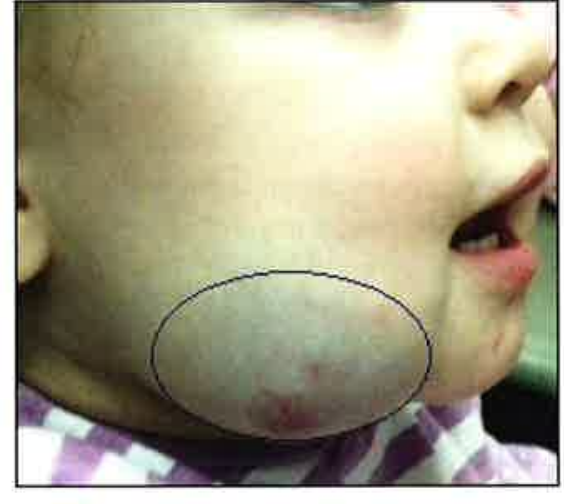

Figure 2. Mixed lymphatic-venous malformaindistinct margins (circle) and wases wanes in size, often increasing with stimulation.

tissue with or without over involvement of the overlying skin as a "mixed" or complex lesion. Patterns of distribution include localized, multifocal or segmental (dermatomal) occurrence. Larger segmental distribution in the facial region has also been associated with syndromic manifestations of vascular lesions. PHACES (Posterio fossa, Hemangiomas, Arterial abnormalities, Cardiac defects, Eye anomalies, Sternal cleft) and PELVIS syndrome (Perineal hemangioma External genitalia abnormalities, Lipomyelomeningocoele, Vesicorenal abnormalities, Imperforate anus, Skin tags) may be associated with lower body segmenta hemangiomas. ${ }^{27,28}$ These syndromic associations and those with diffuse hemangiomatosis may be at risk for high-output cardiac failure..$^{30}$ The most common complication of $\mathrm{IH}$ is ulceration of the superficial dermis due to sluggish flow and thromboses. These may become secondarily infected. Visual impairment may result from tumor growth in the periorbital region resulting in amblyopia by disruption of the visual axis or astigmatism from persistent compression of the globe ${ }^{1.16,26}$ Hemangiomas of the nasal-oral cavities present risk for airway obstruction or bleeding 27,28,
Management

Observation

Simple serial assessments of a newly presenting $\mathrm{IH}$ may be all tha is necessary. A single lesion with no functional threat or issues can be measured, photographed and periodically evaluated to determine its biologic behavior and probable clinical course. ${ }^{16,19}$ More aggressive proliferating or threatening lesions require more frequent assessment with a view to medical intervention should behavior, symptomatology or

\section{Medical}

Treatment of $\mathrm{IH}$ has included

corticosteroids, proprablon,

intereron imiqued vincristine

cyclophosphamide or laser therapy

Pharmacological therapy is targeted

at cellular proliferation. However

since many children are seen later

during or following the period of

greatest proliferation, efficacious

medical utility is minimized and

often there is little difference noted

in final lesion appearance between

treated and untreated lesions. $9.30,31$

As some of these pharmacologic

agents are associated with potentia

serious side effects including

Cushingoid appearance, growth

retardation, adrenal and immun

suppression and hypertension, a

more benign modality is desirable

especially in infants and young

children. Successful response

of $\mathrm{IH}$ to propranolol therapy was

first reported in 2008 by Léaute-

Labreze et al. while treating a

child with obstructive hypertrophic

cardiomyopathy with propranolol.

They noted significant simultaneous

since this a nasal hemangloma.

Since this first reported case and

has become the standard of

in many pedictric

Propranolol

Propranolol's mechanism of

action is theorized to involve

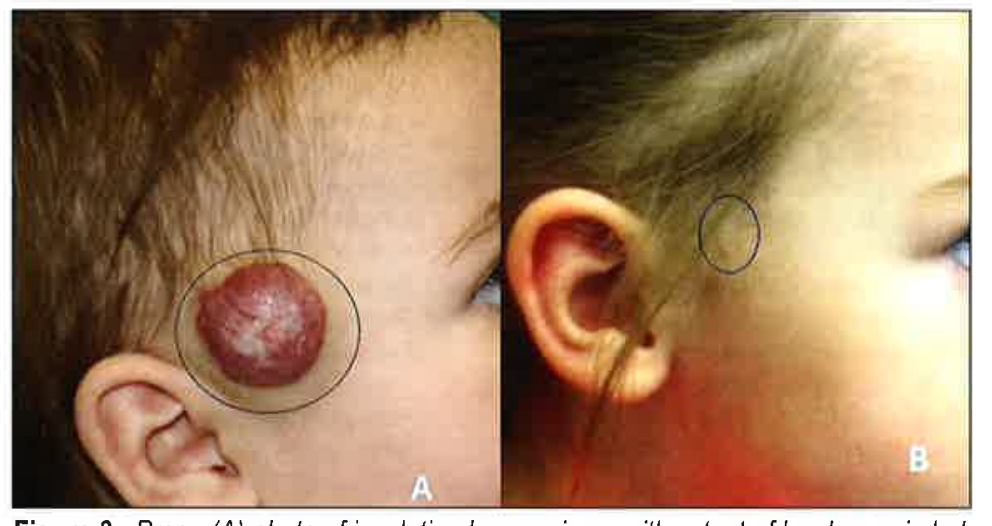

Figure 3. Preop (A) photo of involuting hemangioma with extent of border encircled.
Positop (B) scar (circle) after excision of residual hemangioma. Final review at 3 years

Postop

decreased capillary flow with an of VEGF (vascular endothelial growth factor) and FGF (fibroblast growth factor) thereby inhibiting angiogenesis. ${ }^{33,34}$ Studies have also demonstrated triggered apoptosis of capillary endothelial cells after

$\beta$ blocker administration. ${ }^{35}$

Propranolol's non-selective beta receptor antagonism may lead

to several well-known adverse

effects. ${ }^{31,36,37}$ The most commonly

observed side effects of propranolo

treatment include sleep disturbance

bronchospasm, and diarrhea or

vomiting. ${ }^{31-37}$ Decreased heart

rate and hypoglycemia are less

frequently observed and related to

immediacy after administration. ${ }^{33}$

These risks have prompted inpatie

observation in many centers

the start of therapy. $20,90,31,37,-39$
Pretreatment testing for possible

Pretreatment testing for possible
comorbidities is indicated in a select comorbidities is indicated in a select

subset of patients. A consens

statement presented in 2013

by Drolet et al. recommended

with PHACES syng for patients

anomalies) or concomitant

cardiovascular disease. ${ }^{40}$ They

recommended baseline ECG,

echocardiography and chemistry

panel. Large volume chemisty

may result in some degree of

high cardiac output Ther fore

institution of propranolefore,

should be undertaken with pretreatment monitoring and

To minimize the adverse et al. recommended that infants administration..$^{40}$ This is especialy true for premature infants and neonates less than two months corrected age. ${ }^{43}$ If oral feeds are not possible, then IV dextrose solutions should be administered coupled with blood glucose levels. Nocturnal feeding should be done if propranolol is given $3 x /$ day or just prior to sleep to prevent transient hypoglycemia which may occur $1-2$ hours after administration. ${ }^{45}$ Recent prospective studies have demonstrated the efficacy of early propranolol therapy at the onset of proliferative growth. Leaute-Labreze et al. reported on a large multcenter randomized, controlled study and found that $88 \%$ of 188 patie day of propranolol were noted to have significant improvement by five weeks of treatment compared to five $5 \%$ of patients receiving placebo 30 It was interesting to note that there was no significant difference in adverse side effects between the propranolo and placelween the Other studies have reported significant responses of $1 \mathrm{H}$ with reduced dosages of propranth $2 \mathrm{mg} / \mathrm{kg} / \mathrm{day}$ in divided doses $43,45,46$ effect of hypoglycemia, Drolet be fed soon after propranolo
Duration of propranolol therapy is ecommended for the entirety of the proliferative phase. Discontinuation of therapy must be weighed again the benefit of continued therapy with regression of the lesion versus possible rebound growth. Discontinuation of therapy before 9 months of age, presence of a deep component (mixed lesions), female gender and presence of segmental hemangiomas have bee associated with increased risk for rebound growth. After cessation the the She el noted (6\%) all lesins rebon responded to a subsequent 3 month course of propranolol 17

Surgery

Surgery for removal or reduction of IHs of the head and neck region has been relegated to those lesions which require immediate attention due to functional compromise (airway, vision) and haven't or for involuted lesions with associated soft tissue disfigurement or scar. Residual involuted tumor often resides within a mass of lipo-atrophied soft tissue with overlying dermal scar. Mulliken's extensive treatise identified thos indications for early (threatening)

notes that upwards of $40 \%$ of II leave some element of cosmetic deformity of the involved skin and soft tissue, necessitating consideration for further treatme Basically, surgical treatment may be considered when Total excision can

safely performed

Vital organs are preserved

(eye, brain, major nerves)

Surgery affords a better or

Psychosocial impact warrants timely intervention.

The aesthetic zones of the head and neck region often dictate that careful, conservative and at times, 
staged excision of residual tumor is performed in order to preserve surrounding functional soft tissue. Figure 3 demonstrates a partially involuted hemangioma (a) and
postop result (b) at final review.

Summary

Infantile hemangioma has undergone some recent changes in terms of its classification and our understanding of its biologic behavior and consequently, current management schemes. Although $\mathrm{IH}$ typically undergoes some involution, this is often incomplete or affects key functional areas - eyes, airway, oral feeding, etc, which in infancy must be more aggressively and temporally addressed during the proliferative stage. The current standard for management of such aggressive cesions is wh propranolol, although in the medical armamentarium. Current recommendations dosing of propranolol of $1-2 \mathrm{mg} / \mathrm{kg}$ day in divided doses with monitoring of blood glucose pulse and bor pressure upon commencement pressure upon commencement adverse effects appear to be uncommon with propranolol. Finally, surgery is generally reserved for residual tumor or involuted tumors with poor aesthetic soft tissue. It is recommended as a final stage intervention unless there is urgent clinical warrant due to functional compromise, in whic case early excision is necessary.

\section{References}

Drolet BA, Esterly NB, Frieden IJ,
Hemangiomas in children, NEJM. 1999; 31(3): 173-8

Kilcline C, Frieden IJ. Infantile hemangiomas: how common are they? A systematic review of
the medical literature. Pediatr Dermatol 2008;

Ifineang T. Withers A Davis P. Swee Bilnalogy of infantirs A, Davis $P$, Swee $T$.
Bingioma. Front Surg. 4. Notri PE, Waner M, Mizeracki A, Mihm MC. GLUT-1: a a newly discoverered marker for juvenile hemangiomas, Human Pathol 2000;
31(1): $11-22$.

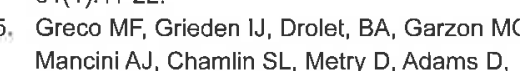

Lucky A, Wentzel MS, Hori KA, Baselga E,
McCuaig CC. Powell J. Haggstrom A Siegel D. Marel KD, Cordisco Jag gstrom A, Siegel (Hemangioma Investigator Group). Infantille hemangiomas in twins: a prospective cohort
study. Pediatr Dormatol. 2016; 33(2): 178-83. study. Pediatr Dermatol. 206; 33(2): 178

Chamlin SL, Garzo $W C$ Mancini AJ, Metry DW, Newell B, Nopper AJ, Frieden IJ. (Hemangioma Investigator Group). demographic, prenatal, and perinatal characteristics. J Pediatr 2007; 150:291-4. Burton BK, Schulz CJ, Angle B, Burd LI. An infasts born following haerionic vilitus in (CVS). Prenat Diagn 1995; 15:209-14.

. Alfrevic Z,Mujezinovic $F$, Sundberg $k$. Amniocentesis and chorionic villus sampling
for prenatal diagnosis. Cochrane Databos Syst Rev (2003).

9. Solman L, Murabit A, Gnarra M, Harper JI, Syed SB, Glover M. Propranolol for infantile haemangiomas: single centre experience of
250 cases and proposed therapeutic protoco. Arch Dis Child 2014;99: 1132-1136.

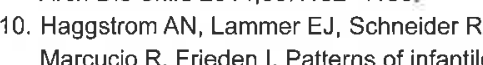
hemangiomas: new clues to pathogenesis and embryonic facial

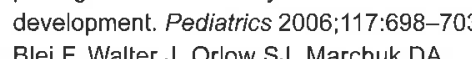
Familial segregation of hemangiomas an
vascular malformations as an autosomal dominant trait. Arch Dormatol 1998

12. Berg JN, Walter JW, Thisanagayam U, Evans heterozygosity of $5 q$ in sporadic

haemangiomas: are somatic mutations
involved in haemangioma formation? Pathol 2001;54:249-52

13. Nosher JL, Murillo PG, Liszewski M, Gendel $V$, Gribbin C. Vascular anomalies: a picton review of nomenclature, diagnosis and
treatment. World $J$ Radiol, 2014:28:677-692. 14. Wassef $M$, Blei F, Adams D, Alomar A, Baselga E, Berenstein A, Burrows P, Frieden 1, Garzon $M$, Lopez-Cutierrez J, Lord D,
Mitchel S, Powell J J Prendivile J, Vikkula Vascular anomalies classifications: recommendations form the international society for the study of vascular ano
Pediatrics 2015 Jun: 2014-3673.

15. Mulliken and Glowack; Marler JJ, Mulliken JE Vascular anomalies: Classification, diagnosis
and natural history. Facial Plast Surg Clin No Sun Y, Ma L., "Clinica characteristics and treatment options of infantile vascular anomalies." Medich MD. 00000000000001717

77. Padwa BL, Hayward PG, Ferraro NF, Mulliken

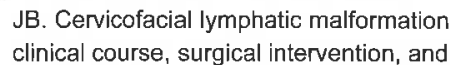
Clinical course, surgical intervention, and
pathogenensis. Plast Reconstr Surg 1995, 95(6):951-60.

P. Munden A, Butschek R, Tom WL, Marshall JS Poeltler DM, Krohne SE, Alio AB, Ritter $M$,
Friedlander DF, Catanzarite $Y$, Mendoza
Smith L, Friedlander M, Friedlander SF (2014) incidence, clinical characteristics and association with placental anomalies. Brit Dermatol 170:907-913

hemangioma r rad C). Congenital

noninvoluting congenital hemangiomas. Arch Facial Plast Surg 2005; 7(5):307-11.

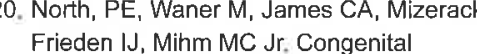
nonprogressive hemangioma: a diststrat clinicopathologic entity unlike infantile hemangioma. Arch Dermatol 200

Lee PW, Frieden IJ, Streicher JL, McCalmo
T. Hagsstrom AN Characteristics of noninvoluting congenital hemangioma: $A$ restrospective review. J Am Acad Dermato
2014 Mayy 70(5):899-903

22. Chang L, Haggstrom A, Drolet B, Baselga E, Chamlin SL, Garzon MC, Horii KA, Lucky AW, Mancini AJ, Metry DW, Nopper AJ, Frieden IJ characteristics of infantile hemangiomas Implications for management. Pediatrics

2008; 122:360-367
23. Mulliken J J G lowacki J. Hemangiomas and vascular malformations in iniants and
a classification based on endothelial characteristics. Plast Reconstr Sur

of the classification and the natural course of
ond the strawberry mark, J Dermatol 1981

25. Marler JJ, Muliken JB. Current management of hemangiomas and vascular malformations.
Clin Plast Surg 2005; 32(1):99-116. . Missoi TG, Lueder GT, Gilbertson K, Bayliss periocular infantile hemangiomas. Arc Ophthalmol 2011: 129(7):899-903.

Orlow SJ, Isakoff MS, Blei F. Increased risk of association with cutaneous hemangay in "beard" distribution. J Pediatr 1997; 131:643-6. 2. Bent JP. Airway hemangiomas: contempor 1(4):331-5.

29. Kim JS, Kwon SH. Sinonasal hemangioma: Diagnosis, treatment and followup of 37 Surg 2017; Jan. doi:S0278-2391. Epub

30. Leaute-Labreze C, Dumas de la RE, Hubiche T, Boralevi F, Thambo JB, Taieb A, Propranolo 2008; 358: 2649-51.

31. Lawley LP, Siegfried E Todd II Propranolol treatment for hemangioma of infancy: risks and recommendations. Pediatr Derma

32. Zimmerman AP, Wiegand $S$, Werner JA, hemangiomas: Int $J$ Pediatr Otorthinolaryngol.

3. De Graaf M, Breur JM, Raphael MF, Vos M,
Breugem CC, Pasmans SG. Adverse effects of propranolol when used in the treatment hemangiomas: a case series of 28 infants.
Am Acad Dermatol. 2011 Aug $65(2): 320-7$.
34. Shah S, Baselga E, McCuaig C, Pope E, Coulie J, Boon L, Garzon M, Haggstrom A, Garci-Romero M, Chute C, Roe E, Siegel

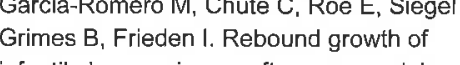
Infantile hemangiomas after propranolol
therapy. Pediatrics Volume 137 , number 4

35. Sommers Smith SK, Smith DM. Beta blockade
Aprite induces apoptosisi in cultured capillary endotheolial cells. In Vitro Cell Dov Biol Anim
2002; 385(5):298-304.

Chen TS, L F. Eich Infantille hemangiomas: an update on pathogenesis and therapy. Pediatrics 201

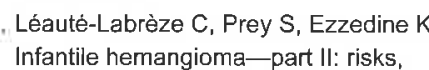
complications and treatment. $J$ Eur $\mathrm{ACO}$

Holland KE Frieden IJ,

Mancini AJ, Wyatt D. Drolet BA. Hypoglycemia in children taking propranolol for the treatment 146( infantile hemangioma. Arch Dermato 78 .
P

39. Pavlakovic $H$, Kietz $S$, Lauerer $P$, etal.
Hyperkalemia complicating propranolo Hyperkalemia complicating propranolo
treatment of an infantile hemangioma. Pediatrics; 2010; 126(6): 1589-93.

20. Drolet BA, Frommelt $\mathrm{PC}$, Chamlin $\mathrm{SL}$,
Haggstrom A, Bauman N, Chiu $Y$, Chun R, Garzon M, Holland $K$, Liberman $L$, MacLell
Seefeldt M, Sidbury R, Ward K, Blei F, , Boucek R, Frieden I. Inititation and use of propranolol for infantile hemangioma: report of a consensus conference. Pediatrics 2013;

41. Siegfried EC, Keenan WJ, Al-Jureidini S. More on propranolol for hemangiomas of infa
(letter). NEJM; 2008; 359(26):2846.

42. Leaute-Labreze C, hoeger P, Mazereeuq-
Hautier J, Guiband L, Baselga E, Posiunas G, Philips $R$, Caceres $H$, Lopez Gutererez JC. Ballona R, Friedlander SF, Powell J, Perek D, Metz B, Barbarot S, Maruani A, Szzalai ZZ, Grantzow $R$, Wargon $O$, Wyrzykowski $D$, Roessler $J$, Bernabeu-Witel J, ValenciaA, Benjamin L. Mancini A, Vabres P. Souteyrar P. Frieden I, Berul C, Mehta C, Prey S, Boralevi F, Morgan C, Heritier $S$, Delarue $A$ proprandolol in infomizede, controlled trial of of 2015; 372:735-46 Sondhi V and Patnaik SK. "Propranolol for Mlantile hemang oma (PINCH): an open-labe reating infantilie hemangiomamas and for determining the decline in heart rate to predict "esponse to propranolol." J Pediatr Hemato
44. Haggstrom MA, Garzon M, Baselga E, Chamlin S, Freden I, Holland K, Maguiness
$S$, Mancini A, McCuaig C, Metry D, Morel K. pow PHACE syndrome in infonts with. Rist lacial hemangiomas. Pediatrics 2010; 126:e418-e426. Hogeling M, Adams S, Wargon O. A
Randomized Control Trial of Propranolol for Infantile Hemangioma. Pediatrics. 2011 Aug; 128(2)::259-66. Chang $L, Y, X$, Qiu $Y, M a G$, Jin $Y, C$ Chen $H, L$ Safe and Effective for Outpatient Use for Infantile Hemangioma? A Prospective Study o 679 Cases From One Center in China. Ann Plast Surg. 2016 May; 76(5):559-63. Rousseav $E$. Ondro chak S, McCuaig C. L rebound of infantile hemangioma after cessation of oral propranolol. Pediat

48. Mulliken, JB. Treatment of C C

Hemangiomas. In, John B Mulliken, Patrice Burrows, Steven J Fishman, editors. Mulliken and Young's Vascular Anomalies:

Oxtord Un edil

49. Boyd VC, Bui D, Naik B, Levy M, Hicks MJ,

Hollier L. Surgery: The Treatment of Choice

for Hemangiomas. Semin Plast Surg. 2006
Join Our Growing

Team of Primary

Care Providers

Charleston Area Medical Center is recruiting compassionate, highly skilled primary care physicians for

employment opportunities with

the CAMC Primary Care Group.

Charleston Area Medical Center
Join our remarkable staff of providers and become a part of a financially-sound, thriving and innovative health care system.

Benefits include:

- Generous compensation model with performance bonus

- Excellent benefit package and sign-on bonus

- Ability to consult with specialists across the health care system and region

- Leadership opportunities

- Occurrence based malpractice insurance

- Paid time away from practice/CME allowance

If you have a desire to achieve work-life balance while having a positive impact on your community, send your $\mathrm{CV}$ to carol. wamsley@camc org or call 866-551-8927 regarding our

multiple opportunities and locations. 
Imaging surveillance for pneumothorax after

\section{CT-guided lung biopsy: Conclusions from a year of data at a tertiary care center}

Robert Grammer, MD

Radiology Resident, West Virinini University
School of Medicine, Morgantown, WW

Michael Nagib, MD

Radiology Resident, West Virinini University
School of Medicine, Morgantown, WW

Mohamad Kassar, MD

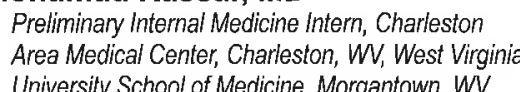

ana Winkler, MD

Assistant Proferssoro of Radiology, West Virginia
University School of Medicine, Morgantown, WW

Vahid Etezadi, MD

Assitant Professor of Radiology, West Virginia
University School of Medicine, Morgantown, WW

Universitit of Mary
Battimore, $M D$

Corresponding Author L Lana Winker, MD, Assistant
Sofessor of Radiology WUu School of Medicine

Dofessor of Radiology, Wh

Keywords : Lung biopsy

pneumothorax

Abstract

This study was performed to

identify the minimum observational

time and post-procedura imaging

ide and posto

necessany before safely discharg

a pallent befor cr-guided lung

was conducted on 167 CT-guided

lung biopsies performed in 2015

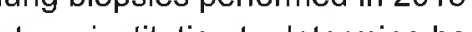

at our institulion to determine how

ofen pneumothoraces occurred

on post-procedure chest ima

Patient age, gender,

and size, core needle size, lateral

background emphysema, and

backgrll as clinical history of chronic

as well active pulmonary disea

obstructive pulmonny disease

were recolded. If pneumothorax

tube, and ultimate medical outcomes

were logged Chi mquared outcomes

analysis was utilized. Post-biopsy pneumothorax rate was $38 \%$, with $87 \%$ incidence at the time of the biopsy and $13 \%$ within the first hour. No new pneumothorax was detected beyond the first hour. Overall pneumothorax interventio rate was $51 \%$. The leading risk factor for pneumothorax was concomitant radiographic evidence of emphysema, with $48 \%$ inciden versus $30 \%$ of patients without underlying emphysema. These patients were also significantly more likely to have a pneumothorax requiring intervention $(p<0.05)$. We concluded that post-biopsy imaging can safely be limited to immediate post-procedure $\mathrm{CT}$ and one hour chest radiograph in the absence of pneumothorax. In patients with pneumothorax, further imaging, intervention, and/or discharge may be considered based on imaging results and patient's condition.

\section{Introduction}

CT-guided percutaneous core needle lung biopsy has become an invaluable method of obtaining a tissue diagnosis in patients with lung pathology varying from large pulmonary masses to numerous lesions and chronic focal infiltrate of uncertain etiology, providing a minimally invasive technique and a means to access lesions or areas of the lung that would otherwise be difficult to would using alternative methods such as bronchoscopy and open excision biopsies. However, along with all of the benefits of $C T$ along with biopsy there are associated risks, as with any other procedure. Amon the most commonly encountered complications following $\mathrm{CT}$-guided lung biopsy are pneumothorax, pulmonary hemorrhage, and hemothorax. Reported post-biopsy pneumothorax rates range from $0-60 \%$ with up to $15 \%$ of these pneumothoraces requiring chest tube placement. ${ }^{1.2}$ Not only does this translate to increased morbidity and mortality, but also increased patien and institutional expenses with an average cost per inpatient day of $\$ 752-\$ 1656$ in the state in which our institution resides. ${ }^{3.4}$ There are to increased risk of complications following CT-guided lung biopsy of the lesion, size of the needle, trajectory of the biopsy approach, and number of pleural surfaces crossed. ${ }^{5.6}$ The purpose of our pneumothorax and evaluate risk laterality, patient gender and age, core needle size, and presence of emphysema. Furthermore, our aim post-biopsy follow up directed toward eliminating unnecessary imaging and decreasing length of stay.

Materials and Methods Permission to perform this study was granted by the Institutional Review Board. A retrospective chart review was performed. All patients who had a CT-guided core needle lung biopsy perform our institution from January 2015 through December 2015 were analyzed. These biopsies were different radiologists with or witho many factors that may contribute such as size of the lesion, location study was to evaluate incidence of factors, such as lesion size and was to identify these risk factors in hopes to create an algorithm for performed or supenvised were resident assistance. All biopsies utllized CT-guidance only. Patient positioning was determined by lesion location. Standard coaxial techniques were applied, with use of Cook Quick-Core ${ }^{2}$ Coaxia Biopsy Needle Sets (Cook Medical Inc., Bloomington, IN). The majority of biopsies, 139, were performed with an 18 gauge biopsy needle and a 16 gauge trocar needle (18G/16G). Three used the 20G/19G set, and one with the $16 \mathrm{G} / 14 \mathrm{G}$ set. Typically, three or four core specimens were obtained to ensure adequate sample for diagnosis. Following removal of the trocar needle, an occlusive dressing was placed, and post-biopsy CT imaging was obtained. If a pneumothorax was present, a chest tube was placed at the discretion of the operator. Indications for chest tube placement versus additional serial monitoring were based on symptoms and pneumothorax size and rate of change. Those requiring chest tubes went on to have monitoring chest radiographs at routine intervals. Patients not requiring an immediate chest tube were ordered AP chest radiographs, scheduled at one hour and two hours post-biopsy, as patients have traditionally been observed at least two hours postbiopsy. These images were reviewed for pneumothorax development stability, or increase. (Figures 1a-c \& 2a-c). Patients were discharged if no pneumothorax had developed or the pneumothorax was stable over the two-hour period and the patient was asymptomatic. Chest tubes and pneumothorax aspiration procedures following these follow up radiographs are referred to as "Delayed" for the purposes of this study. From January through December of 2015, images from a total of 167 CT-guided lung biopsies were reviewed. Of these, 24 were excluded. Two were excluded as the procedure was canceled due to resolved or decreased lesion size following acquisition of pre-biopsy imaging. Five were cancelled due to lack of safe needle approach to the lesion. Thirteen were excluded due to chest wall location of the lesion. An additiona two were excluded on the basis of a persistent pneumothorax at the start of the procedure (as a result from a recent attempted biopsy). Two biopsies were excluded due to technical/procedure discrepancies, as these were performed as an FNA only. Therefore, 143 patien were included in this study. Four investigators (three radiology residents and a medical student) reviewed charts and recorded the gender, laterality of patient's a size of core needle. The greate dimension of the biopieg greates dis medium $(1.5-3 \mathrm{~cm})$ and large $(>3 \mathrm{~cm})$, as meas and $\mathrm{CT}$. (>3cm), as measured on CT biopsy pneumothora on immeriste biopsy CT inages was reconde biopsy CT inages was recorded, as well as at he tho or follow up chest radiographs. If a pneumothorax cccurred, is size was recorded as small ( $25 \%$ of hemithorax), moderate (25-50\% of hemithorax) or large ( $>50 \%$ of hemithorax), as well as whether a chest tube (immediate or delayed) was needed for treatment. The ultimate outcome of the medical encounter was also noted (same day home discharge or required hospitalization for either pneumothorax monitoring or chest tube management). Pre-existing emphysema at time of biopsy was also denoted, based on subjective observation of CT biopsy images. Presence of clinically-diagnosed COPD was also recorded base on patient histories obtained from electronic medical record.

\section{Statistics}

Statistical analysis was performed using Pearson's Chi-Squared Test,

aided by Apple Numbers software, version 3 (Apple Inc., Cupertino, CA)

Results

Of the 143 patients included in this study, 70 were male and 73 were female, with an age range and mean of 22-87 years and 65 years, respectively (Table 1 ) Emphysema was present in 64 patients, $44 \%$ of our study population. Clinically diagnosed COPD was found in 71 patients. $50 \%$ of the study population. Eighty-three of the lesions were within the medium range, 52 were large, and 8 were small. Overall, 55 biopsies (38\%) were complicated by pneumothorax, 41 small, 9 medium, and 5 large. Of these 55 pneumothoraces, $48(87 \%)$ were present during immediate procedural CT imaging, and the remaining $7(13 \%)$ were found on initial one-hour post-biopsy chest radiograph. When comparing the one-hour and two-hour post biopsy radiographs, no new pneumothorax was identified after two hours that was not present after one hour. Out of the 55 pneumothorax cases, 28 patients $(50 \%)$ required chest tube placement $(n=26)$ or pneumothorax aspiration $(\mathrm{n}=2)$. Seventeen $(61 \%)$ procedures were performed immediately, and $11(39 \%)$ were done in a delayed manner, ranging from three hours post-biopsy to the following day for increasing volume (Table 1). Forty-eight pneumothoraces were present on immediate post biopsy CT imaging, seventeen of these patients $(34 \%)$ underwent immediate chest tube placement or aspiration 8 patients $(17 \%)$ required delayed chest tube placement. Of on 7 pneumothoraces diagnosed 
Demographics and Data

\begin{tabular}{|c|c|c|c|c|c|c|c|c|c|c|}
\hline \multirow{3}{*}{\begin{tabular}{|l} 
Patient Number \\
\end{tabular}} & \multirow{2}{*}{\multicolumn{6}{|c|}{ IMMEDIATE }} & \multirow{2}{*}{\multicolumn{2}{|c|}{$2 \mathrm{HR}$}} & & \\
\hline & & & & & & & & & \multicolumn{2}{|c|}{ TOTAL } \\
\hline & 88 & $(62 \%)$ & 48 & $(34 \%)$ & 7 & $(5 \%)$ & 0 & (\%) & 143 & \\
\hline \multicolumn{11}{|l|}{ Age } \\
\hline Average & 65 & & 66 & & 61 & & - & & 65 & \\
\hline Range & $22-87$ & & 41-86 & & $32-87$ & & & & $22-87$ & \\
\hline \multicolumn{11}{|l|}{ Sex } \\
\hline Male & 37 & (53\%) & 29 & $(41 \%)$ & 4 & $(6 \%)$ & - & & 70 & $(49 \%)$ \\
\hline Female & 51 & $(70 \%)$ & 19 & $(26 \%)$ & 3 & $(4 \%)$ & - & & 73 & $(51 \%)$ \\
\hline \multicolumn{11}{|l|}{ Laterality } \\
\hline Left & 39 & (65\%) & 17 & $(28 \%)$ & 4 & (7\%) & - & & 60 & $(42 \%)$ \\
\hline Right & 49 & $(59 \%)$ & 31 & $(37 \%)$ & 3 & $(4 \%)$ & - & & 83 & $(58 \%)$ \\
\hline \multicolumn{11}{|l|}{ Lesion Size $^{a}$} \\
\hline Small & 3 & $(38 \%)$ & 4 & $(50 \%)$ & 1 & $(13 \%)$ & - & & 8 & $(6 \%)$ \\
\hline Medium & 50 & $(60 \%)$ & 29 & (35\%) & 4 & (5\%) & - & & 83 & $(58 \%)$ \\
\hline Large & 35 & (67\%) & 15 & $(29 \%)$ & 2 & $(4 \%)$ & - & & 52 & $(36 \%)$ \\
\hline \multicolumn{11}{|l|}{$\begin{array}{l}\text { Needle Size (Biopsyl } \\
\text { Trocar) }\end{array}$} \\
\hline $16 \mathrm{G} / 14 \mathrm{G}$ & 1 & $(100 \%)$ & 0 & $(\%)$ & 0 & (\%) & - & & 1 & $(1 \%)$ \\
\hline $18 \mathrm{G} / 16 \mathrm{G}$ & 86 & $(62 \%)$ & 47 & $(34 \%)$ & 6 & $(4 \%)$ & - & & 139 & (97\%) \\
\hline $20 \mathrm{G} / 19 \mathrm{G}$ & 1 & $(33 \%)$ & 1 & (33\%) & 1 & $(33 \%)$ & - & & 3 & $(2 \%)$ \\
\hline \multicolumn{11}{|l|}{ Emphysema } \\
\hline Present & 33 & $(52 \%)$ & 27 & $(42 \%)$ & 4 & $(6 \%)$ & - & & 64 & $(45 \%)$ \\
\hline Absent & 55 & $(70 \%)$ & 21 & $(27 \%)$ & 3 & $(4 \%)$ & - & & 79 & $(55 \%)$ \\
\hline \multicolumn{11}{|l|}{ COPD } \\
\hline Present & 45 & $(63 \%)$ & 24 & $(34 \%)$ & 2 & (3\%) & - & & 71 & $(50 \%)$ \\
\hline Absent & 43 & $(60 \%)$ & 24 & (33\%) & 5 & (7\%) & - & & 72 & $(50 \%)$ \\
\hline \multicolumn{11}{|l|}{ PTX $^{b}$} \\
\hline s & - & & 34 & (83\%) & 7 & $(17 \%)$ & - & & 41 & $(29 \%)$ \\
\hline M & - & & 9 & $(100 \%)$ & 0 & (\%) & - & & 9 & $(6 \%)$ \\
\hline $\mathrm{L}$ & - & & 5 & $(100 \%)$ & 0 & (\%) & - & & 5 & $(3 \%)$ \\
\hline Resolved PTX & - & & 12 & $(92 \%)$ & 1 & $(8 \%)$ & & & 13 & $(9 \%)$ \\
\hline Chest Tube Placed & - & & 25 & $(89 \%)$ & 3 & $(11 \%)$ & - & & 28 & $(20 \%)$ \\
\hline Immediate & - & & 17 & $(100 \%)$ & - & & - & & 17 & $(12 \%)$ \\
\hline Delayed & -1 & & 8 & $(73 \%)$ & 3 & $(27 \%)$ & - & & 11 & (8\%) \\
\hline
\end{tabular}

a. Small: $<1.5 \mathrm{~cm}$, Medium: 1.5-3cm, Large: $>3 \mathrm{~cm}$
b. Small: $<25 \%$, Medium: $25-50 \%$, Large: $>50 \%$

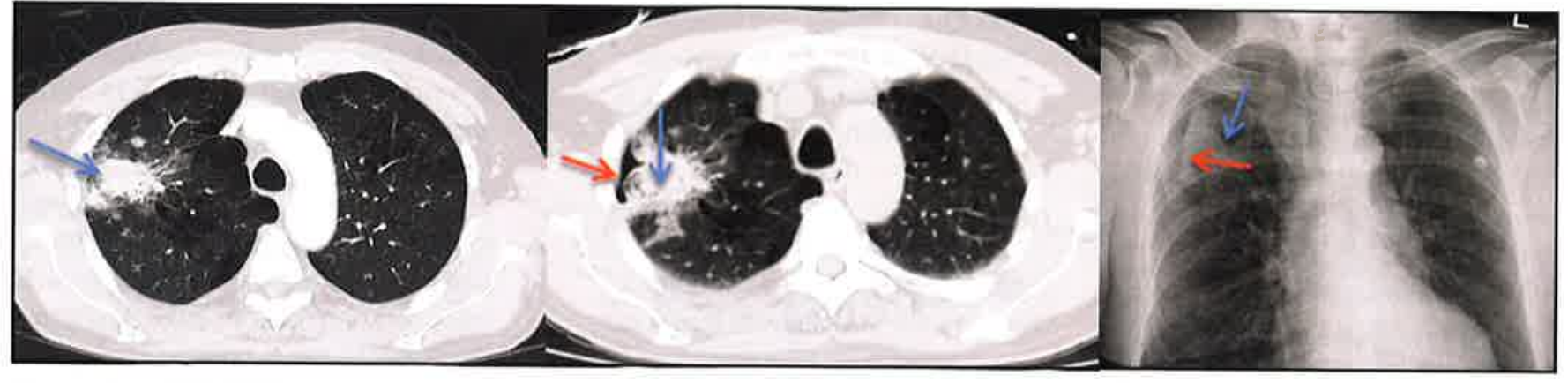

Figures 1a-c: Axial CT pre-biopsy (Figure 1a), axial CT post-biopsy (Figure 1b), and chest $x$-ray post biopsy (Figure 1c), demonstrate a large right upper
lobe mass (blue arrow) as well as a small pneumothorax (red arrow), seen on both post-biopsy CT and x-ray.

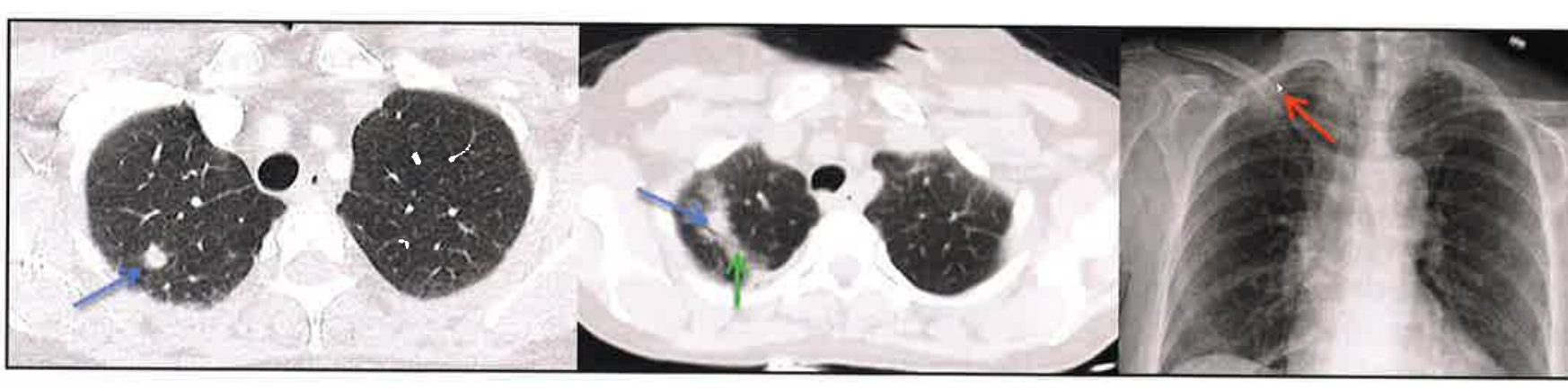

Figures 2a-c: Axial CT pre-biopsy (Figure 2a), axial CT post-biopsy (Figure 2b), and follow-up chest x-ray post-biopsy (Figure 2c), demonstrate a right upper
lobe nodule (blue arrow), with post-biopsy hemorrhage identified on CT (green arrow). Small post-biopsy pneumothorax was present on follow-up chest $x$-ray (red arrow) that was not seen on immediate post-biopsy $C T$.

pneumothorax was found to be

emphysema (based on CT-imaging

findings), with an incidence of

$48 \%$ vs. $30 \%$ ( $p<.0 .027)$. Clinically

diagnosed COPD was not found

to be a significant risk factor for

pneumothorax with $37 \%$ of COPD

patients developing pneumothoraces

versus $40 \%$ of non-COPD

patients $(p<0.65)$. However,

both radiographic evidence of

emphysema and clinical evidence

of COPD were associated with an

increased likelihood of requiring

chest tube placement with $34 \%$ vs.

$8 \%(p<0.00006)$ and $27 \%$ vs $13 \%$

$(p<0.03)$, respectively. Additionally,

pneumothoraces were more likely to

require treatment with a chest tube

in the presence of radiographically

diagnosed emphysema as well as

clinically-diagnosed COPD $71 \%$

vs. $25 \%(p<0,0007)$ and $73 \%$ vs

$31 \%(p<0.002)$, respectively.

Other potential risk factors for

development of pneumothorax were assessed, including patient age, relative lesion size, and lesion laterality; however, none of thes were shown to be statistically significant. Additionally, needle size was not evaluated due to low number of alternative sizes. Deviations from our standard imaging protocol were encountered. The most typical alternate scenario was skipping the one hour image when the immediate CT was negative. These deviations did not have any statistical or clinical significance, as no new two hour pneumothorax was found on these patients.

Discussion

Existing literature confirms that pneumothorax is a significant

complication of lung biopsy Cho

al. has reported an overall Cost-

biopsy pneumothorax rate of $21.8 \%$

(using 18 or 22 gaune $21.8 \%$

$3.3 \%$ occurring ater thee hou
R.P. Byrd et al. similarly reported a delayed pneumothorax (greater than 4 hours post-procedure) rate of $3.1 \%$ using a 22 gauge Chiba needle. ${ }^{8}$ Geraghty et al. reported a significant decrease $(50 \%)$ in pneumothorax rate with the use of a 19 gauge core biopsy needle compared to an 18 gauge. ${ }^{9}$ Patients in that study underwent a three hour post-biopsy chest radiograph if initial CT was negative.

Dennie et al. reported a pneumothorax rate of $22.9 \%$ using needles smaller than 18 gauge 10 They suggest discharge at $30 \mathrm{~min}$ if no pneumothorax is found $\mathrm{m}$ his study also attempted to quantify the morbidity of a sing follow up radiograph, 30 minutes postprocedure Out of 506 patients, only 7 pneumothoraces were matists, only heyound the 30 miner missed Stevens et al muntes. However, monitoring (24 hour) is delayed $43 \%$ of their patients demed as 
progression of pneumothorax."11 Perlmutt et al. recommends followup radiograph at one and fou hours post-biopsy. ${ }^{12}$ Of the patients who required a chest tube, 100\% were detected before or at the one hour post-biopsy imaging. There have been several risk factors correlated to pneumothorax occurrence including needle size, ${ }^{9}$ depth/size of lesion, ${ }^{13}$ and emphysema. 'Multiple studies have confirmed the association between presence of COPD emphysema and increased risk for pneumothorax, as well as increase requirement for chest tube draina of pneumothorax after CT-guided lung biopsy. ${ }^{2} \mathrm{Ko}$ et al. studied 150 post-biopsy CTs and found that both emphysema along the needle path and obstructive pulmonary function tests increased necessity for post-biopsy chest tubes. Fish et al. found that in a study of 160 patients, pneumothoraces occurred in $42 \%$ of patients who had obstructive airway disease diagnosed by chest $\mathrm{x}$-ray findings, compared with $25 \%$ of patients with normal chest $x$-rays. The patients with obstructive airway disease in that study also required more chest tube placements. ${ }^{14} \mathrm{Cox}$ et al. had similar conclusions when studying 346 patients, as emphysema increased the risk of pneumothorax and patients with emphysema were three times more likely to require chest tube placement. ${ }^{15}$ Based on our results, imaging diagnosis of emphysema was a risk factor por phopy pneumothorax, was not, possibly due to the fact that COPD encompasses both entities of chronic bronchitis and alveolar destruction, wh radiographic findings were assessed for alveolar abnormalities only. This observation allows the operator to more confidently rely on the imaging diagnosis of emphysema as an assessment fo post-biopsy risk of pneumothorax rather than relying on the clinica diagnosis to be documented in the patient's chart. However, both emphysema and COPD were risk factors for increased requirement of chest tubes in the presence of pneumothorax, which dynamics and air trapping We use relatively larger diameter needles (18G needle through 16G Trocar) to obtain core and FNA samples per consensus with departments in our institution This likely explains the higher the literature. However, despite using larger needles, our data demonstrates minimal risk of following lung biopsy with only initial computed tomography scan follow-up imaging beyond one hour after CT-guided lung biopsy does not appear to be necessary. hour after lung biopsy would reduce may relate to altered respiratory the pulmonology and pathology rate of pneumothorax $(38 \%)$ in our cohort compare to $20-30 \%$ in late presentation pneumothorax $5 \%$ of cases occurring after the and no cases occurring after the one hour post-biopsy chest x-ray. Therefore our data suggests th health care costs. It would free up beds in post-operative areas, whic is a necessity now more than ever with expanding busy hospitals. Nurses would require less overtime pay as well, as they sometimes have to stay after hours to monitor these patients until the series of timed follow-up exams are completed and the patients can be discharged. Additionally, patients would benefit from earlier discharges. Their medical bills and time spent in the be reduced. Many patients travel hours to our tertiary care center to receive these biopsies and incur hotel costs the night of the biopsy after late discharges due to waiting for serial images. Patient satisfaction is expected to increase with implementation of new post-biopsy imaging policies, which in turn would help hospitals with reimbursement. Our data demonstrates that all pneumothoraces large enough to require chest tube placemen ocurred within the first hour. Therefore, the risk of a large enough pneumothorax to require treatmen occurring after patient has been Our study has multiple limitation including its retrospective nature. was evaluated for on imaging and the influence of other disease processes such as consolidations or fibrotic changes on development of post-biopsy An additional limitation is that only An additional limitation is that on as a post-biopsy complication. hospital and away from work would discharged would be minute. Additionally, only emphysema

\section{Do we have your email address?}

If we don't have it, you are missing out on important legislative updates, Call Bethany

304-925-0342, ext. 110 or email: bethany@wvsma.org CALLS to ACTION \& other important announcements.
Stay Connected! 艛
Biopsies can result in other complications, such as hemorrhage, which could necessitate serial imaging even in the absence of pneumothorax. However, significant intraparenchymal hemorrhage and hemothorax are invariably evident in the immediate or one hour imaging surveillance. When comparing clinical diagnosis of COPD with presence of post-biopsy pneumothorax, it is possible that incomplete documentation of this diagnosis in the medical record influenced our results. Finally, patien symptoms should be considered when designing a policy for follow-up imaging and discharge in the setting of post-biopsy pneumothorax.

Conclusion

In conclusion, our data suggests that in the absence of pneumothorax on immediate post biopsy CT

scan, follow up imaging can safely

be limited to on hour chest

radiograph. In patients with small pneumothorax, longer clinical observation and further imaging should be considered based on the patient's respiratory condition.

\section{References}

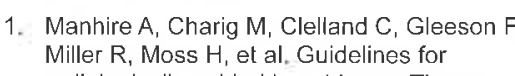
radiologically guided lung biopsy. Tho
2003: 58 (11). $920-93$.

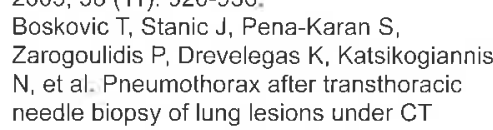
needle biopsy of lung lesions under CT
guidance, Journal of Thoracic Disease. 2014. Suppl 1: S99-S107.
Rappleye, Emily. "Average cost per inpatient

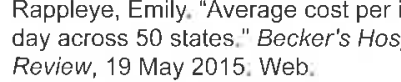
Hospitial adjusted expenses per
npatient day., The Henry J Kaiser Fam

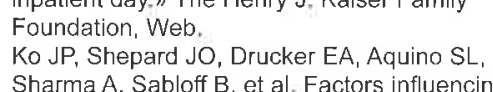
pneumothorax rate at lung biopsy: Are dwell

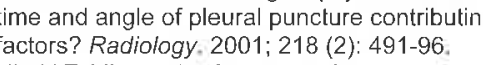
Hiraki T, Mimura H, Gobara H, Shibamoto K,
Inoue D, Matsui Y, et all Incidence of and risk Inoue $D$, Matsui $Y$, et al. Incidence of and $K$
factors for pneumothorax and chest tube
placement after $C T$ f fluoroscopy gusided

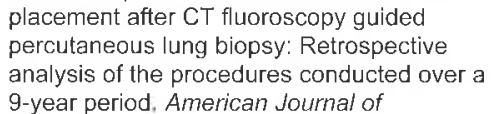
9-year period. American Journal of
Roentgenology. 2010; $194.809-14$.

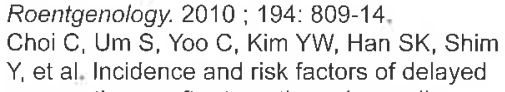

biopsy of the lung, Chest. 2004; 126(5)

Byrd RP, Fields-Ossorio C, Roy TM. Delayed pneumothorax following CT-guided fine

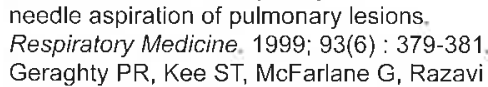
Geraghty PR, Kee ST, McFarlane G, Raza
MK, Sze DY, Dake MD. CT-guided transthoracic needle aspiration biopsy
pulmonary nodules : Needle size and
and 229(2):475-481. . Stevens GM, Jackman RJ. Outpatient need biopsy of the lung: its safety and utility 12. Permut LM, Braun SD, Newman GE, Oke
EJ, Dunnick R. Timing of chest filim follow-up after transthoracic needle aspiration. 13. Yamagami T, Nakamura $T$, lida S, Kato $T$, Nishimura T. Management of pneumothorax
after percutaneous $C T$-guided lung biopsy. Chest. 2002:121(4): $1159-1164$. and SE Sutherland. Postibiopsy radiography and dulmonorary function tests.
American J Juurnal of Roentgenology. 1988 . 15. Cox J., Chiles C, McManus CM, Aquina SL, Choplin RH. Transthoracic needle aspiration
biopsy Variables that affect risk of
pneumothorax. Radiology. 1999 ; 212(1): Ihe lung: Results of early discharge in 506
outpatients. Radiology. $2001 ; 219(1): 247$ -

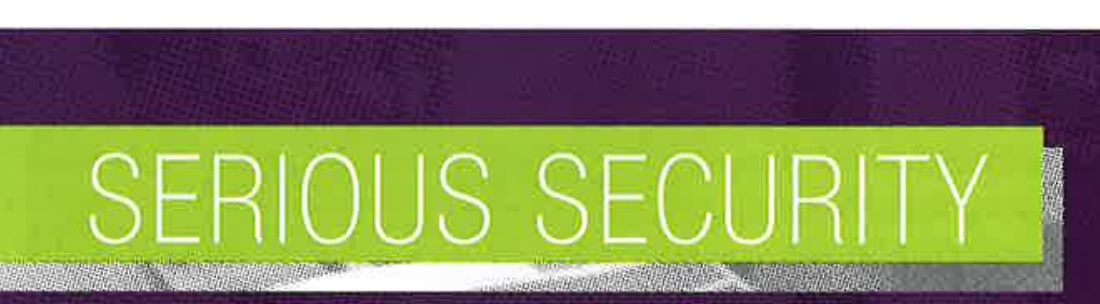

94\% OF ORGANIZATIONS HAVE SUFFERED PHI SECURITY BREACHES. AVOID THE BREACH WITH GRAPHCOM.

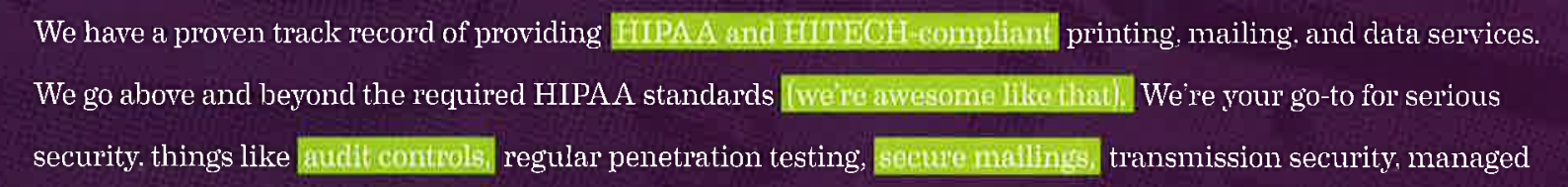

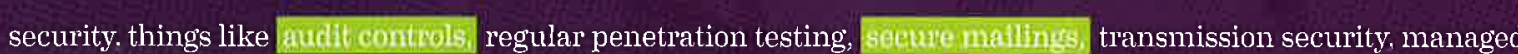

natusion nusection and detection secure variable data, and HIPA A/HITECH/ISO 2rO02 compliant policies

How safe is your data? Let's get together and talk data security

graphcom

800-669-1664 | graphcom.com 


\section{Delays in care of sudden sensorineural hearing loss, an unrecognized emergency}

Scott Shapiro, MD Department of Otolaryngology - Head and Neck
Surgery, West Virginia University

Brian Wiseman, BS

Brian Kellermeyer, MD

Department of Otolaryngology-
Surgery, West Virginia University

Michele Carr, MD, DMD, PhD

Department of Otolaryngology - Head and Nech
Surgery, West Virginia unviversity

Stephen Wetmore, MD, MBA

Department of Otolarnngology - Head and Neck
Surgen, West Virginia University

Adam Cassis, MD

Department of Otolarnngology - Head and Neck
Surgery, West Virginit University

\section{Corresponding Author: Adam Cassis, MD, Room
4520 Health Sciences Center South, Morgantown, WW} 26506-9200. Emaili: acassis1 @hsc.wvu.edu.

There were no sources

of funding for this work.

This study design was evaluate by the Institutional Review Board at West Virginia University and was given expedited approval on March 21, 2017 (Protocol \#1701409758).

\section{Abstract}

Sudden sensorineural hearing loss (SSNHL) is an acute loss of hearing due to poorly understood insults to the inner ear. SSNHL is a medical emergency warranting urgent referral to an otolaryngology specialist because hearing oucom are improved with steroid treat the improd win sterid treat after the onset of hearing loss to be effective, making early diagnosis and triage essential to salvaging hearing. This prospective study catalogued the timeline of the onset of hearing loss, diagnosis, treatment, and settings where care was administered for patients with SSNHL. We diagnosed 21 patients with SSNHL in the otolaryngology University over a 6 month time period. Nine of those patients $(42.9 \%)$ were diagnosed outside of the window for treatment. The most common cause of delayed diagnos was inappropriate treatment and triage in the primary care settin As the quality of life burden of hearing loss is quite significant, improving recognition and triage in the primary care setting would allow for more patients with SSNHL to undergo treatment, improving hearing outcomes and quality of $I$

\section{Introduction}

Making the Diagnosis Sudden sensorineural hearing loss (SSNHL) is an acute onset, usually unilateral, significant hearing loss due to damage to the often emotionally devastating to affected patients. It is a medical emernency and when suspected patients should be referred urgently patlents should be referred urgen for an olo evaluation as early diagnosis and sterid treatment is essential to A can made in the primary care setting based on history and physical exam alone without a formal hearing tes or at least can create a high enoug degree of suspicion to prompt an urgent referral to an otolaryngology specialist. The hearing loss of SSNHL may occur over a period of 3 days or less, but patients most commonly describe loss of hearing over a few hours, or that they awoke from sleep to find their hearing significantly decreased ${ }^{1,2}$ specialty clinics of West Virginia inner ear that is frightening and A tenlative diagnosis of SSNHL
They typically do not have pain, but may have a sensation of aura fullness, tinnitus, and/or problems with balance. Any patient with acute hearing loss should have a tuning fork test and an otoscopic exam. The Rinne test is always used in conjunction with the Weber test to determine the nature of a patient's hearing loss (see Figure 1 for instructions on how to perform and interpret basic tuning fork testing). In SSNHL the Wor tong test lateralizes to the unafect test lateralizes to hise unariected, better hearing ear (indicating asymmetic hearng), and the Rinne test demonstrates air conduction greater than bone conduction on both sides (confirming sensorineur hearing loss). Tuning fork testing and otoscopic exam can identify a conductive versus a sensorineural pattern of hearing loss in almost all cases. Patients with SSNHL have a sensorineural pattern to their hearing loss with no signs of conductive or middle ear pathology such as middle ear fluid, acute titis media or tympanic nember perforation Patients with thera findings should be urg thes Gindings should be ungently referred to an otolaryngology specialist for possible SSNHL, ideally the next day, where it can be confirmed with a formal hearing test and treated if indicated. ${ }^{2}$ In cases of sudden hearing loss where the diagnosis is unclear, these should also be treated as time-sensitive and referred to a specialist urgently.

Pathophysiology and Epidemiology

SSNHL occurs due to an inner ear insult to the cochlear and/or auditory nerve (as distinct from a conductive

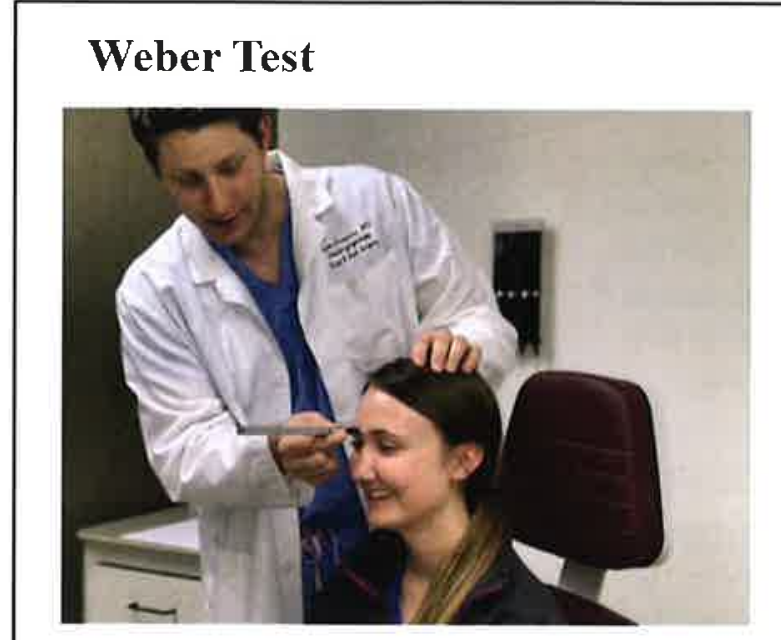

Weber Test Procedure: A $512 \mathrm{~Hz}$ tuning fork is gently set vibrating and it is held firmly on the patient's forehead in the midline for a few seconds. The patient is asked if the tone is heard more clearly on one side (lateralization) or if they cannot identify side which hears the tone better (no lateralization).

Interpretation: If there is no lateralization there is unlikely to be asymmetric hearing loss. If the tone lateralizes to one side, there is an ipsilateral conductive hearing loss or a contralateral sensorineural hearing loss.

Rinne Test

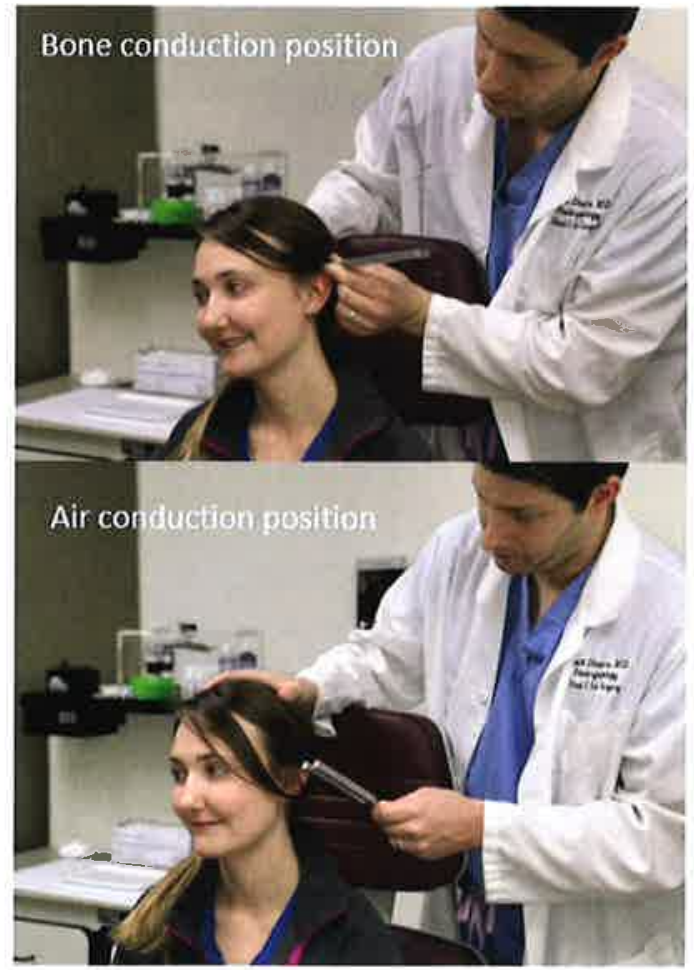

Rinne Test Procedure: A $512 \mathrm{~Hz}$ tuning fork is gently set vibrating and it is held firmly on the mastoid just behind and above the external ear for few seconds (bone conduction position). While the fork is still vibrating (expect the vibration to have diminished somewhat) it is moved off the mastoid and held $1-2 \mathrm{~cm}$ from the ear canal with the tines of the fork oriented in line with the ear canal (air conduction position). The patient is asked in which position the tone is heard louder.

Interpretation: An ear with a significant conductive hearing loss hears bone conduction louder than air conduction. An ear that is normal or has

sensorineural hearing loss hears air conduction greater than bone conduction.

Figure 1: Tuning Fork Testing. The Rinne test is always used in conjunction with the Weber to determine the nature of a patient's hearing loss. In SSNHL

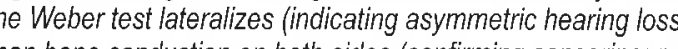




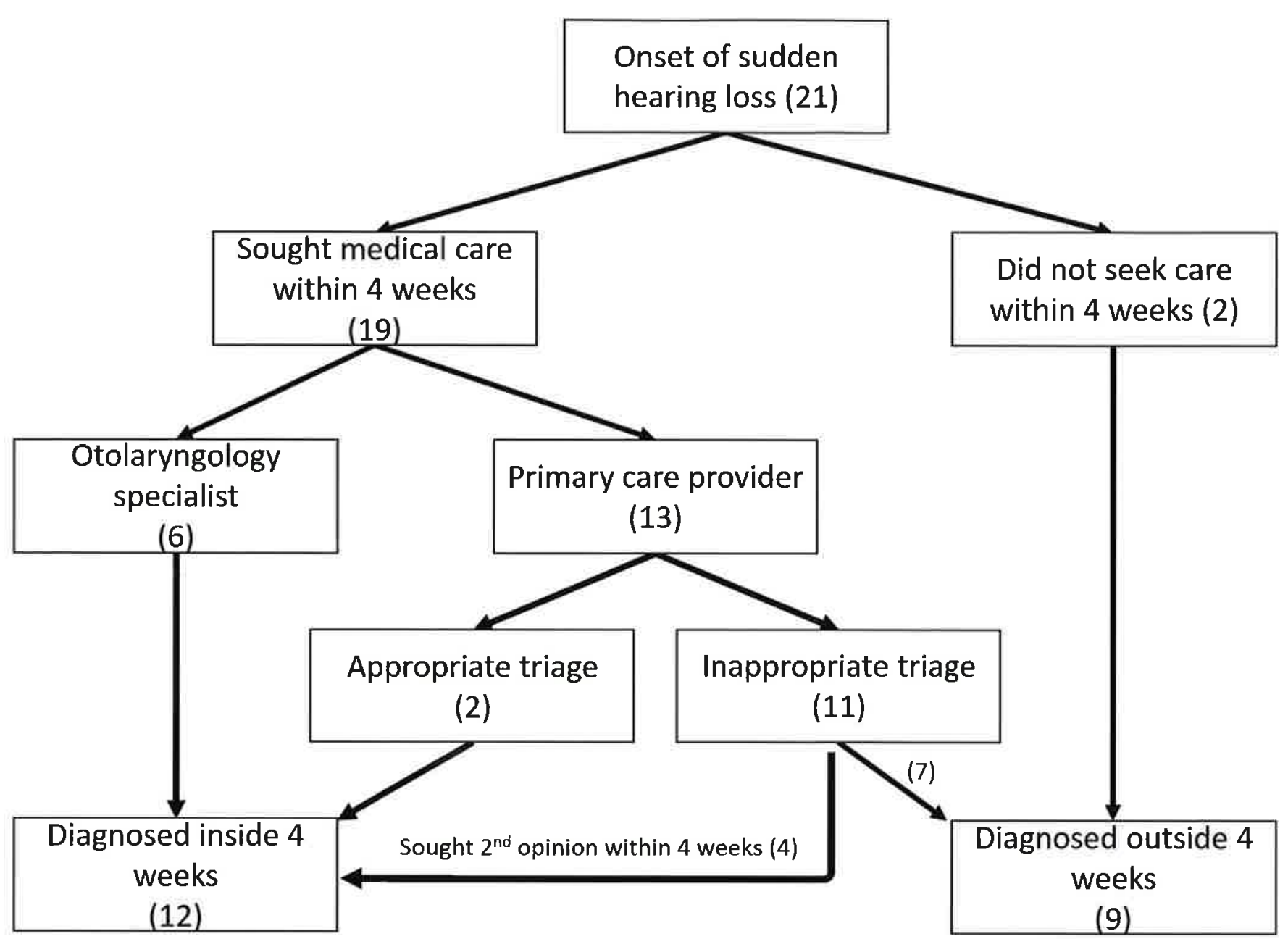

Figure 2: Flow diagram of events atter onset of hearing loss to diagnosis of SSNHL: Of the 12 patients who were seen within the window for treatment, 6 (50\%) were seen initially by an otolaryngology specialist, while the other 6 were seen by a primary care provider initially. Of these 6 seen by a primary care provider initially, 2 were appropriately triaged and an urgent specialist referral made. The other 4 sought a specialist evaluation on their own after being

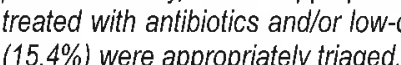

hearing loss due to interference with conduction of sound such as a tympanic membrane perforation middle ear effusion, or ossicular chain discontinuity). The etiology of SSNHL is poorly understood. The cause is identified in only $10 \%$ of cases, which are usually due to vestibular schwannoma, stroke, or malignancy. In the remaining $00 \%$ the caus is unknow, though viral and/or vascular causes are suspected. ${ }^{3}$ The incidence of SSNHL is relatively rare, estimated between 5 and 160 cases per 100,000 people. ${ }^{2,4}$
Natural History and Treatment

ear where il can difuse into the cochlea. This is also a good option Whout treatment, approximately half of patients with SSNHL will see at least some meaningful mprovement in their hearing in the weeks following the acute loss, though most in this group will not reach their pre-loss hearin level. Currenty, the ons proveng level. for improving heaven treatnent is high-dose nou or intratympanic steroid injection. or intrympanic steroid injection, in which high doses of steroid are injected through the tympanic membrane directly into the middle for diabetics or other patients for whom a high-dose oral steroid with oral and/or intratympanic hearing outcomes in cases where a cause for the hearing loss is identified such as in patients with estibular schwann pas we idiopatic cases; however in ces in cases the window for efficacy of hearing improvement has been as 4 weeks from the onset of hearing loss, but most will not improve that late in the course of the disease. Steroid treatment is much more likely to be effective, and to have a larger effect the ealier it is given, ideall effect, the earlier it is given, ideally within a rew days of heaning loss onset. Thus, promptidentification of patients wIh SSNHL and urgr refertal to an otolaryngology specialist is crucial for salvaging as much hearing ability as possible. ${ }^{2}$

\section{Delays in Care}

Due to the acute nature of SSNHL, most patients are seen by primary care providers, not specialists. They often present with other associated symptoms such as tinnitus, fullness, or dizziness, all of which are also associated with much more common ear conditions such as middle ear effusion or otitis media. This loads to frequent misdiagnosis, improper course is contraindicated. Treatment steroids has been shown to improve treatment is short. In rare instances, demonstrated with treatment as long treatment, and delays in care, often to the point where treatment is no longer beneficial. ${ }^{2}$ Any strategy to maximize the effectiveness of care to patients with this devastating condition and salvage as much hearing ability as possible must address the delays in care. The objective of this prospective study was to quantify the causes for delays in care for patients with SSNHL.

Materials \& Methods Study design was evaluated by the Institutional Review Board at West Virginia University and was given expedited approva on March 21, 2017 (Protocol \#1701409758). Patients who were diagnosed with SSNHL at a tertiary referral otolaryngology clinic in West Virginia were prospectively identified for 6 months from 2017 - September 2017. Inclusion criteria were 1) history of subjective unilateral hearing loss over a audiogram demonstrating sensorineural hearing loss of least $30 \mathrm{dBHL}$ over 3 contiof frequencies (if they presented withi the window for treat). If present 4 . presented grealer than 4 weeks from the onset or their hearing loss, this criterion was relaxed to $10 \mathrm{dBHL}$, as it is possible that these patients may recover som hearing prior to presentation. Exclusion criteria were concurrent conductive hearing loss or previous surgery in the affected ear. Patients meeting inclusion exclusion criteria had the following aspects of their care categorized: Did they seek evaluation by any healthcare provider within the 4 week window for treatment? If what was the specific 
setting (emergency room, primary care doctor, specialist, etc.) and was there appropriate treatmen or triage? Four weeks was set as the window period from the onset of hearing loss because this is the longest time interval from the onset of hearing loss that treatment has been shown to be effective. We determinown be there was appropriate treatment or triage if SSNHL was diagnosed and treated, or if an urgent refe was made to an ENT specialist, even if a diagnosis was not ma or the patient was not treated appropriately. Appropriate treatmen was considered to be a prescriptio of at least $40 \mathrm{mg}$ of oral prednison (or an equivalent dose of a differen steroid) and for at least 5 days. From this data set, the following proportions were calculated: the proportion who sought care within the 4 week window, the proporion seen at the ofolic seen at the otolaryngology specia clinic within the 4 week window,
and the proportion inappropriately and the proportion inappropria triaged or misdiagnosed pir

\section{Results}

Twenty-one patients were diagnosed with SSNHL over the 6 month course of the study. The mean age was 59.0 years (SD

13.1) and ranged from $18-75$ years. There were 9 males $(42.9 \%)$ and

12 females $(57.1 \%)$. The righ

12 females $(57.1 \%)$. The righ

(47.6\%) and the if 10 cases

$(52.4 \%)$. $(52.4 \%)$. The average hearing loss of those who presented with
the window was 56 decibels. the window was 56 decibels. The sequence of events for al patients from onset of hearing loss to eventual diagnosis is summarized in Figure 2. Twelve patients $(57.1 \%)$ were seen by an otolaryngology specialist inside the 4 week window from the onset of hearing loss with an average time until specialist evaluation of 10.3 days. Nine patients $(42.9 \%$ ) were seen outside of the window, with an average of 161 days from onset to specialist evaluation. In all 9 delayed cases, the delay was due to one of two causes: the patient to one of two causes: the patient did not seek any medical care (2 patients), or the palien was seen by a primary care provider within the window for treatment and was inappropriately triaged ( 7 patients). Of these 7 patients who were inappropriate triaged/misdiagnosed, all were given a diagnosis of either middle ear fluid or acute otitis media and prescribed antibiotics and/ or a low dose steroid course.

\section{Discussion}

The most salient finding from ou prospective study was the large proportion of patients $(42.9 \%)$ who became ineligible for treatment because of delayed diagnosis. Because hearing outcomes are improved with treatment, this represents a significant amount of hearing ability that could have potentially been recovered with proper treatment. In general, patients seemed to realize the urgency of sudden loss of hearing, as all but 2 of 21 patients sought medical care within 4 weeks, and 6 went straight to an otolaryngology speciastraight addition of the 11 patients that we to their PCP and wefents that we with middle ear effusion 4 sought a ear effusion or infection, 4 sought a specialist opinion on their own within 4 weeks even when a referral was not made. The main driver of delayed diagnosis was the high rate of inappropriate triage and/or misdiagnosis of SSNHL in the primary care setting, as only 2 of 11 patients who initially presented to a primary care provider were appropriately triaged. SSNHL is less common than other causes of hearing loss, such as middle ear effusion or acute otitis media, which contributes to frequent misdiagnosis. However, an appropriate history, otoscopic and tuning fork exam can easily differentiate the two, or at least identify those with potentia SSNHL who need an urgent refia to a specialist ${ }^{2}$ The authent referra to a specilst. The authors suspect that knowledge gaps in the primary care misdian misclagnosishapprophate triage, The this has not been studied. These delays are a modifiable contributor to loss of potentially salvageable hearing ability. The burden of hearing loss is significant, with even moderate levels of hearing loss being comparable with emphysema or diabetes in terms of quality of life decrement. ${ }^{5}$ Thus, increasing the proportion that are diagnosed and treated early in the disease course would significantly increase the quality of life of patients affected by SSNHL. As overall SSNHL is rare, and patients may initially present in variety of care settings, improving triage and diagnosis is a challenging endeavor, and would likely requing fr-reaching education The ming educational efforts. The man weakness of this study is the limitation to the geographic area that he ololaryngology clinics of West Virginia University serve, although the goal of the study was to characterize delays in care specifically for this population and region. The study may also suffer from selection bias, because there may be a significant number of patients who have SSNHL and never see a specialist or ever get diagnosed. This could occur because the patients themselves never seek medical care, or they never see a specialist evaluation after seeing a primary care provider.
There is also a subset of patients who fully recover to their pre-loss hearing level. If these patients are seen after full recovery has occurred they may never have an objective hearing loss on audiometric testing and thus are not diagnosed, or may and hus are not diagnosed, or may their hearing abilty their heang abilly returns. This potential for selection bias could
result in the study over-representing result in the sludy over-representing those patients with worse final hearing outcomes and those that seek or have access to medica and particularly specialist care.

\section{Conclusion}

SSNHL is a rare but treatable

medical emergency with potentially devastating functional and emotional consequences for affected patients. Patients with SSNHL often cann receive treatment due to delays in diagnosis related to high rates of inappropriate recognition and triage in the primary care setting which contributes to loss of potentially recoverable hearing ability. Improving diagnosis and triage of SSNHL patients in the primary care setting would reduce delays in diagnosis, improve hearing outcomes, and quality of life for persons affected by SSNHL. However, due to its rarity relative to other otologic conditions with similar symptoms, and diverse settings in which patients present, this is a challenging endeavor requiring far-reaching

\section{References}

1. Rauch $S$, Halipin $C$, Antonelli P. Oral vs
intratympananic corticosteroid therapy for idiopathic sudden sessorininurara hearing loss:
a randomized trial. JAMA. 2011;305(20):20712079 , 2. Stachler R. Chandrasekhar S, Archer S, et at. Clinical Rractice Guideline Sudden Sensorineural Hearing Loss. Otolaryngology
Head and Neck Surgerr. 2012:146(3) Sup S1-S35.
Conlin A, Parnes L. Treatment of sudder sensorineural hearing loss: a systematic 2007: 133(6):573-581. Byl F. Sudden hearing loss: eight years'

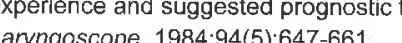
5. Simpson A, Simpson K, Dubno J. Heathrelated quality of life in older adults: Effects of hearing loss and common chronic conditions 


\section{Image-guided balanced orbital decompression for the management of thyroid eye disease: An analysis of outcomes and complications}

Chadi A. Makary, MD Department of Otolaryngology-Head and Neck
Surgery, School of Medicing - Eastem Division,
West Virginia University, Martinsburg, WW West Virginia University, Martinsburg, Justin Douglas, MD, MS
Southern WVENT, Beckley, WV

Hassan H. Ramadan, MD, MSc Department of Otolaryngology-Head and Neck
Surgent, School of Medicine, West Virginia

John Nguyen, MD
Departrment of Ootalayngology-Head and Neck
Surgeny, School of Medicing, West Virginia Surgent, School of Medicine, West Virginia Department of Ophithalmology, School of Medict
West Virginia University, Morgantown WV

None of the authors has any proprietary interest in the material presented herein.

Key words: Graves' disease, thyroid eye disease, proptosis, lid retraction, lagophthalmos, orbital decompression, exophthalmometry, diplopia, inferio medial strut, image guidance

\section{Corresponding Author: John Nguyen, MD:} Medicine, 1 Medical Center Dite, Morgantown, W

Abstract

Background: Thyroid eye disease (TED) commonly presents with proptosis, lid retraction, and diplopia. Multiple surgical techniques have been described to rehabilitate the orbit and to restore vision. Balanced orbital decompression is advocated as a standard surgical technique, and image guidance is encouraged to minimize surgical risks. We evaluated the outcomes of patients who underwent imageguided balanced three walls orbital decompression for TED.
Methods: An IRB approved retrospective chart review study Was performed on all patients who underwent image-guided balanced

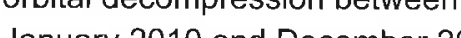
January 2010 and December 2016 Demographics, pre-operative including hdications, presence of pre- and post-operative diplopia, and exophthalmometry were abstracte Results: 169 orbital decompressions in 103 patients were performed. The mean age was 56 years, and the prevalence of pre-operative diplopia was $73 \%$. The incidence of newonset post-operative diplopia was $5.8 \%$. Among patients who had pre-operative diplopia, $48 \%$ had resolution of their diplopia postoperatively. The mean reduction in proptosis was $4.7 \mathrm{~mm}$. No patient experienced intraoperative and or post-operative complications. Conclusion: Image-guide balanced lateral, medial and inferior orbital decompression can result in improvement of visua acuity and resolution of preexisting diplopia while allowing for

\section{Introduction}

Thyroid eye disease (TED) or Graves' orbitopathy, often associated with Graves' thyroid disease is the most common chronic autoimmun orbital disorder. ${ }^{1}$ Lymphocytic infiltration along with fibroblast reaction generates a volume expansion for the orbital cavity which manifests in several ophthalmic consequences including lid lag, retraction, proptosis, exposure at and post-operative clinical data significant reduction in proptosis keratitis, strabismus, and diplopia. TED occurs in about $50 \%$ of cases of Graves' disease, and significant corneal dryness, orbital pain, double vision, and proptosis can lead to visual deterioration and functional disability in $20-30 \% .^{2}$ In $3-5 \%$ of patients, severe cellular proliferation inflammation, and accumulation of hydrophilic glycosaminoglycans also resulted in compressive optic neuropathy for which patients are at risk of permanent blindness

without rapid intervention

High-dose corticosteroid therapy can limit the progression of ocular sequelae. ${ }^{4}$ However, for those with severe disease-causing compressive optic neuropathy, or proptosis with exposure keratitis, surgical decompression is recommended. The methods of decompression have varied with mixed results with respect to symptomatic improvement and morbidities. Two-wall (lateral and medial) and three-wall (lateral, inferior and medial) balanced decompressions approaches used. In addition image-guided surgery has been gradually adopted for use in orbital decompression surgery to provide intraoperative anatomic localization with the goal of improving surgeon confidence in minimizing potential rare serious surgical complications such as ocular laceration, periorbita hemorrhage, and nerve injury, ${ }^{6,7}$ Dural tear and cerebrospinal fluid (CSF) leak have also been reported. ${ }^{8,9}$ Diplopia, however, is not only one of the most common symptoms but also one of the most common side effects of orbital decompression surgery, are the most common surgical and the incidence of new onset or worsening of existing diplopia in balanced orbital decompression surgery is $7-33 \% \%^{10,11}$ Several modifications have been suggested to decrease the diplopia rate such as preserving optic strut, preserving periosteal band over rectus muscles, and avoiding decompressing of the orbita floor. We report our experience of image-guided balanced orbita decompression without fat excision in patients with thyroid eye disease.

Material and Methods An institutional review board (IRB) approved retrospective chart (IRB) appiaved retrospective chart consecutive patients undergoin conseculve patients undergoin ron an for Graves orbitopathy between All petien 2010 and Decomber 2016. All palients were evalualed preoperatively and post-operatively in che otolaryngology and oculoplastic clinics at the West Virginia Univers Hospitals. Demographic data including age, sex, gender, date, and side of surgery were collected Preoperative and postoperative formal ophthalmologic evaluation included Snellen visual acuity, pupillary response, ocular motility, color vision, sil lamp biomicroscopy, fundoscopy, palpebral fissure heigh scleral show, lagophthalmos, Herte exophthalmometry, and Humphrey visual fields. Nasal endoscopy was performed preoperatively to evalua the nasal anatomy and presence of any pathologies, and postoperative to monitor healing. Pre-operative BRAINLAB (Munich, Germany) computed tomographic (CT) scan of the sinuses and orbits to evaluate for anatomic variations was routinely performed on all patients and used for intra-operative navigation. Al decompressions were performed by the same otolaryngologist and same oculoplastic surgeon (HR, JN).
Surgical techniques Endoscopic medial and inferior decompression was performed first by the otolaryngology service, (HR) under intraoperative navigation with BRAINLAB (Figure 1A). Bilaten nasal cavities were initilly packed with cotton pledgets soally packed $0.5 \%$ oxymetazoline After allowing time for initial hemostasis, $1 \%$ lidocaine with $1: 100,000$ epinep docaine with 1:100,000 epheph was inject into the nasal sep mucosa and lateral nasal wall mucosa. Open or endoscopic when necessary formed when necessary for access. An by a wide mide The maxillary sinela antrostomy. The maxillary sinus ostium was identied and enlarged posteriony and inferionly. Complete anterior and postenor ellmoidectomy and fronta sinusotomy was then performed. The sphenoid rostrum and lamina papyrecea were identified. Using BRAINLAB, the most posterio aspect of decompression was mapped. The lamina papyrecea was removed. The vertical buttress of the maxillary sinus was partially removed posteriorly enough to allow for inferior periorbital incision. After exposure of the periorbita, it was incised with a sickle knife in a posterior to anterior direction inferior to the medial rectus muscle and another incision superior to it. The septae with the intraoral fat are gently divided, and gentle retropulsion of the globe is

performed to assess for orbital fat extrusion (Figure 1B). Finally, the maxillary antrostomy and nasofrontal recess are assessed for patency to prevent any postoperative stenosis by orbital fat. Lateral orbital decompression began with infiltration of the lateral canthal region consisting of $2 \%$ lidocaine with $1: 100,000$ epinephrine. A 2-cm lateral canthal incision was made. Dissection was carried through the orbicularis to the

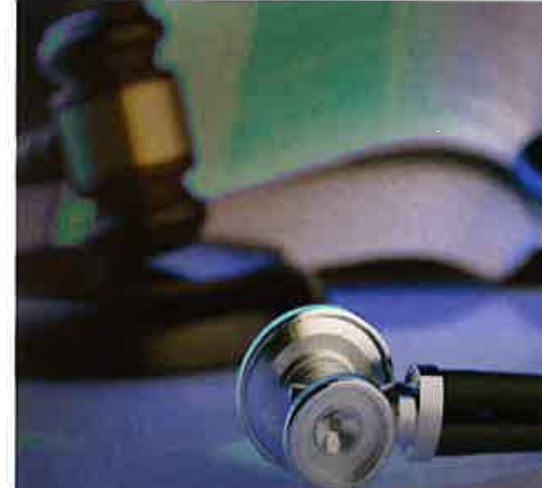

Protecting the interests of healthcare professionals

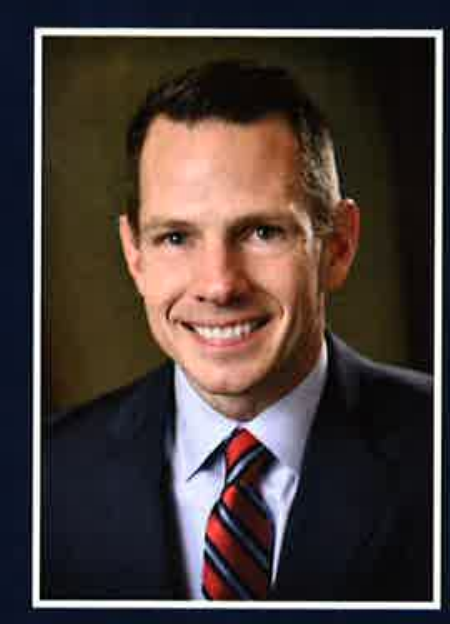

William J. Ihlenfeld, II Healthcare Litigation Lawyer

Former U.S. Attorney

BAILEY GLASSER LLP

304.905.1592

Responsible Attorney:

William J. Ihlenfeld,II

2001 Main Street, Suite 203 Wheeling, WV 26003 


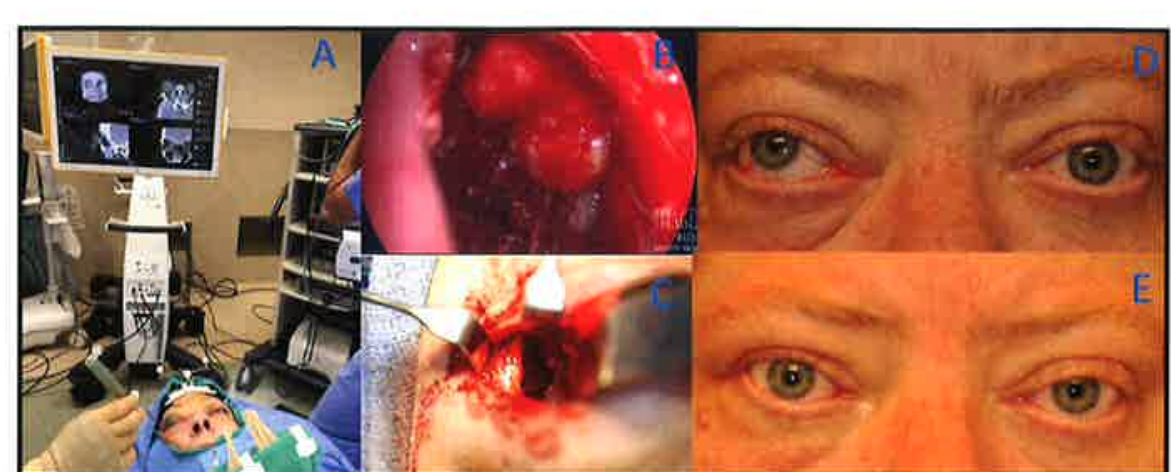

Figures 1A-E

Table 1. Descriptive statistics of study population (total 169 orbits in 103 patients)

\begin{tabular}{|l|l|}
\hline CATEGORY & \multicolumn{1}{|c|}{ SAMPLE SIZE } \\
\hline Gender & \\
\hline Male & $33(32 \%)$ \\
\hline Female & $70(68 \%)$ \\
\hline Ethnicity & \\
\hline Caucasian & $97(94.2 \%)$ \\
\hline African-American & $5(4.9 \%)$ \\
\hline Others & $1(0.9 \%)$ \\
\hline Thyroid Disease & \\
\hline Hyperthyroid & $83(80.7 \%)$ \\
\hline Hypothyroid & $19(18.4 \%)$ \\
\hline Hashimoto thyroiditis & $1(0.9 \%)$ \\
\hline Smoking & $79(76.9 \%)$ \\
\hline Thyroid treatment & \\
\hline Thyroidectomy & $13(12.6 \%)$ \\
\hline Radioactive iodine & $29(28.2 \%)$ \\
\hline Antithyroid medications & $61(59.2)$ \\
\hline Orbital decompression surgeries & \\
\hline Unilateral & $37(21.9 \%)$ \\
\hline Bilateral & $132(78.1 \%)$ \\
\hline
\end{tabular}

Table 2. Post-decompression outcomes.

\begin{tabular}{|l|l|l|l|}
\hline & \multicolumn{1}{|c|}{ Pre-op } & \multicolumn{1}{|c|}{ Post-Op } & p-value \\
\hline Vision (logMAR) & $0.4(0.1-1)$ & $0.1(0-0.7)$ & 0.021 \\
\hline Lagophthalmos (mm) & $1.1(0-4)$ & $0.6(0-3)$ & 0.168 \\
\hline Exophthalmometry (mm) & $24.1(19-30)$ & $19.4(17-25)$ & 0.039 \\
\hline Diplopia & $75(72.8 \%)$ & $45(43.7 \%)$ & \\
\hline
\end{tabular}

lateral orbital rim using monopole cautery. The periorbita was incised along the lateral orbital rim, and blunt dissection was performed to expose the lateral orbital wall. The Sonope ultrasonic bone aspirator (Stryker, Kalamazoo, MI) was then used to methodically remove the lateral wall including the trigone of the sphenoid greater wing (Figure 1B). Superior, posterior, and inferior limits of decompression were noted to vary depending on bony anatomy, and in each case, the safe maximal limit of bone removal was determined using BRAINLAB navigation. At the completion of the osteotomy the periorbita was fenestrated, allowing retrobulbar fat to fill the space created. The lateral canthal wound was closed in two layers.

\section{Results}

One hundred sixty-nine orbits of 103 patients underwent imageguided three-wall balanced orbital decompression (Table 1). 66 patients had 37 parients a 37 pale of one orbit. Mean age was 56 years old, ranging from 31 to 73 years. 70 $(68.0 \%)$ were women. 79 patients $(76.9 \%)$ were smokers. Average postoperative follow up time was 22 months (range of 11-48 months) The indications for surgery were proptosis, lagophthalmos with exposure keratopathy, and/ or compressive optic neuropathy. Eighty-eight $(52.1 \%)$ surgeries were performed on the left orbit. Seventyfive $(72.8 \%)$ patients presented with pre-operative diplopia and the incidence of new-onset postoperative diplopia was seen in six $(5.8 \%)$ patients (Table 2 ). In the 75 patients with pre-operative diplopia thirty-six $(48 \%)$ had resolution of their diplopia post-operatively, $51(68 \%)$ of which had bilateral orbital decompression. All patients maintained or had improved Snellen visual acuity. The mean reduction in proptosis was $4.7 \mathrm{~mm}(3-8 \mathrm{~mm})$. All patients also had improvement of lagophthalmos (Figures 1D-1E). No intraoperative complications were encountered during any of the cases, and immediate post-operative sequalae included pain, regional hypoesthesia, and epiphora which resolved at subsequent follow up.

\section{Discussion}

Orbital decompression is a well-established surgery for the treatment of exophthalmos and visual loss from optic neuropath in Graves' orbitopathy. ${ }^{6}$ Since the 1950s; its indication has widened from treatment of optic neuropathy to include disfigurement from proptosis and eyelid retraction along with ocular complications of exposite keratoconjunctivitis ${ }^{7,8} \mathrm{Walsh}$ popularized Transantral approach popularized Transantral approach 1957 ? With the introduction of the endoscope Kennedy introduced endoscope, Kennedy introduced approach of the medial wall and of the orbital floor in the 1990 s, with fewer complications and better outcomes. ${ }^{9}$ While balanced orbital decompression was more commonty performed, rare cases of orbital roof decompression have been reported in severe cases refractory to traditional decompression $7.121,13.14$ The incidence of new-onset diplopia after orbital decompression has been reported to occur from 0 to $64 \%$ depending on the technique. 10,11 Our results showed a $5.8 \%$ incidence of new-onset post-operative diplopia which is lower than $7-33 \%$ in similar series of balanced orbital decompression. Several modifications to lower the incidence of diplopia have been described, including the orbital sling technique described by Metson and Samaha in 2002,16 and preserving the inferomedial bony strut between the medial orbital wall and the orbita floor which was utilized in our case series. $17,18,19$ Kingdom et al. reported no new incidence of diplopia among patients who underwent three-wall orbital decompression. Their surgical technique included preserving the vertical inferomedia strut in all patients, and their improvement in proptosis was 3.2 $\mathrm{mm} .{ }^{19}$ Furthermore, the rate of smoking in our patient population is among the higher of the reported series which had been known to produce more severe disease and are more resistant to medica and surgical interventions. Few studies reported on diplopia resolution which ranged from $0-36 \%$. Leaving an intact periorbita was described to minimize diplopia in the series by Mainville et al. that reported a rate of $28.1 \%, 20$ However, leaving an intact periorbital significantly reduces the decompression achieved. The periorbital was opened in all of our patients, and $42 \%$ of our patients had resolution of their diplopia which is higher than all reported series. In our series, the imaged-guided balanced orbital decompression with partial removal of the inferomedial strut and the orbital sling technique described by Metson resulted in exophthalmometry improvement of $4.7 \mathrm{~mm}$ which is similar to what is reported in the literature. ${ }^{14}$ Surgical techniques have contributed to the difference when compared to certain series with less proptosis reduction. Various techniques have been described including temporary removal of the lateral orbital wall for access to the deep lateral orbital wall, removal of the lateral wall without replacement of the frontal process of the zygoma, and valgus rotation of replaced lateral wall to add volume to the orbit. ${ }^{21-23}$ Complete removal of the sphenoid trigone has been advocated by some authors, and the contribution of this bony remova has been shown to be $2.3 \mathrm{~mm}$. however, this was not performed in our series ${ }^{24} \mathrm{All}$ the current patients had resolution of optic neuropathy, exposure, and proptosis, and none required subsequent surgery for lateral orbital wall remt surgery

The application of image guidanc system to orbital decompression 
surgery provides orbit surgeons as well as ENT surgeons with real-tim feedback of the anatomy and can potentially enhance the surgeons comfort in deep orbital bony remo This may lead in a given case to greater orbital decompression or may lead to greater decompression with more benefits for the patients over a surgeon's personal series as she/he becomes more comfortable with the anatomy based on realtime navigation output. As there is variation of anatomy and agreement of the extent of bony removal in the literature, the posterior limit of orbital decompression is difficult to define intraoperatively. The surgeon is often restrained with the dee orbital bony removal to prevent complications. Image guidance is, therefore, advantageous for deep orbital decompression, in that it enhances the surgeon's radiologic view of the posterior orbit. If virtually eliminates any benefits of concurrent radiographic examination such as intraoperative CT. This study is limited by its descriptive nature and lack of control or comparison cohorts. Studies of this technique on larger numbers of patients are desirable to reaffirm the advantages of this technique compared with other operating techniques. No serious complications were encountered in this cohort. Image guidance systems are relatively accurate and reliable enough to aid in orbital decompression surgery. The registration process for image

guidance is quick and poses no distraction from the surgery. In addition, the single handplece ultrasonic bone aspirator aid in improving safety to orbital tissues and might increase some surgeons' confidence, especially while learning the procedure.

\section{Conclusion}

The image-guidance three-wall balanced orbital decompression is an effective treatment strategy for Graves' orbitopathy with restoration of visual acuity, lowering the risk of new-onset diplopia, and improved proptosis.

References

1. Borumandi F, Hammer B, Noser H, Kamer Classification of orbitial morphology
decompression surgery in Groves decompression surgery in Graves'
orbitiopathy: two-dimensional versus three dimmensinonal orbital parameters.
Ophthalmol $2013.97 .659-662$ Bartalena L, Tanda ML. Clinical practice.
Graves' ophthalmopathy. N Engl J Med 2009: Graves' ophthalmopathy. N Engl J Med
360:994-1001. Weisman RA, Osguthorpe DJ. Orbital decompression in Graves' disease. Arch
Otolannmool Head Neck Sis 1994: 120 Guy RR, Fagien S, Donovan JP, et al.

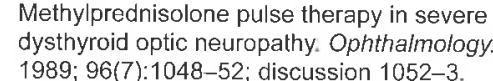
1989; 966(7):1048-52; discussion 1052-3,
Silver RD, Harrison AR, Goding GS. Lateral Orbital Decompression for Progressive Thyroid Eye Deck Sese, Ololaryngology-Hest 6. Mourits MP, Rose GE, Garrity JA, Nardi M

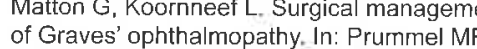
editor(s). Recent developments in Graves'
Ophthalmooathy. Boston, Dordrecht, Lond Kluwer Academii Publishers, 2000: $133-52$
Walsh TE, Ogura JH. Transantral orbital decompression for malignant exophth
Laynngoscope $1957 ; 67(6): 544-68$. 8. Bahn RS. II orbitital decompression a safe and
effective treatment for Graves' orbitiopathy? Effective trealment for Graves' orbititopathy?
Nature Clinical Practice Endocrinology and

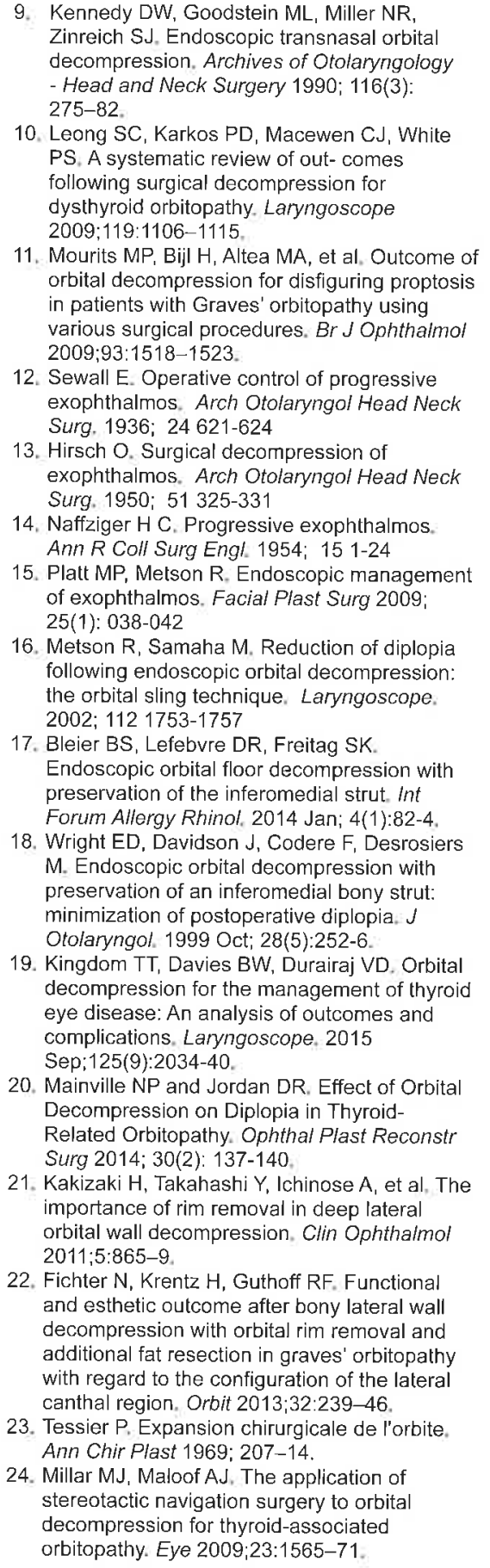

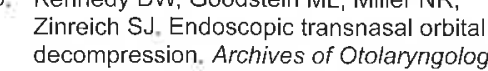
275-82. Leong SC, Karkos PD, Macewen CJ, White
PS. A systematic review of out- comes dysthyroid orbitopathy. Laryngoscopo

Mourts MP, Bijl H, Altea MA, et al. Outcome of in patients with Graves' orbititopathy using 2009:93:1518-1523. Hirsch O. Surgical decompression of Surf, 1950; 51 325-331
Naffziger HC. Progressive exophthalm of exophthalmos. Facial Plast Surg 2009; Ollowing endoscopic orbitalact decompression sopic orbital floor decompression with
vation of the inferomedial strut. Int Frum Alilergy Rhinol. 2014 Jan; 4(1):82-4.

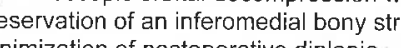
aj VD. Orbital Maintiving

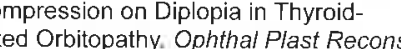
Kakizaki H. Takahashi Y, Ichinose A, et al, T rbital wall decompression, Clin Oohthalm esthetic oulcome after bony lateral wal Dof AJ. The application of decompression for thyroid-associated
orbitopathy: Eye 2009:33:1565-71.
WANTED: Full-time Clinical Administrator Orthopedic Private Practice-Scott Orthopedic Center

We are seeking a strong, dynamic, clinical administrator with knowledge of health care operations, including physician practice management, to join the administrative team of a busy established private practice. Must have knowledge of nursing and MA scopes of practice and health care regulations. Compliance policy and procedure development and $\mathrm{PI}$ development experience preferred. Experience in a surgical practice is a plus. At least 2 years managerial experience in a health care setting is required. Salary is negotiable.

\section{You're here to practice medicine}

We're here to make your life easier.

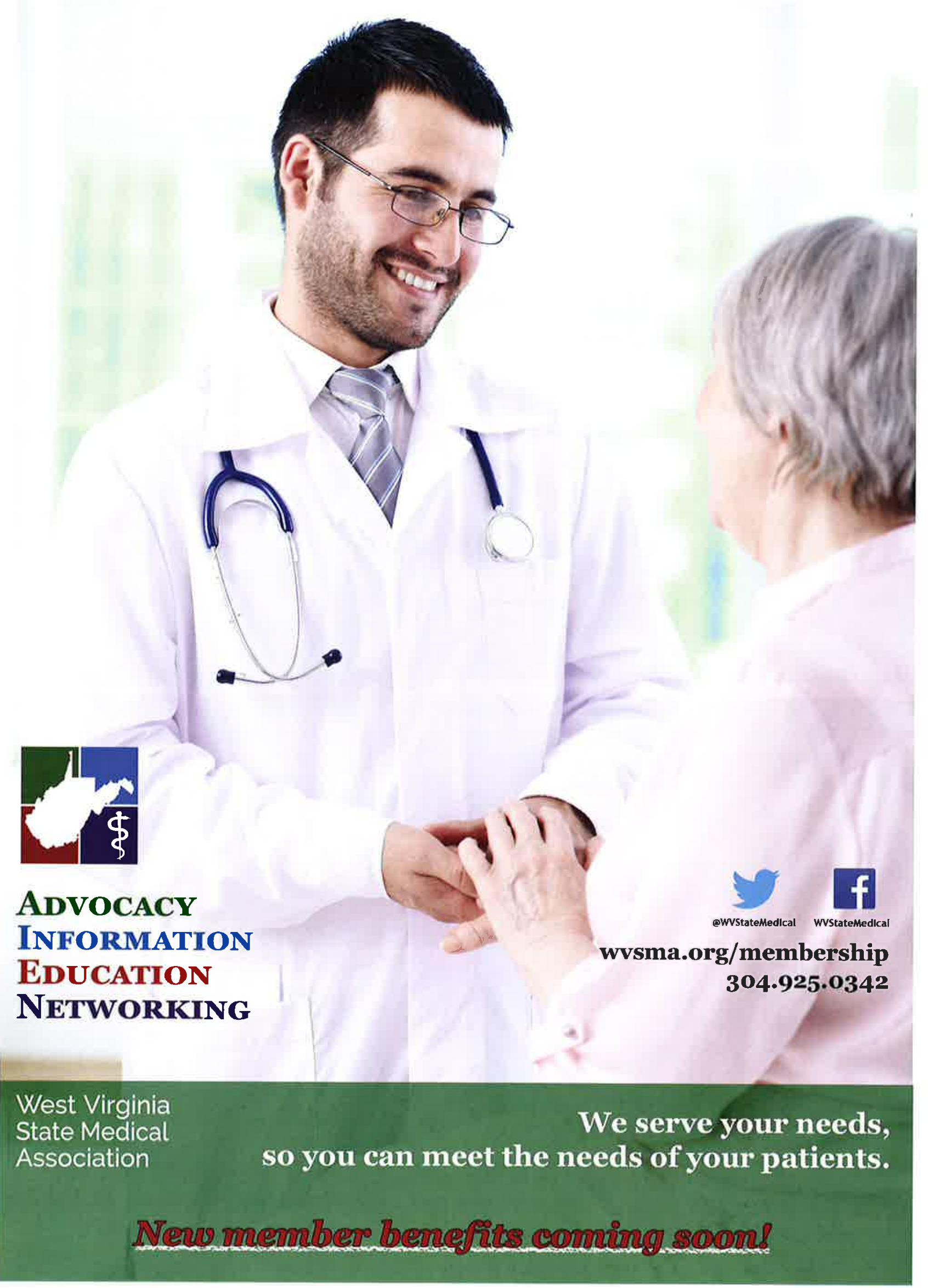




\section{muTulaL} Chairman \& CEO Insurance Company
R. Austin Wallace, $M D$

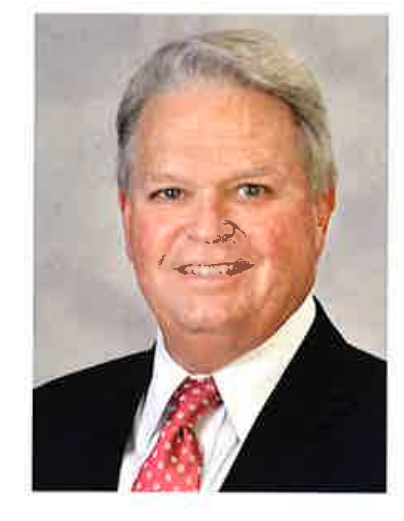

We Are Committed to Your Risk Management

Your West Virginia Mutual Insurance Company strongly values risk management as a means for practitioners to provide quality healthcare and ensure patient safety, thereby avoiding medical liability pitfalls. We have excellent risk management professionals that work every day with the physicians of our area, and practitioners often have the same question: What can I do to prevent a lawsuit? Interestingly, some relatively simple measures can help to avoid the immense future hear heartache or going through the defense of a medical malpractice lawsuit. First, since our area is at the epicenter of the opioid crisis, always ensure that you prescribe opioids responsibly and that you follow state guidelines, as should be obvious. Second, it is definitely not a good idea to use single-dose medication vials in a multiple-dose way, as this will come out during the discovery process and will be a huge hurdle in defending the claim if it involves infection. Thind, in defending the che document afler-hours telephone conversations with a short note, as it is not uncommon that even a simple notation of "go to the ER" can make the defense of the lawsuit much easier and, indeed, make some lawsuits go away completely. Fourth, never keep unlabeled and/ or pre-filled syringes in the office, as medication errors are a very significant driver of medical malpractice claims. Fifth, even though it is an onerous duty, please ensure ensure that EvR documentation is accurate and that medication and allergy lists are current. Autopopulation of electronic health records can be a huge problem, in that allergy lists and medication lists can be dated and no longer accurate leading to therapeutic misadventures. In addition, spurious information can make defending a claim quite difficult. For example, "normal prostate exam" in a female or "normal pelvic exam" in a male can make the entire medical record very suspect, even if the remainder is truthful and is recognized and amended immediately including a ime and date along wh an expand as 10 why the addendum is necessary, never, ever add a later undated be considered spoliation of the medical record. This

tort reforms that we so vigorously fought for and won, which has the consequence of markedly increased potential damages, including punitive damages that are rarely granted in a medical liability lawsuit. Sixth, please make sure that your medical assistants are adequately trained to their level of allowed responsibility and that you and your staff have an excellent system adverse health outcomes, which, in turn, lead to lawsuits. Finally, please ensure the security of the health record, as HIPAA claims can be quite expensive. To this end, our compliance specialist, Michael Harmon, can help you, our insureds, in establishing and maintaining proper procedures and protocols. Our risk management specialists stand ready to assist you in these and other matters impacting patient safety and the quality delivery of health care, and please be assured that your Mutual's commitment to risk management is unwavering, as we are Physicians Insuring Physicians. accurate. Furthermore, unless an error or omission addendum to a medical record after the fact, as this can leads to the lawsuit falling outside the medical liability
PHYSICIAN gOVERNED

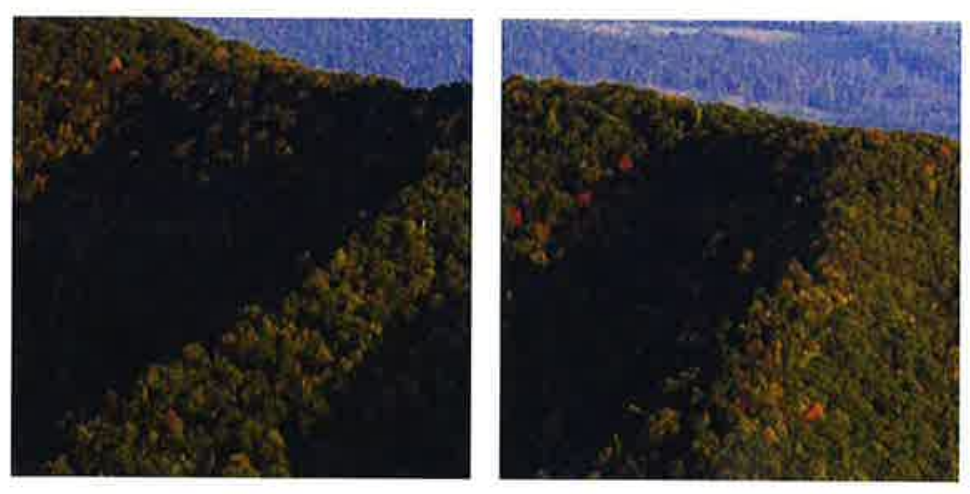

PHYSICIAN

MANAGED

PHYSICIAN DRIVEN
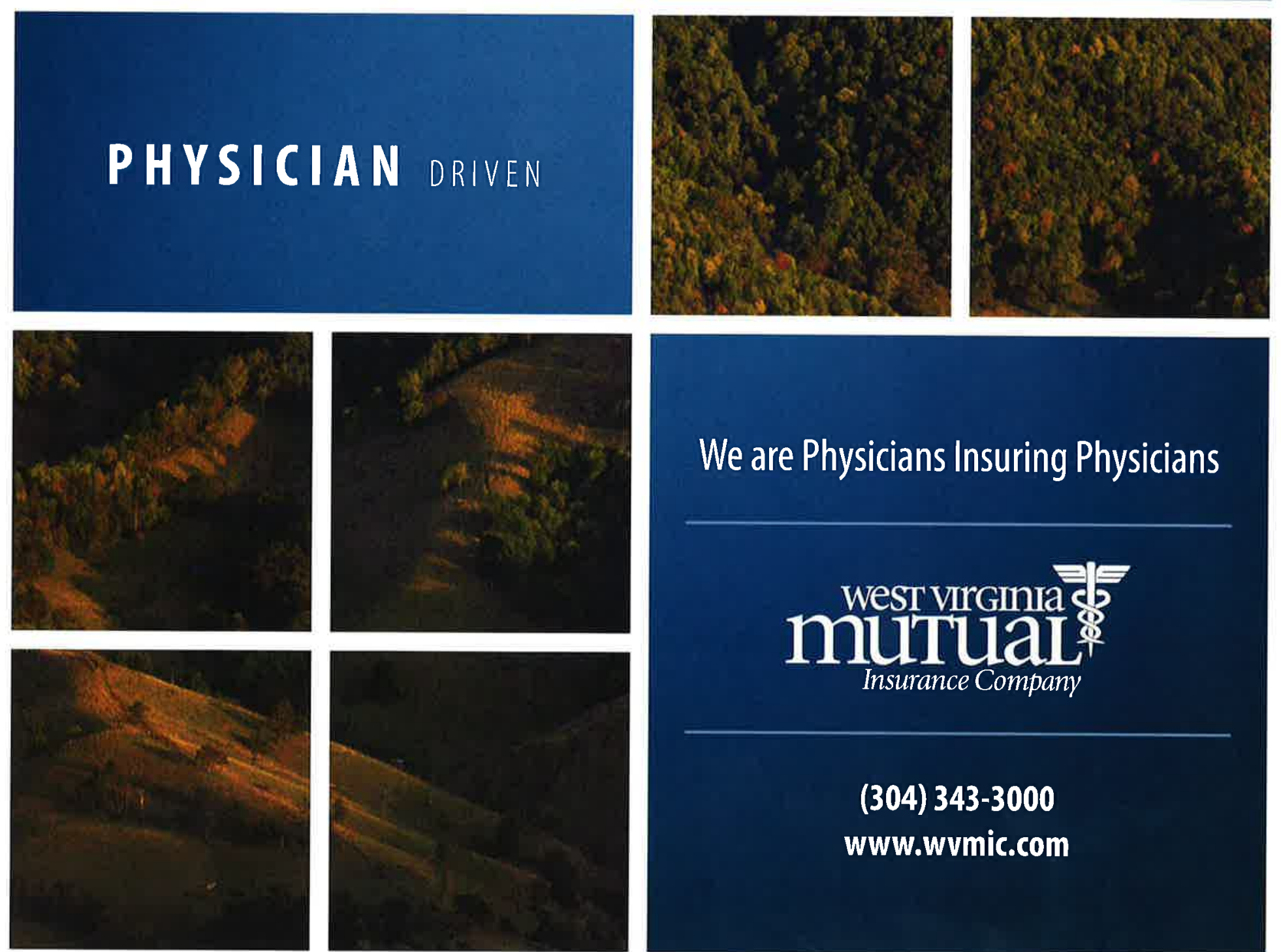

We are Physicians Insuring Physicians

\section{west virgina $\overline{0}=$ mutual\% \\ Insurance Company}

(304) $343-3000$

www.wvmic.com 
Confronting a Crisis: How West Virginia's Health Commissioner Took on the Opioid Epidemic

Reprinted with permission. Governing Magazine
PUBLIC OFFICIALL of the YEAR, Rahul Gupta, MD 2018 HONOREE Photo by Danny Scalise, WVSMA Executive Director

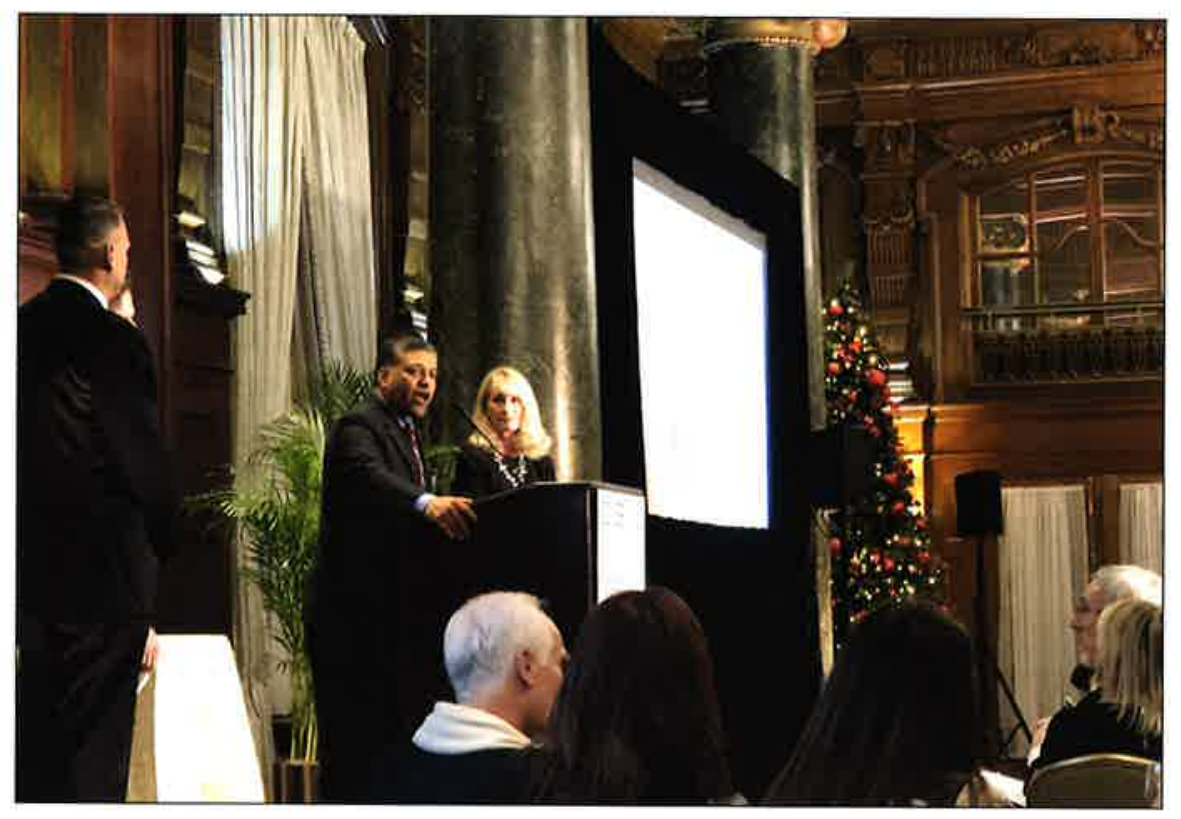

It was an unlikely journey that led Rahul Gupta, MD to become the public health commissioner for West Virginia, but it was one that followed his passion for treating the most vulnerable patients in the world from plague victims in New Delh to opioid addicts in rural America. The son of Indian diplomats, Gupta was raised in the Washingto D.C., area, but returned to his native New Delhi for medical school. There, he worked on a vaccination campaign to eradicate pollo. llwas the first time such a country, and it wo "It the me a sense of what's possibl" Gupta says. "I've seen childre, die because of polio tetanus and the plague We don't really and those public health problems in America, and that gives me a larger perspective for what I do. Gupta's sense of medical possibility was reinforced for him when he returned to America to work as a doctor in Birmingham, Ala. He dealt with Medicaid patients who had trouble meeting $\$ 1$ copays on pharmacies and found he could get them to waive those fees. His work led him to West Virginia, where he won notice for his handling of the 2014 Elk River chemical spill, which left more than 300,000 of the state's residents in nine counties without safe tap water. He was praised for working quickly to get clean water restored preventing larger-scale public healh problems. Soon after that Dirginia's Upon taing office, he with on were overdosing from opioids ans alarming rate. Nearly 900 people even more died in 2017. "The opioid epidemic has been a punch their prescription drugs. He called asked Gopta to be Tomblin the state's history West Virgics in died from opioid abuse in 2016: to West Virginia. It's crippled us," says Danny Scalise, executive director of the West Virginia State Medical Association. "But Gupta has been the counterpunch." In order to curb overdoses, Gupta sought to understand exactly who the victims were and how they were falling into danger. He led a team that conducted what he calls a "postautopsy autopsy." The findings were illuminating: Four out of five of those who died had come into contact with the health-care system, and those who had visited three or more pharmacies getting prescriptions filled were 70 times more likely to die. Only 2 in 10 of those who died had received naloxone, the antidote to an overdose. Gupta established an opioid response panel that asked affected communities what they wanted from the state. This year, as a result of the state legislature passed the Opioid Reduction Act, a multipronged approach that, among other features, expands the availability and limits when and how ofen coctors can prescibe opids. It's tor soon to say whether Gupte's efforts and the new legislation will make a serious dent not be there to see the impact: He accepted a position with the March of Dimes in September. Still Scalise says that the commissioner's his tenure "We are going to see drawback in overdoses " he says. "The reason we have any good news is because of Dr. Gupta."

-Mattie Quinn research and community input, the in the epidemic. Gupta himself will impact on the state will far outlast

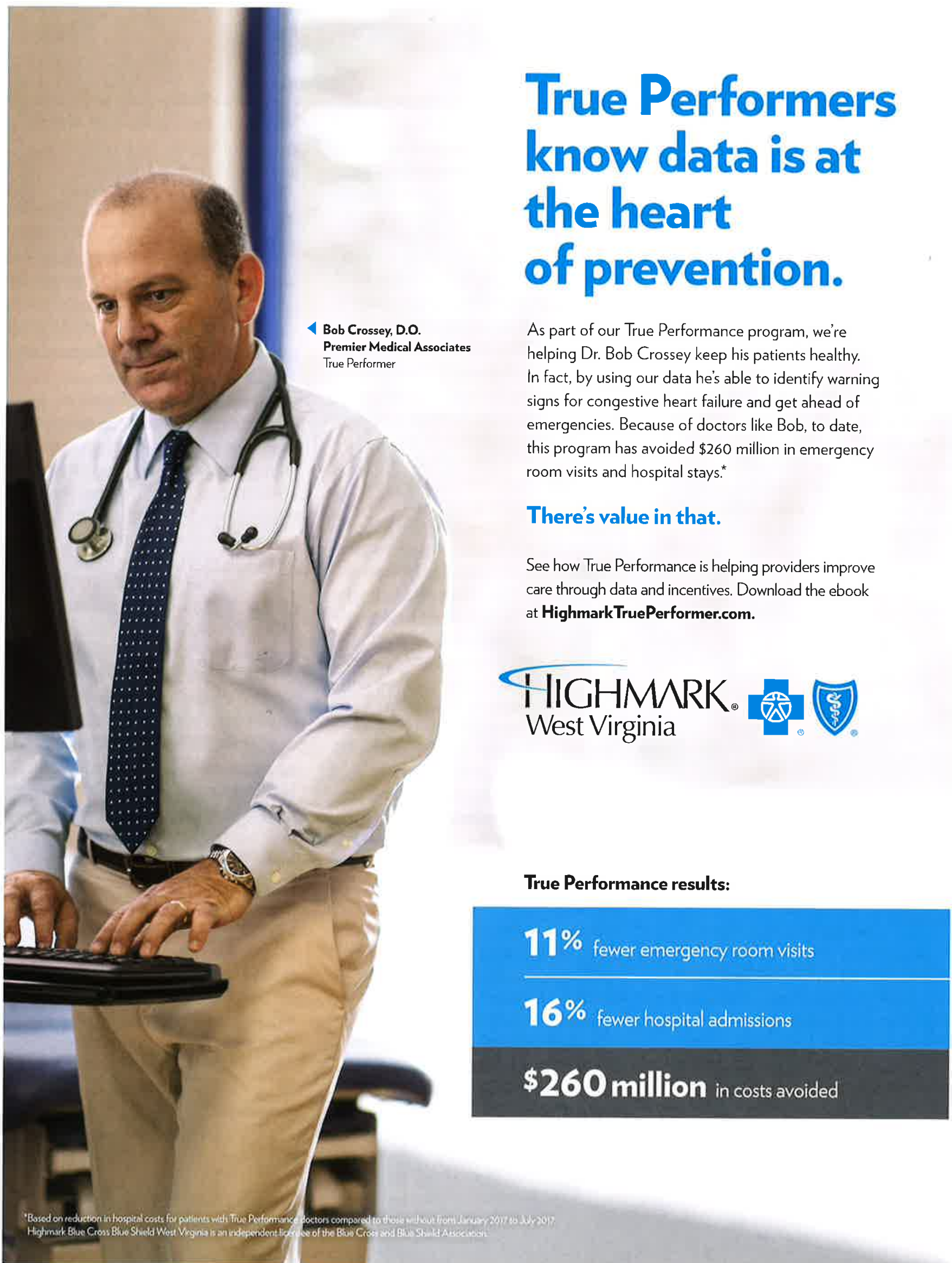




\section{OPIOID REDUCTION ACT}

Briana Breault West Virginia University College of Law

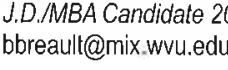

Garrett Grafton

West Virginina University College of Lan n June 7, 2018, the Opioid Reduction Act ("ORA"),
formerly known as Senate Bill 273, was enacted into the West Virginia Legislature.' While the goal of the ORA is to address the opioid crisis currently affecting the majorily of the United States, including West Virginia, the ORA places significant limitations on the ability of a practitioner to prescribe opioids. Furthermore, the ORA addresses opioid prescription notifications,

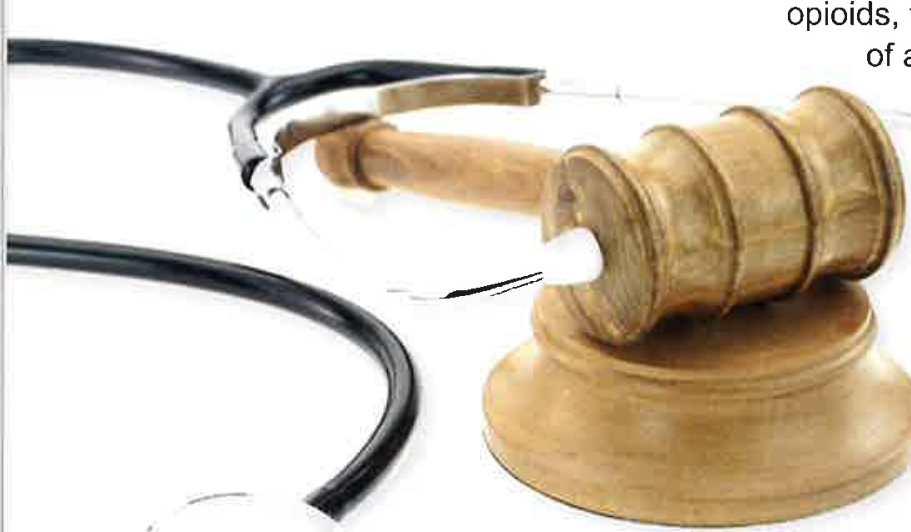

from issuing an opioid prescription a minor for more the (3) increases the likelihood of a patient's days, and the practition three (3) education, but it could also reduce

to discuss the risks associated with opioid use with the parent guardian of the minor ${ }^{4}$ Dentists and guarchar or he minor. Dentists and

further, allowed to only issuc a three (3) day initial opioid prescription ${ }^{5}$ Similarly, a health care practitioner may not issue a prescription for more than a four (4) day supply an adult patient seeking treatment in an emergency room or urgent care facility setting for outpatient use This provision specifically highlights the legislature's attempts to contro the opioid crisis. The legislature reasoned that limiting opioid prescriptions in emergency settings Oill reduce the overall exposure to of addiction. Reducing the
of thus reducing the threat hreat of addiction will also reduce the trequency of opioidrelated emergencies and The legislature hopes that the restrictions placed on initial opioid prescriptions will reduce follow-up visits for subsequent opioid prescriptions. To

subsequent opioid treatment, and referral to pain clinics or pain specialists. A violation of the ORA is grounds for disciplinary action by the board that regulates the health care practition Who commits the violation.

mand ORA defines very narrow physician to issung a piod

prescription only for a maximum of seven (7) days at the lowest effective dose, unless the patient has executed a narcotics contract with their prescribing physician. ${ }^{3}$ The ORA further prohibits a practitioner accomplish this goal, the ORA prohibits physicians from issuing subsequent opioid prescription within six (6) days after issuing the initial opioid prescription.' During a follow-up visit, the physician or other health care practitioner is required to educate the patient on the risks that are associated with opioid prescriplions. "To ensure hat a patient acknowledges pescriptions, physicins and healh care practitioners are encourad o prepare a form the patient will sign as an indication of the patient's understanding of the associated risks. This documentation not only
Upon the issuance of a third is required to consider referring the and must discuss the benefits of or specialsto However, if the patent declnos to seek treatment and the physicin continecilst prescribe opioid to the patient, physian is requied to attem, the stop or decrease the use of opioid prescriptions and document the efforts mode by the physician.10

The ORA does not apply to a prescription for a patient who is currently receiving treatment for cancer, palliative care, substance abuse or opioid dependence, or post-surgery care ${ }^{11}$ Furthermore the ORA does not apply to an existing practitioner-patient relationship established before January 1,2018 , where there is an established and current opioid treatment plan, reflected in the patient's medical records. ${ }^{12}$ The provisions of the ORA affect the way that a physician or other health care practitioner may prescribe opioids. Therefore, physicians and other health care practitioners are encouraged to review the changes set forth by the ORA and to consult with legal counsel regarding the ORA's implication on practicing medicine in West Virginia.

Endnotes

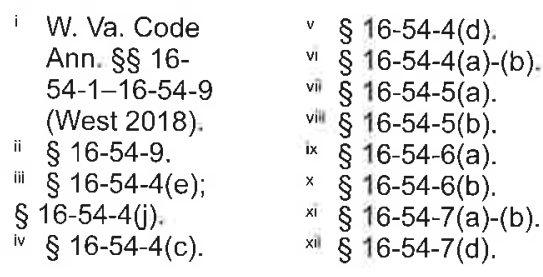
opioid prescription, the physician patient to a pain clinic or specialis treatment through a pain clinic

\section{HPV Vaccine Update}

Sherri Young, DO, FAAFP

$\mathrm{n}$ a press release on October 5,2018 , the US Food and Drug Administration (FDA) announced the expanded approval for the human papillomavirus (HPV) vaccine to be available for men and women between the ages of 27 to 45 . Previously, the FDA, as well as the Advisory Committee for Immunization Practices (ACIP) recommended the HPV vaccine be given to patients age 9-26. Th expanded age group will allow greater protection to more patien against cervical, vulvar, anal, vaginal, and oropharyngeal cancers On October 7, 2016, the FDA approved a 2-dose schedule for doses were required for everyone receiving the HPV vaccination. The $H P V$ vaccine can be given using a 2-dose or 3-dose schedule. For shot should be given $6-12$ months shot is given less than 5 mond fter the first shot, a third shot should be given a teast 4 mor shord be given at least 4 month 3-dose schedule, the second dose patients age 9-14. Previously, 3 the 2-dose schedule, the second after the first shot if the second should be given 2 months after the first, and the third shot should be given 6 months after the first. Patients age 15 or older should be given the vaccine using a 3 -dose schedule; the second shot should be given 2 months after the first shot, and the third dose should be given 6 months after the first be HPV is the most common sexually transmitted infection (STI). With mansmis 100 stion (STI). WTH 40 an 00 strans or HPV, 40 are specifically linked Io STls. HPV has no signs or symptoms, partners without any warning of the disease. 79 million Americans are currently infected with HPV. 14 million are newly infected each year. 31 thousand new HPV associated cancers are diagnosed each are diagnosed each year. Most of these prevented with the us
of the HPV vaccine. The HPV vaccine. vaccine, Gardasil $9 \odot$ therefore is easily passed between protects against the following strains of HPV: $6,11,16,18,31,33,45$ decreases cervical cancer risk by $90-95 \%$, vaginal cancers up to $85 \%$ vulvar and anal cancers up to $90 \%$ while decreasing the risk of genital ( addition vaccin please visit www.cdc.gov/vaccines. $52 \& 58)$. This 9 -valent vaccine

\section{Stay Connected!}


Marshall Health, School of Medicine launch 'dementia café'

Marshall Health and the Marshall University Joan C. Edwards School of Medicine are launching a new experience that takes a different approach in caring for patients with dementia. A concept that originated in the Netherlands in 1997 and came to the United States in 2008, the "dementia café" offers creative activities, socia interaction and refreshments in a with dementia and their caregivers. "As dementia progresses, it often becomes difficult for persons Wh dementia to be around people, places or events they M. Neitch M. D a a seriatrician a Marshall Health director of the Maier Institute for Excellence in Prescribing for

\begin{tabular}{|c|c|}
\hline $\begin{array}{l}\text { Elders with Dementia at the Joan } \\
\text { C. Edwards School of Medicine. } \\
\text { "In addition to concern about } \\
\text { their forgetfulness, persons with } \\
\text { dementia may also worry about } \\
\text { being too messy or slow." } \\
\text { The dementia café experience } \\
\text { will allow participants to interact } \\
\text { with others who understand the } \\
\text { challenges and concerns they } \\
\text { face. Activities will include musical } \\
\text { performances, gallery-type art } \\
\text { displays, art creation and crafts, as } \\
\text { well as other literary activities such } \\
\text { as poetry writing and journaling. } \\
\text { Participants may drop in briefly } \\
\text { or stay the entire time. Caregivers } \\
\text { will also be able to engage with } \\
\text { other caregivers without having } \\
\text { to plan activities or clean up. } \\
\text { The dementia café is an } \\
\text { extension of the specialized care }\end{array}$ & $\begin{array}{l}\text { Marshall Health patients receive } \\
\text { through the Susan Edwards Drake } \\
\text { dementia clinic, which integrates } \\
\text { physicians, pharmacists, social } \\
\text { workers and caregivers into a } \\
\text { patient's care and communication. } \\
\text { For more information or to } \\
\text { volunteer, call Marshall Internal } \\
\text { Medicine at 304-691-1681. }\end{array}$ \\
\hline
\end{tabular}

Marshall School of Medicine brings monthly training sessions to primary care providers across West Virginia

\begin{tabular}{|c|c|c|}
\hline $\begin{array}{l}\text { Marshall University Joan C. } \\
\text { Edwards School of Medicine, in } \\
\text { partnership with Project ECHO® } \\
\text { (Extension for Community } \\
\text { Healthcare Outcomes), } \\
\text { offers teleECHO'T training } \\
\text { sessions at noon on the first } \\
\text { Tuesday of each month. } \\
\text { "TeleECHO clinics are basically } \\
\text { interactive sessions between } \\
\text { specialists and primary care } \\
\text { providers who are serving an } \\
\text { often rural patient population," } \\
\text { said Jennifer Plymale, director of } \\
\text { the Robert C. Byrd Center for Rural } \\
\text { Health at the Joan C. Edwards } \\
\text { School of Medicine. "These }\end{array}$ & $\begin{array}{l}\text { sessions allow rural providers } \\
\text { to participate from their clinics, } \\
\text { therefore eliminating time away } \\
\text { from their offices or their families." } \\
\text { The clinics connect primary care } \\
\text { providers from multiple locations } \\
\text { with a team of specialists using low } \\
\text { cost, multi-point videoconferencing. } \\
\text { The providers present de-identified } \\
\text { patient cases, and the specialists } \\
\text { provide expertise on managing } \\
\text { patients with chronic, common and } \\
\text { complicated conditions. The case- } \\
\text { based discussions are supplemented } \\
\text { with short didactic presentations } \\
\text { to improve content knowledge } \\
\text { and share evidence-based best }\end{array}$ & $\begin{array}{l}\text { practices. TeleECHO topics currently } \\
\text { alternate between endocrinology } \\
\text { and cardiology, with further } \\
\text { expansion related to substance use } \\
\text { disorder and geriatrics expected. } \\
\text { Primary care provider participation } \\
\text { in teleECHO clinics is free and } \\
\text { includes continuing medical } \\
\text { education (CME) opportunities. The } \\
\text { technology needed to participate can } \\
\text { be a desktop or laptop, a hand-held } \\
\text { mobile device or videoconferencing } \\
\text { capabilities for group participation. } \\
\text { Primary care providers interested } \\
\text { in participating in these teleECHO } \\
\text { clinics may contact Plymale } \\
\text { at plymale@marshall.edu. }\end{array}$ \\
\hline
\end{tabular}

\section{PROACT opens in Huntington}

The Provider Response Organization for Addiction Care and Treatment, or PROACT, bringing an innovative approach to recovery with it.

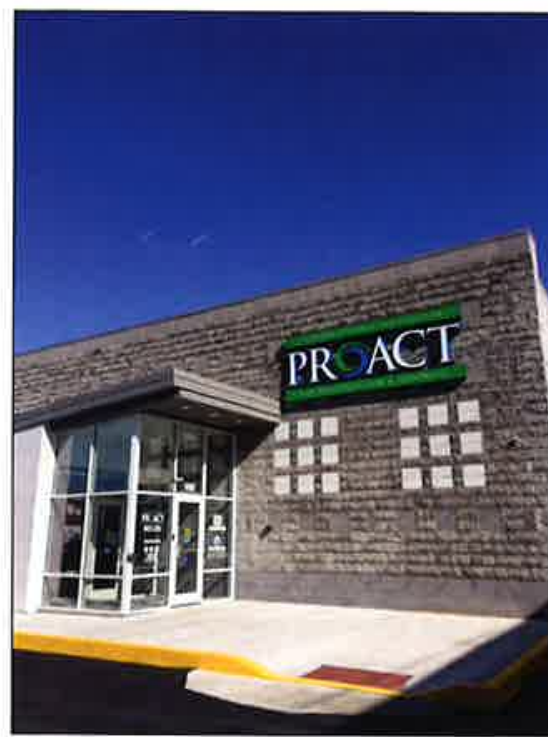

physician quickly and receive timely access to an individualized plan of reatment," said Stephen M. Petrany, M.D., professor and chair of the department of family \& community health at the Marshall University Joan C. Edwards School of Medicin and member of the PROACT board of directors. "Our goal for each patient looks beyond the initia stages of recovery as we work to help them become long-term, committed members of society." This outpatient facility acts as a regional referral point to assess patients following discharge
from local emergency rooms from local emergency rooms referral from community and by quick response teams and other emergency medical responder PROACT also accepts self-referrals. Cabell Huntington Hospital St. Mary's Medical Center Marshall Health, Thomas Health System

"The PROACT model consolidates what can be a very confusing individuals who need help see a and Valley Health came together to establish PROACT as a separate nonprofit organization that leverages dynamic partnerships with other clinical providers, substance abuse organizations, education groups and other support services to leverage existing community resources. Plans are underway to establish a second PROACT location in the Charleston area in 2019. For more information about PROACT, visit www. proactwv. org or call 304-696-8700.

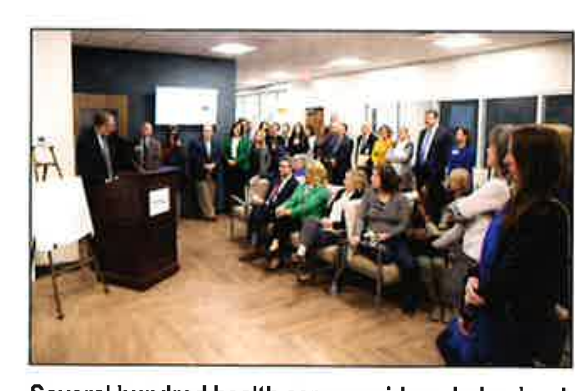
Several hundred health care providers, behavioral
specialilists and community members attended
PROACT's open house on Nov. 7

Marshall establishes multidisciplinary ALS clinic

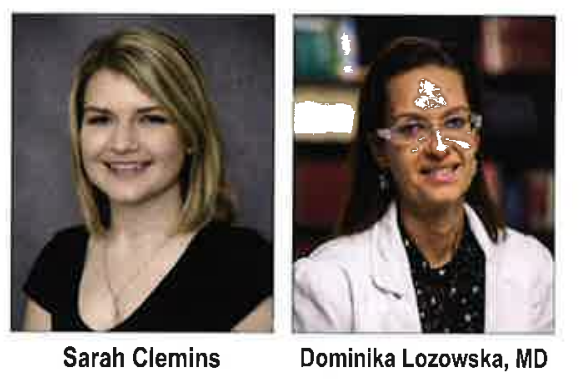

Marshall University now offers multidisciplinary clinic for patients with ALS, or amyotrophic lateral sclerosis, a condition commonly referred to as Lou Gehrig's disease. The clinic's care team consists of an onsite neurologist, physical therapist, speech therapist dietilan, respiratory Dominika Lozowska a board-certified, fellowship- trained neurologist with Marshall Health and assistant professor in the department of neurology at Edwards School of Medicine, leads the clinic's neurology services. "The convenience and expertis of a multidisciplinary ALS clinic is a much-needed resource in southern West Virginia," she said. "There are many patients sufferin from motor neuron disease who need the type of services this clin provides," Lozowska said. "By establishing with a neuromuscular clinic, we're giving our patients access to the type of care they need-a team of experienced qualiffied providers facilitating monitoring disend closely monloring disease progression. patient will receive a comprehensive assessment by their care team followed by the opportunity to ask questions as well as review tre up visits. In addition to of followcare the clinic also connects ALS patients and their caregivers with information about a support group and resources available through the ALS Foundation. The clinic is open to patients from noon to 4 p.m. on the third Friday of every month at the Marshall University Speech \& Hearing Center, located in Smith Hall 143 on Marshall University's Huntington campus. For more information or to schedule an appointment, contacl Clinic Coordinator Sarah Clemins at nuckels@marshall.edu or 304be faxed directly to $304-606-2086$. 
New training model mimics real-world surgery for WVU residents

Instinct- surgeons act on it in difficult-- though not but it can be teach, thanks to a perfused cadave training model at the West Virginia University School of Medicine that mimics real-world surgery conditions. Surgical residents are placed in simulated operating rooms, working with fresh cadavers which are connected to perfusion machines that pump simulated blood through the body. This allows the blood vessels and tissues to "bleed" The surgeons con thents. the "patient" as if they were treating a real iniury - exposing and controlling blood vesselsultimately stopping the "bleed." "It's as close as we've come to mimicking the effects and intensity of the operating room," Daniel Grabo, M.D., director of trauma education at WVU, said. "When you have moments to react, you draw on your experience. Today, the majority of routine surgeries are done with less invasive procedure which create gaps in handsemergencies and critical injuries. cadaver model to train in trauma, open vascular, thoracic and advanced liver and biliary procedures. In some cases, the training provides immediate results, M.D., WVU surgery resident. day he performed the procedure on an admitted patient. "Surgery is about repetition and being comfortable in your skillset. You have a split-second to manage bleeding and perform care," Bonasso said. "I was better prepared to treat my patient becau in the actual operating reom." The Fresh Tissue Training Program, which houses the perfused cadaver model, is a collaborative effort between WVU's Critical Care and Trauma Institute an the Departments of Pathology
and Surgery. Faculty from these on training and experience for as was the case for Patrick Bonasso, Dr. Bonasso completed a perfused cadaver model the sam Scenario just hours before I wa

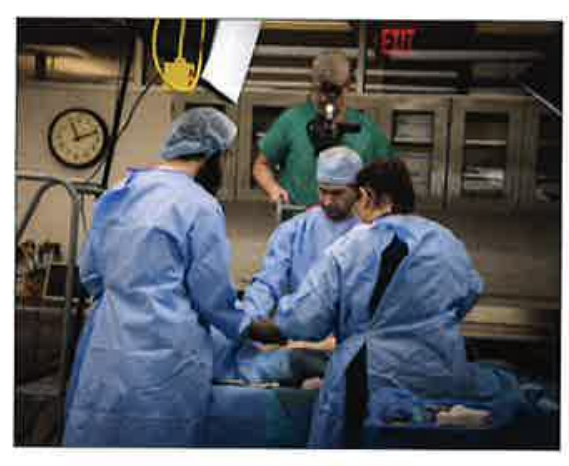

disciplines identify emerging trends from the Accreditation Council for Graduate Medical Education and cases residents perform at WVIU. Based on that data, they identify any potential deficiencies in surgica opportunities and mediate that with he perfused cadaver training develop these skills only at a patient's "You need to be able to act in the moment - and it's not just something we can create for our residents." To learn more about surgery education at WVU, visit medicine. hsc.wvu.edu/surgery.
WVU researchers investigate how hospital lighting may hinder patient recovery

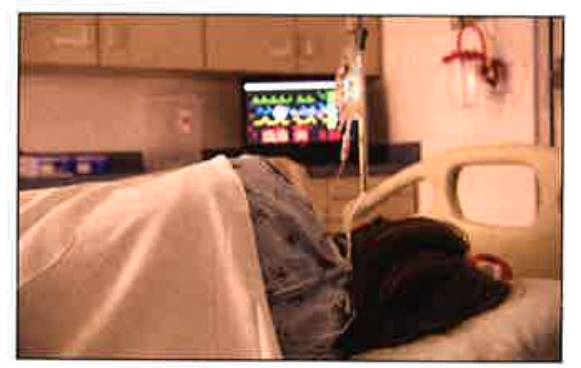

ound-the-clock brightness of hospital roon some patients' recovery. Randy Nelson, who chairs the Department of Neuroscience in the WVU School of Medicine, and Courtney DeVries, the John T. and June R. Chambers Chair of Oncology Research at WVU, are studying how light at night may worsen outcomes in cardia patients. Both researchers are members of the WVU Rockefelle Neuroscience Institute. The awarded them nearly $\$ 12$ has for their three-year investigation. "This research actually grew. of one of our student's hospitat stays," says Nelson, who also directs basic science research at The WV Rockefeller Neuroscience instifute. "He said, 'The lights are all alight. I can't sleep.' So we constant light exposure do to folks in critical-care areas, like to folks intensive Cardiac arrest doesn't just hurt the heart It also hurts the brin. way this happens is that cardiac arrest and the subsequent oxyge system and overstimu ervous cells so much that they can die. down units, where peopical stepalready immunocompromise deprivation inflame the nevous

Nelson and DeVries suspect that
spending nights in hospital rooms spending nights in hospital rooms these responses. Earlier work they conducted with preclinical models suggests that a light no brighter than a child's nightlight may be enough to trigger inflammation in the brain, "overload" brain cells an make cardiac arrest more lethal. Building on their previous finding the researchers will now explore link light at night to neurological damage-and a greater mortality rate-after cardiac arrest. They also want to determine whether certain wavelengths of light are more detrimental than others.

To do this, they will expose pardiac and will then measure the models' brain inflammation, determine the extent brain-cell damage and evaluate how nimbly the heart can beat faster or slower to meet the body's changing needs. Next, they will pinpoint whic lighting environments correlale

"The circadian systomes.

by short-wavelength light affech is blue, like from your phone or tablet. Fluorescent light is also quite bluish. But if we can use longerwavelength lights-sunset colors that doesn't affect the circadian clock," says Nelson. Perhaps replacing the fluorescent bulbs in hospital rooms with sunset-toned bulbs would enable the hospital taff to administer drugs, operate equipment and monitor patients at night without disrupting their their recovery from cardiac arrest Light at night seems to be associated with a range of conditions, including obesity and diabetes. But "unlike a lot of things we've studied so far with dim light at night," says DeVries, "the problem after cardiac arrest is that, if the neurons die, they're dead. It's not reversible. We're interested in preventing that."

WVU, partners announce regional hub to train entrepreneurs, commercialize healthcare technology

Hoping to speed up the move Virginia University and 23 the Virginia University and 23 other together to create a "virtual hub" that will ultimately help speed the commercialization of groundbreaking university research. WVU, as part of its commitmen to create and support a strong entrepreneurial culture in the state, will collaborate with XLerateHealth, a small business that focuses on healthcare technology ste

The hub will help accelerate cutting-edge biomedical technologies and products move from the laboratory into the marketplace and commercialize new innovation in pharmaceuticals, medical devices, healthcare IT and electronics. WVU, the University of Kentucky and the University of Louisville co-lead the university side of this effort and organized a consortium of participating regional universities collaborate with XLerateHeal accelerator will provide unparalleled opportunities to bring the brightest minds together to advance and commercialize technologies that can truly make a difference in people's lives here in West Virginia across Appalachia and beyond " said. "West Virginia University is pleased to be able to join forces with so many of our neighboring institutions to deliver worldchanging discoveries and innovation that will generate economic opportunities while leveraging breakthroughs in healthcare." Through the creation of this online "virtual hub," WVU, XLerateHealth, UK and UofL will coordinate programming, educational resources and commercialization tools for all participating institutions to utilize. There will also be support services to help entrepreneurs protect their intellectual property, assist in technology transfer that will forge mutually beneficial relationships between researchers and the business community and offer business and networking opportunities.
"As WVU's health research and workforce development, we are excited to help pave the way for more leading researchers to commercialize their advanced technologies and products that could ultimately save lives, revolutionize our healthcare system and boost regional economic opportunities," said Laura Gibson, senior associate graduate education. "Thanks these collaborative efforts, this accelerator hub will provide vast resources, training and networking opportunities to help groundbreaking research get off the shelves and enter the real world, making a lasting impact on future medical treatments and long-term health. funded by a three-yb will be funded by a three-year $\$ 3.5$ million General Medical Sciences, a division of the National Institutes of Health, as part of their Institution Development Award program. The Southeast region includes West Virginia, Kentucky, Arkansas, Louisiana, Mississippi, Puerto Rico 
Installation ceremony celebrates Nemitz as WVSOM's seventh president

A huge celebration took place on the West Virginia School of Osteopathic Medicine' (WVSOM) campus during the installation ceremony of James W. Nemitz, Ph.D., the school's seventh president. The installation, which took place in September, is an official recognition of the school's change in presidents and marks a new beginning for the institution. The formal ceremony included word of support from the WVSOM Board of Governors' Chairman Charles Davis, D.O., and Alumni Association President Robert Olexo, D.O. Music was provided by the Greenbrier Valley Chorale and the Greenbrier Academy for Girls. "It's been an honor for me to take part in this selection process and see its completion with Dr. Nemitz as the seventh president," Davis said. "The office of president and the word 'honor' just feel right in the same sentence. It's an honor to hold a position of power, leadership and responsibility. I have no doubt that Dr. Nemitz will keep the honor and integrity of this great institution." Nemitz said he is humbled and filled with gratitude to serve as WVSOM's next president. He thanked his parents for being such an integral part of shaping his values and ultimately passion for the school. "There's something special abou people who are good parents, who raise their kids and let them go and become what they're supposed to be. My parents did that. They gave me my work ethic and gave me my values," Nemitz said during the formal installation. The ceremony also focused on celebrating three main themes that included "honoring our heritage, living our mission and engaging

our future." WVSOM was founded on modest beginnings, but has risen to national prominence due to the dedicated hard work of many. The new president reiterated the importance of the past while also looking toward the future. Nemitz explained the "Living our mission" initiative that encourages students, faculty, staff and alumni immerse themselves in community service projects and share the work they are doing throughout the local area and state.

to highlight the sense of service among the WVSOM community. 'These are a symbol of what I'm going to challenge you with - to go out there and do something for somebody else," Nemitz said. "I wan to inaugurate a year of community service. So go out there and do something for your community. The informal celebration that followed included music by the Ramp Supper Band and RiverJam Band, dancing and West Virginiafocused dinner menu that paid

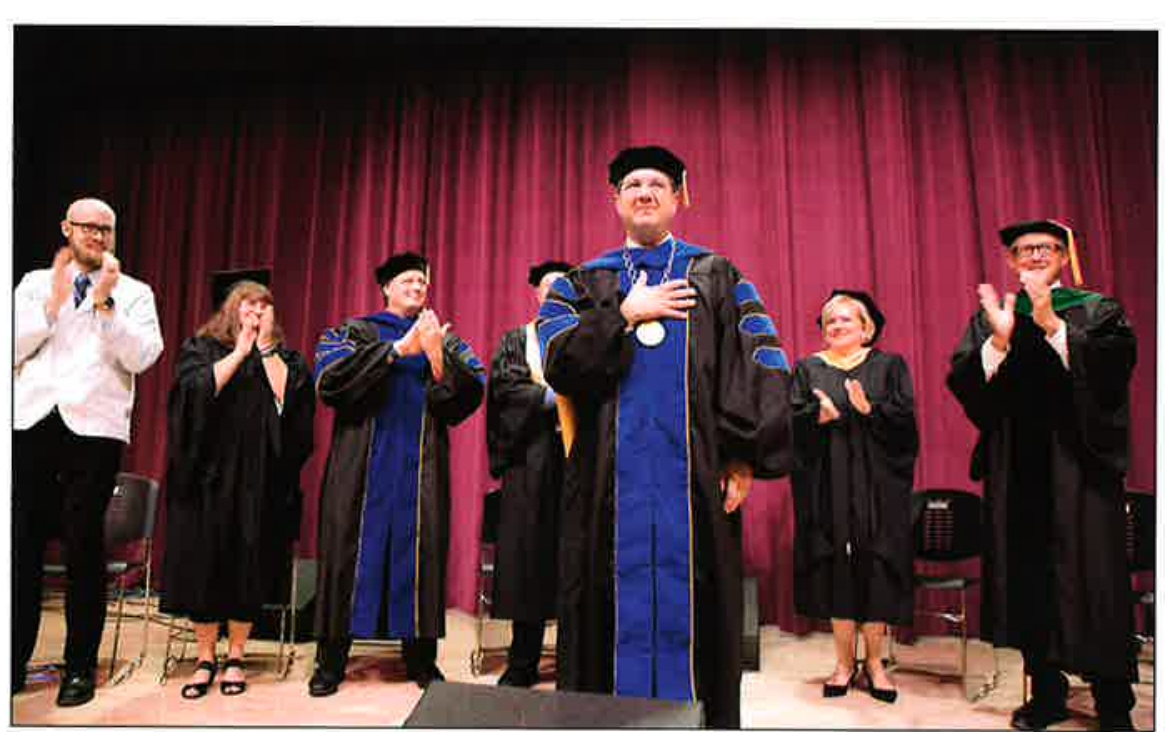

"We are a public institution and we are here to serve this great state we are here to sene this great state and take care of the cilizens of West Virginia. We have to live our mission every day. Many of our alumni are going back to their communities an serving others. We should be taking care of our neighbors, communities and recognizing the diversity and differences of opinion. We need to celebrate those differences and care for our communities," he said. "Living our mission" bandanas were given to all guests in order owner of the former Clingman's restaurant in downtown Lewisburg. often conducted in her restauran and she is credited by many for and soul to many students and their families over the years. WVSOM through the Gwen Clingman Scholarship award for a graduating student who has demonstrated a commitment to serve people and classmates unselfishly and humbly through community service. The early business of WVSOM was continues Mrs. Clinears. WVSOM
Gov. Justice announces funding for WVSOM's

Healthy Children's Initiative

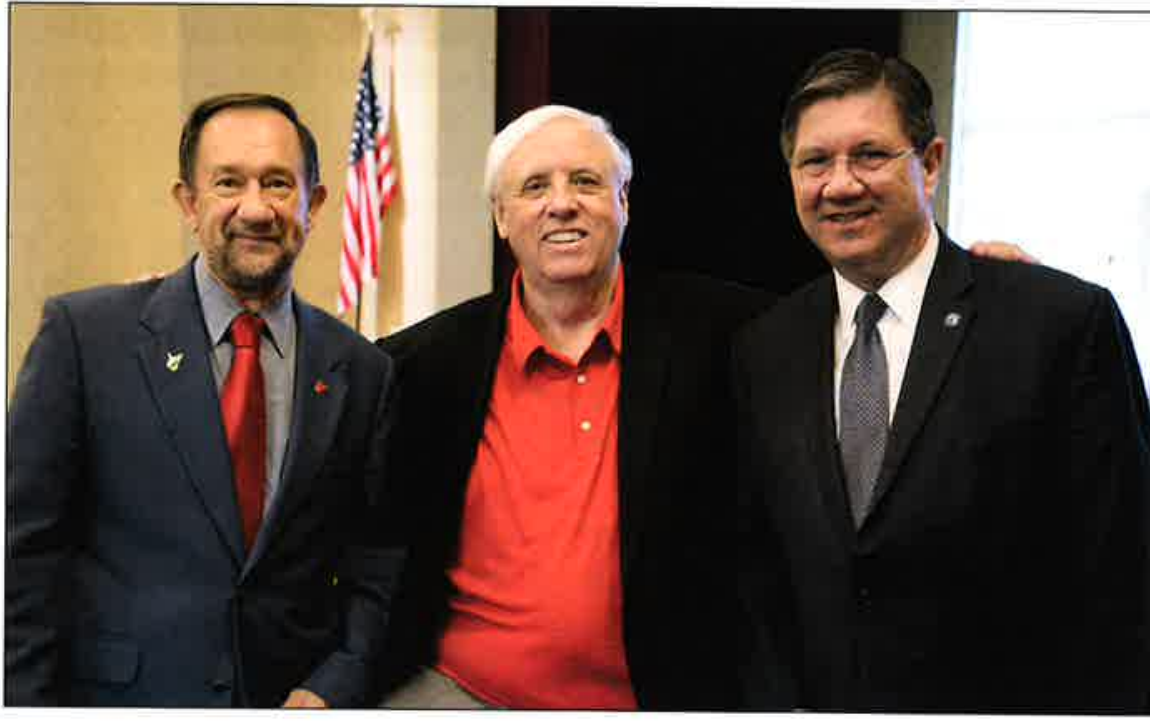

secure funding for the initiative. He said he was pleased to receive the announcement of the governor's funding. "Abracadabra and other parts are fantastic," he said, "Those programs are what we need to moving West Virginia forward." In 2018, Abracadabra raced a regional EMMY Award for a STEM episode. The show is aired on West Virginia Public Media and PBS stations in three other states. In total, the stations reach portion of 10 states and parts of Cantion with the opportunity to West Virginia to a viewing audie of more than 5 million people. Episodes have centered on topics such as bullying, cyber predators, STEM, bicycle safety, visiting the doctor, growing a garden, fire safety and social development including sharing, courtesy and curiosity. "A special episode of Abracadabra in post-production focuses on in post-production focuses on
opioids and the drug epidemic," said Michael Adelman, D.O., J.D., WVSOM's president emeritus and the TV show's creator. "This particular episode is directed toward elementary-aged children and their parents. We are excited about this special, as it is one of a few drug prevention and educational initiative James W. Nemitz, Ph.D. WVSOM's president, said the osteopathic medical school is appreciative of the support from Gov. Justice and funding for what WVSOM leaders think is such an important program for the state "The impact we are having on you in West virghang on profound and we kno lo profound and we know from is effective. It's amazing to see these children respond so well In addition to the television series, coordinator who works with school counselors and teachers at various elementary schools throughou West Virginia to present health, nutrition and STEM educationa concepts that are reinforced by the Abracadabra series. that focuses on this age group. school visits that the initiative to our message," he said. the initiative includes an outreach 
Since March 2018, West Virginia has been experiencing the largest hepatitis A outbreak in the state's history. This outbreak is molecularly linked to the multi-state outbreak in which genotype $1 B$ is the hepatitis A strain of concern. As of November 16, 2018, there have been a total of 1,859 reported cases, 1,119 hospitalizations and five deaths related to the outbreak. The age range is from 12 to 86 years old, with a median of 37 years. Currently, the at-risk populations are:

- people who use illicit drugs:

- homeless persons

- people recently in jail or prison: persons with chronic liver disease such as hepatitis B and/or C;

men who have sex with men;

- persons who provide direct services to those using illicit drugs or are homeless;

- persons exposed to someone

with hepatitis A; and

- anyone who has frequent

contact with any of these populations.

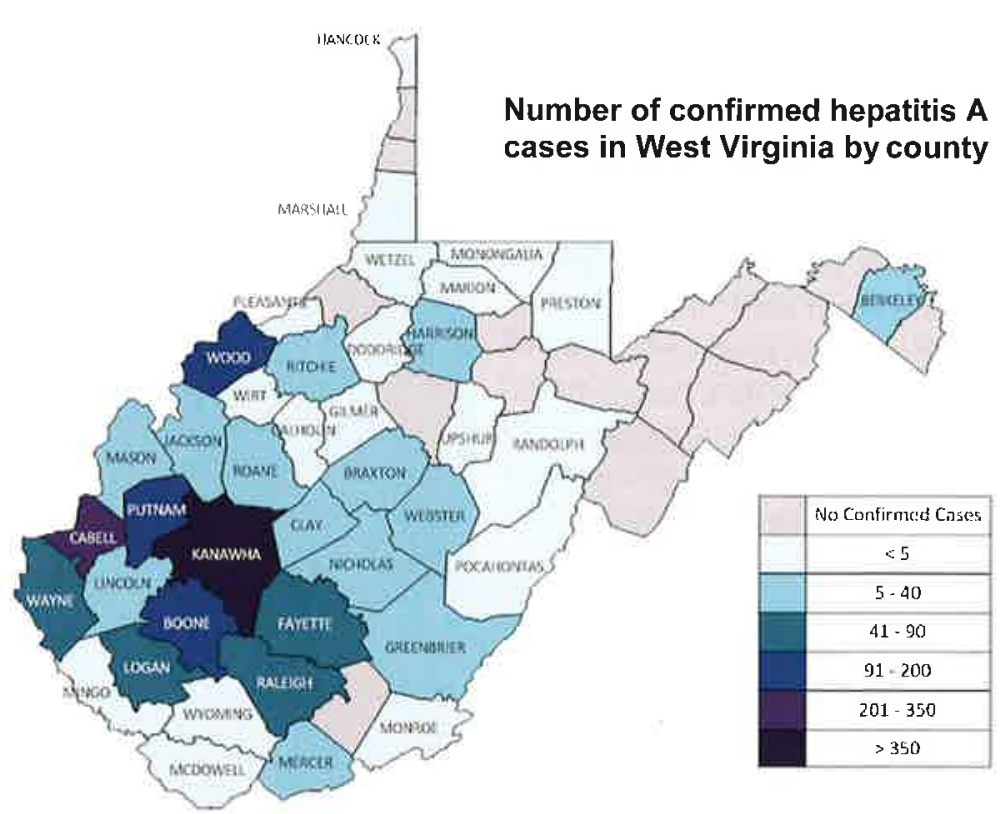

To date, 40 out of 55 counties have been affected by this outbreak.

To reduce and stop the transmission of hepatitis A, the West Virginia Department of Health and Human Resources (DHHR), Bureau for Public Health (BPH) is working with public and private partners to vaccinate the population at-risk. BPH has obtained hepatitis $A$ vaccines which are available to healthcare providers at no cost, and encourages providers to screen and vaccinate at-risk patients during routine medical visits. Free vaccines can be offered to individuals age 19 years and older and fall into any of the risk groups identified above. $\mathrm{BPH}$ recommends one dose single antigen hepatitis $A$ vaccine to protect individuals at highest risk. This has been shown to be 90 $95 \%$ effective and provides protection during an outbreak.

Encouraging patients to get vaccinated and

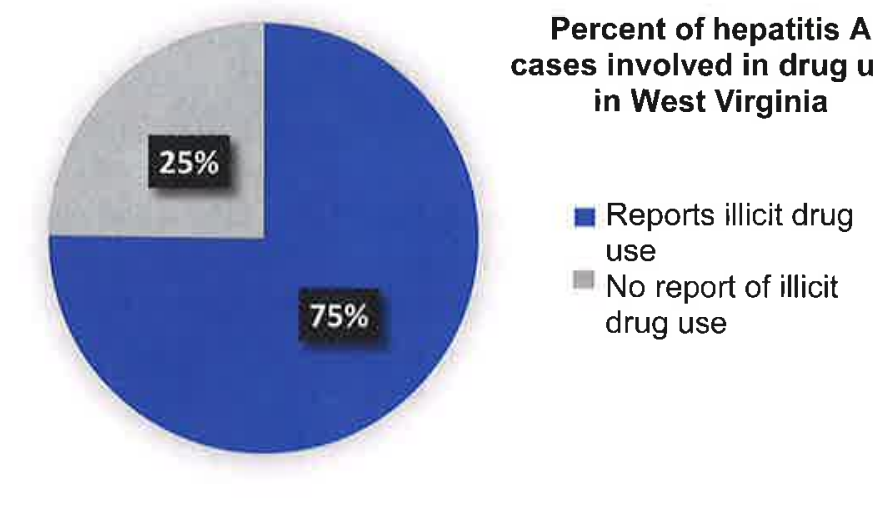
to properly wash their hands is crucial to

informathe spread of hepatitis A. For more state-funded vaccines visit, www. hepawarewv.org or contact DHHR's Office of Epidemiology and Prevention Services at (304) 558-5358.

\section{Author:}

Shannon McBee, MPH, CHES

Syndromic Surveillance Director

Office of Epidemiology and Prevention Service

\section{Legislative Outlook}

\section{by Alex Macia, Esq.}

The next 60 day regula session of the West Virginia on January 9,2019 . While much of the nation seemed transfixed by the recent electoral changes, the most significant political change in West Virginia actually precede the election. Indeed, the House of Delegates got a new Speaker, Roger Hanshaw (R-Clay), when Governor Justice appointed his predecessor to the WV Supreme Court. Speake Hanshaw retained his seat and leadership position post-election. As we go to print with this issue, there is still no word whether there will be any changes to the remaining House leadership positions. Overal, however, the election only yielded minor changes to the composition of both chambers, which the Republicans control. In the House of Delegates, the Republicans held off the Democrats but suffered a net loss of 5 seats and now hold 59-41 majority; in the Senate they sustained a net loss of only 2 seats, leaving them with a 20-14 majority. WESPAC endorsed 7 winners out of the 9 candidates it supported in the Senate races and 25 winners ou of 33 races in the House. The most significant success for WVSMA, however, was the reelection of Dr. Tom Takubo, the Chair of the Senate Health Committee. Dr. Takubo, a WVSMA member, held off a strong challenge to win a second term as a Kanawha County Dr. Takubo was elorion, Dr. Takibo was elevatod to Sena Majority and wil become the will be able to influence he will be able to influence the and enacted by that chamber. Dr. Mike Maroney (R-Marsh.II) Dr. Mike Maroney (R-Marshall), announced as Dr. Takubo's successor as Chair of the Sen Health Committe WVSMA applauds both announcements and looks forward to a more

physician-friendly Senate chamber. WSMA's expected agenda may be reminiscent of the clession movie Groundhog Day Specifically, WVSMA will again pursue a bill regulating Prior Authorizations insurance companies; last year's bill was vetoed by the Governor over an alleged technical defect. Working with other stakeholders in the healthcare practitioner arena we will remedy that concern. To be sure, we have already secured the commitment from legislative leadership to advance this bill rapidly. Screening Certificates of Merit, the statutory prerequisite for the filing of medical liability lawsuits, will be refined so as to require higher standards of proof pre-suit, thus making frivolous lawsuits less likely. While the Legislature enacted the omnibus Opioid Reduction Act of 2018 with the express purpose of reducing opioid addiction rates, it is clear that cleanup bill will have to address some internal inconsistencies and correct some unintended consequences of that legislation. Similarly, the Medical Cannabis Act

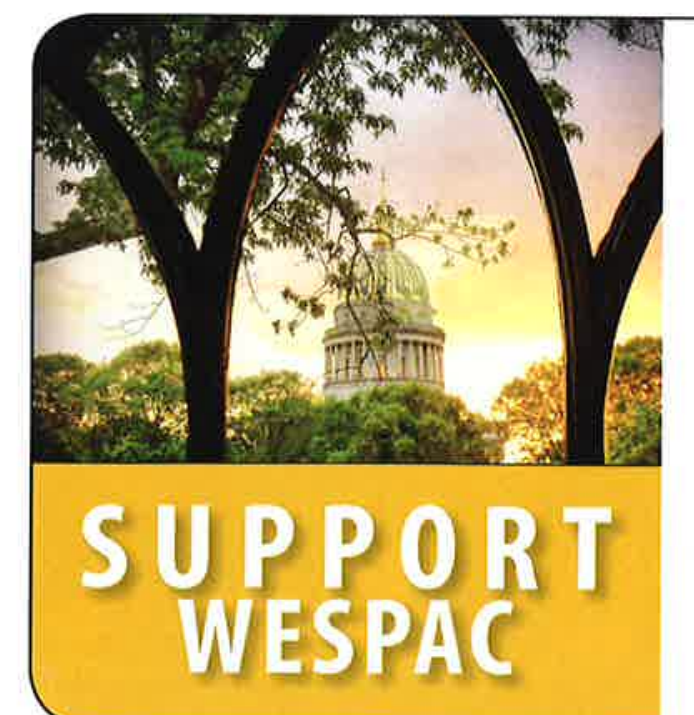

of 2017 must be revised to address ertain open-ended issues and its mplementation will most likely be postponed until after the original July 2019 start date. WVSMA will seek some clarification as to the ole of the physician in the medical cannabis certification process. Cther bills of interest will include Prohibition of Smoking in Vehicles when minors are present, Mandatory CPR Training for 911 centers, and the Sugary Beverage Tax. Finally, and perhaps most critically from a public health standpoint, WVSMA will fight to maintain the protections contained in West Virginia's Vaccination Laws against those who would seek to weaken th same in the name of health liberty. We are hopeful that the appointmen of Dr. Takubo to the role of Senate Majority Leader may prove to be the most important bulwark against this potential public health catastrophe. WVSMA will keep its members informed via e-blasts and other media of significant developments for the 60 days the West Virginia Legislature meets to consider and enact these and other laws impacting public health and he physician community. best interests at heart!

Endorses pro-medicine candidates Supports and promotes tort reform Political Action Committee Visit: www.wvsma.org or or email scalise@wysm.
WESPAC 
2018 Appalachian Addiction \& Prescription Drug Abuse Conference "Prescriber Education Continued"

P. Bradley Hall, M.D. Executive Medical Director,
WVMPHPP

AAPDAC Conference Chair

The 2018 Appalachian Addiction \& Prescription Drug Abuse Conference (AAPDAC) exceeded growth integration and collaboration growh, integration and collaboration of multiple healthcare professional
disciplines. Held October $18-20$ at the Embassy Suites in Charleston WV, with nearly 400 participants from 11-disciplines and 39 exhibitors in attendance. This year's conference opening and overview were led by the AAPDAC organizer, P. Bradley Hall, M.D. Dr. Hall is the Executive Medical Director of the Program and Immediate PastPresident of the Federation of State Physician Health Programs and Christina Mullins, Commissioner WV Bureau for Behavioral Health. Daniel Farmer, DO, MSc, Addictio Medicine Fellow, WV University School of Medicine, Dept. Behaviora
Medicine \& Psychiatry moderated Medicine \& Psychiatry moderated Scott Hambleton, MD. DFASAM Medical Director of the Mississipp Physician Health Program, provided an update on proper prescribing and information on atypical drugs of abuse, with related case studies Pearls for proper prescribing, the use of drug screens, consulting the Board of Pharmacy database and careful prescribing were the

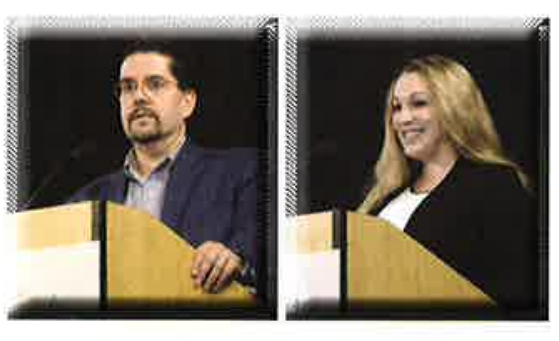

Senator Shelley Moore Capito honored us with her presence providing a brief update and perspective from Washington Scientific Advisory Boarman. Rivermend Health, followed with presentation on obesity, sugar and addiction. Our luncheon program featured John Fromson, MD, Associate Professor of Psychiatry, Harvard Medical School, Chief of Psychiatry, Brigham \& Women's spirituality in medicine and in recovery C. Chapman Sledge Chief Medical Officer Cumberland Heights spoke on the topic of extended release Naltrexone. The first day's presentations ended with Sherri Young DO \& Adam Breinig, DO providing an update including the Monitoring Pronram. The substans concluded with an evening speak on recovery and spirituality. Supreme Court Justice Evan Jenkins opened the second day of the conference by welcoming participants and provided an updat ond his perspective drug epidemic commented on his Washington

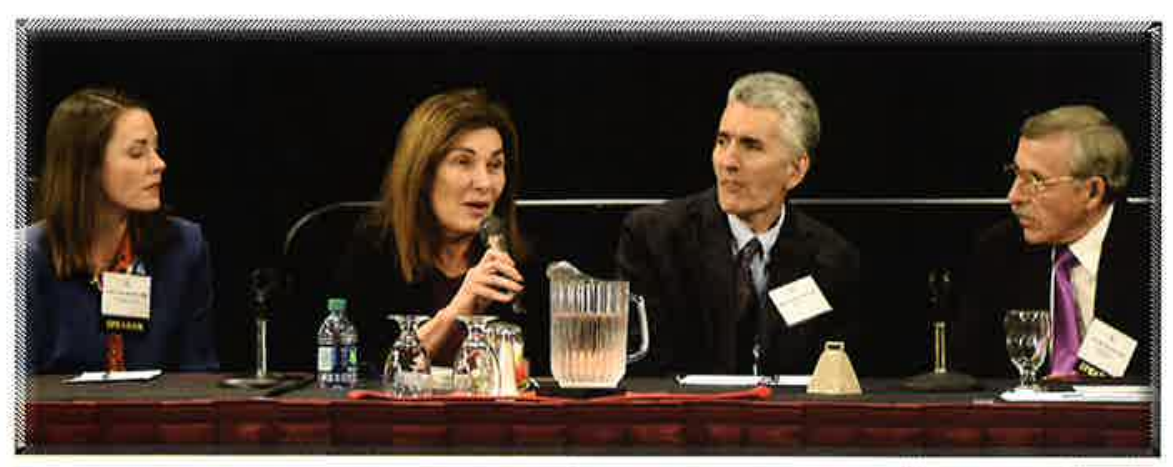

experience and conveyed his

personal support to everyon

Svetlana Grinberg, DO, PGY-III, Lincoln Memorial University, Beckley AccessHealth Teaching Health Center moderated the second day of the conference. David Gastfrien MD, chief archlect, CONTINUUMEngine, discussed ASAMs Patient

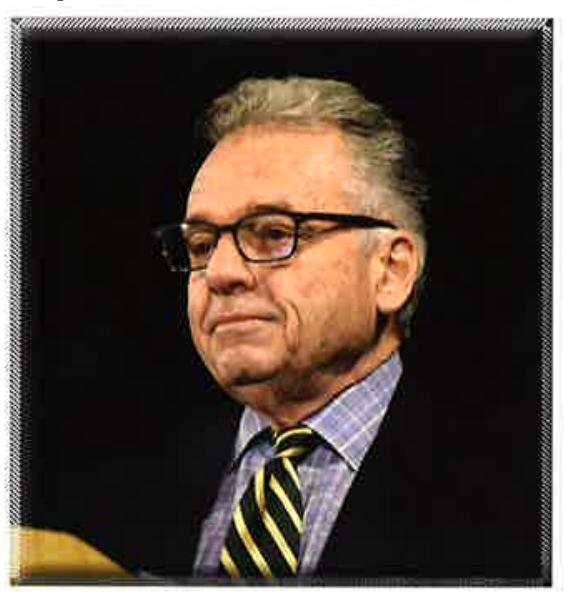
Placement Criteria and Continuum.
James Harrow, MD, PhD DABAM, FASAM, Addiction Medicine Physician \& Consultant, provided an indepth presentation on adolescent addiction and where it all starts followed by Carl Grey, M.D. Dept of Medicine, Section Gerontology and Medicine who spoke on addiction in the older adult, an epidemic of misuse and abuse with an ethical duty to prudently treat pain.

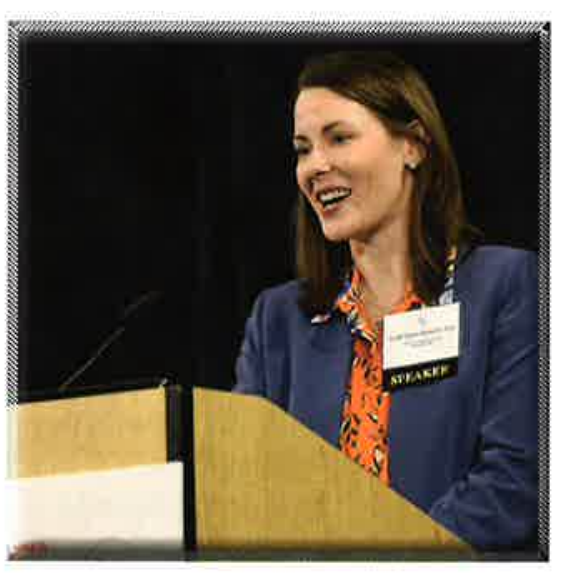

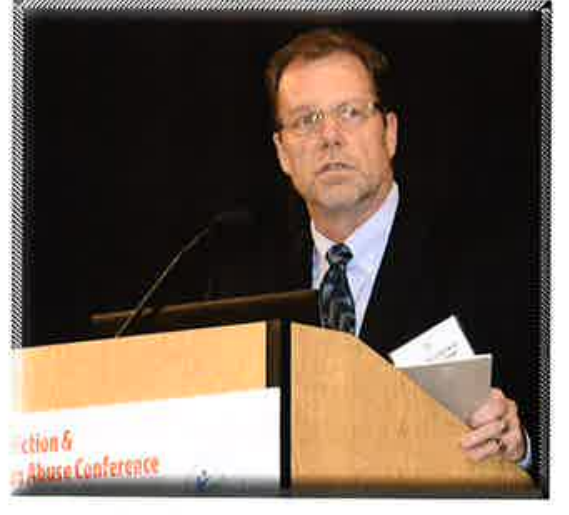

Sky Kershner, LPC, LCSW of KPCC Counseling provided the luncheon program focusing on
mindfulness as a super power. mindfulness as a sup
Leah Claire Bennett, $\mathrm{PhD}$, director of clinical operations, Pine Grove, stressed the importance of "selfcare" and Alexis Polles, M.D., medical director, Professionals RRN provided insights and
management of sex addition Our evening was topped off with
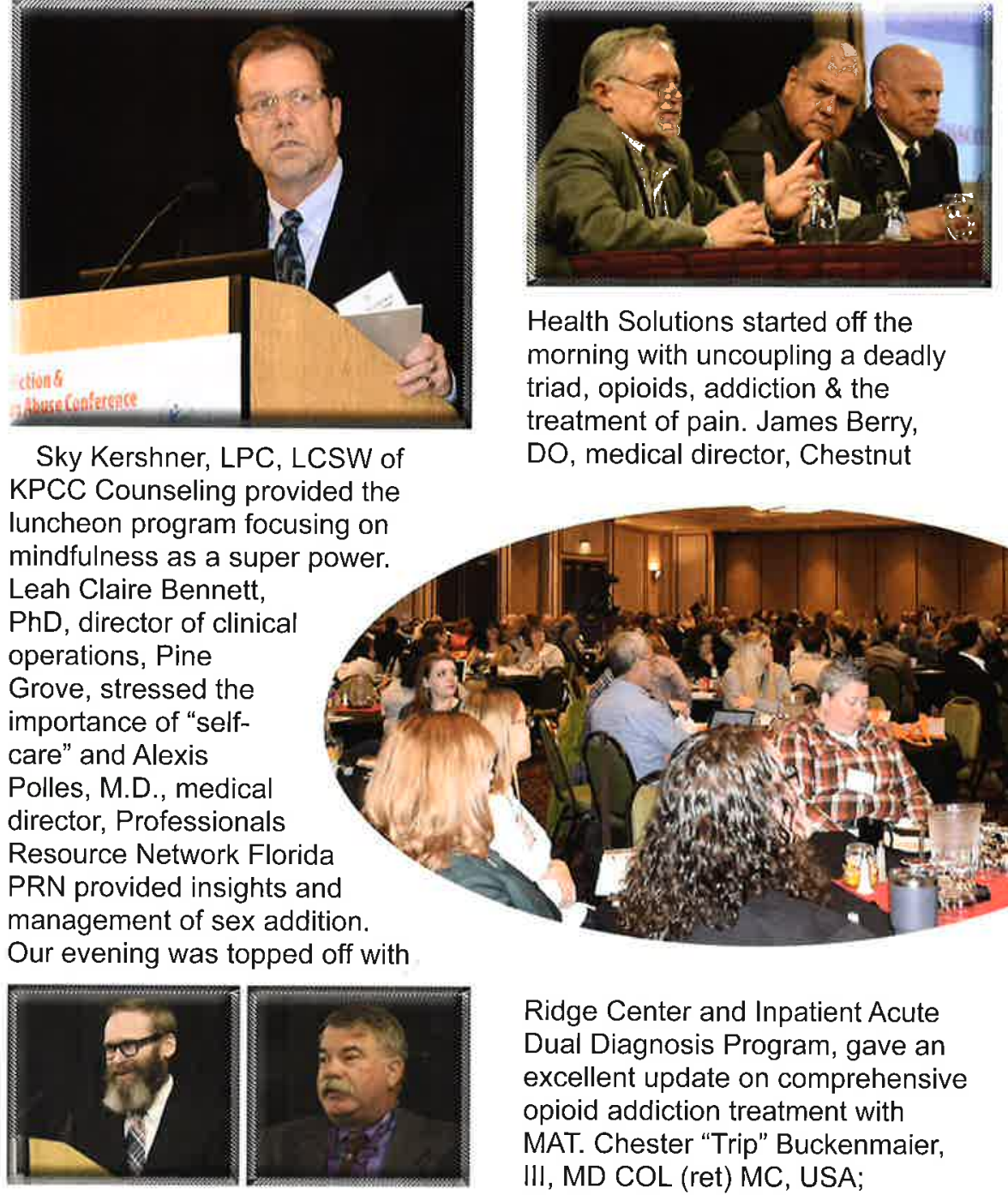

Health Solutions started off the morning with uncoupling a deadly triad, opioids, addiction \& the treatment of pain. James Berry,

Dr. James Berry, DO, medical director, Chestnut Ridge Center and Inpatient Acute Dual Diagnosis Program who gave a compelling presentation on medical marijuan Our moderator for the third day was Loule Olive, MD, PGY-III, Ambrose Health Podicy Fel Paul Ambrose Health Policy Fellow. D
Teater, MD, MPH, owner, Teater
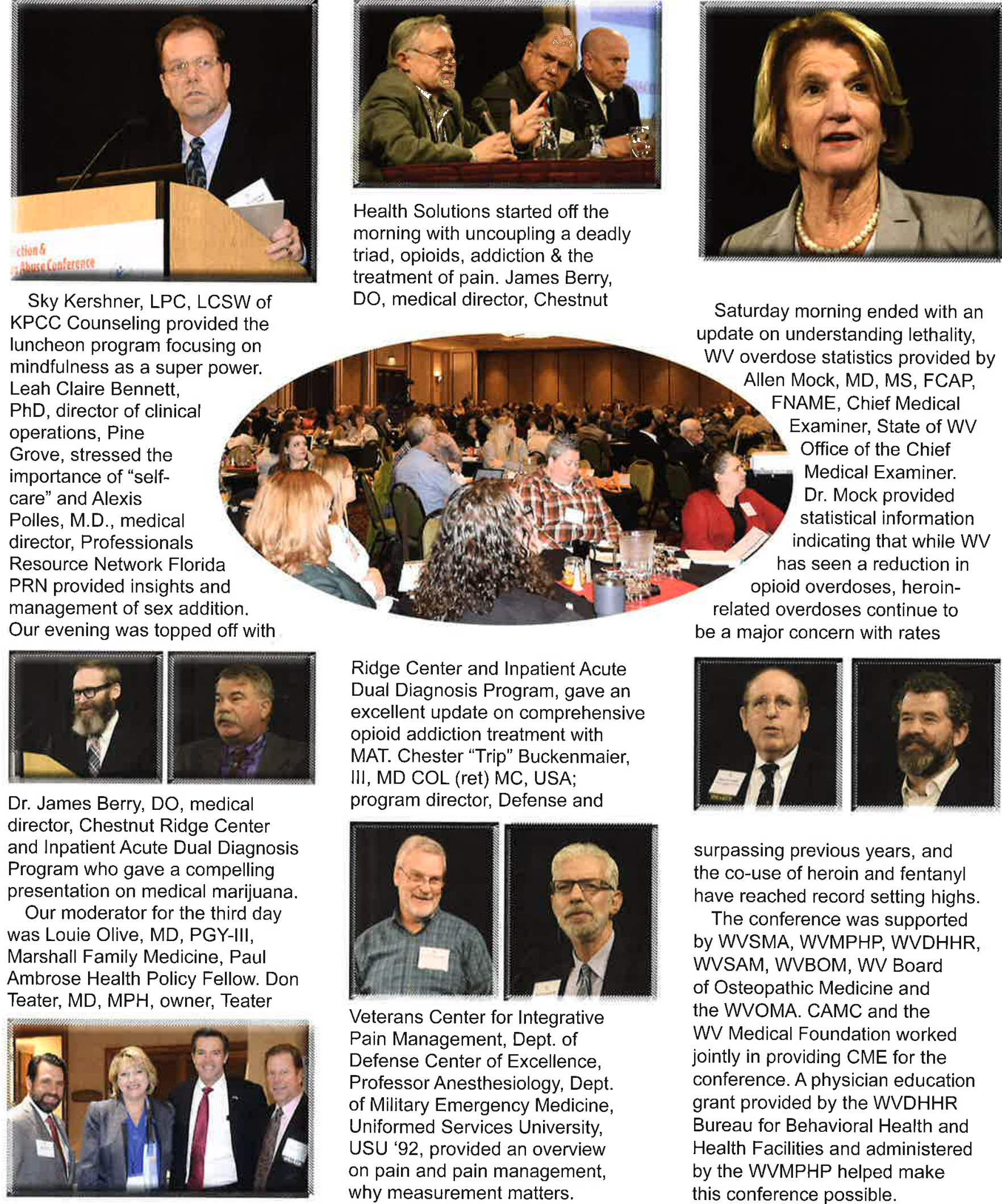

Saturday morning ended with an update on understanding lethality, $W V$ overdose statistics provided by Allen Mock, MD, MS, FCAP,

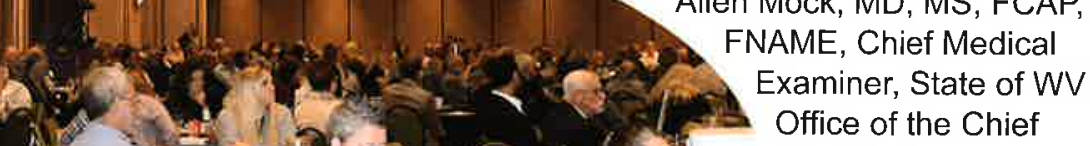

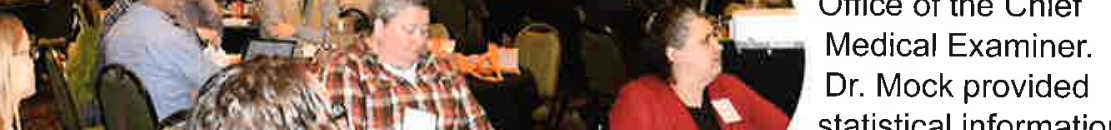
1. Statistical information indicating that while WV overdoses, heroina major concern with rates

Ridge Center and Inpatient Acute Dual Diagnosis Program, gave an pioid addiction on comprehens MAT Chester "Trip" Buckenmi III, MD COL (ret) MC, USA;
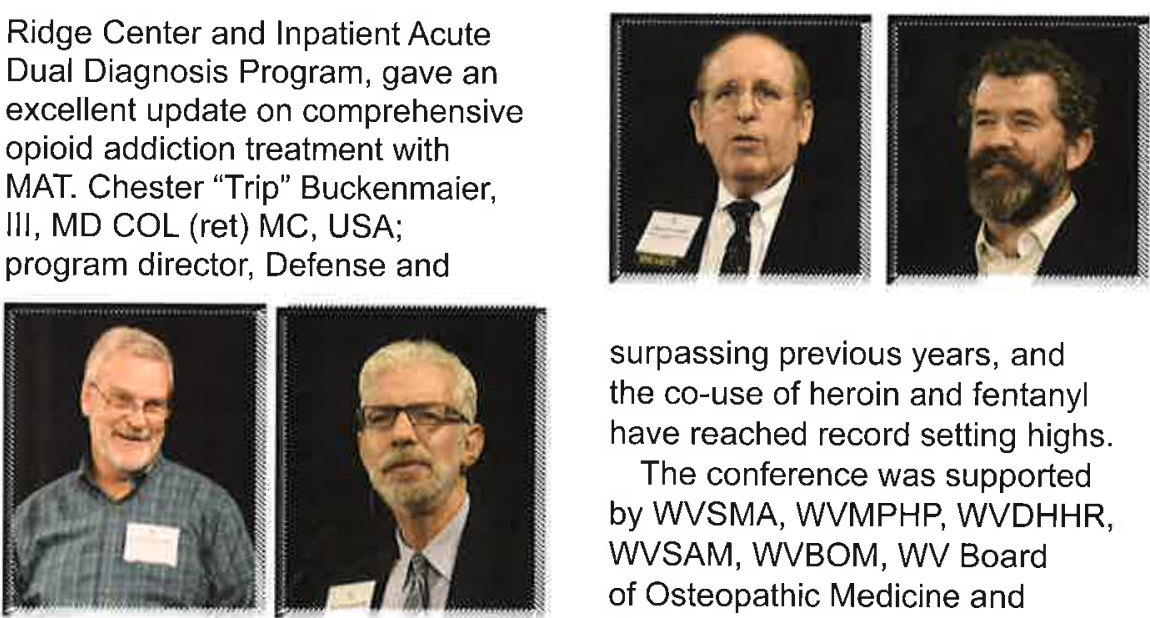
on pain and pain management
why measurement matters.

Pain Manenter for Integrative Pain Management, Dept. of Defense Center of Excellence, of Military Emergesclogy, Dept. edicine, USU '92, provided an overview

Mark your calendars for next year's conference, October 17-19, 2019, 12 surpassing previous years, and
the co-use of heroin and fentany have reached record setting highs. The conference was supported
by WVSMA, WVMPHP. WVDHHR WVSAM, WVBOM, WV Board of Osteopathic Medicine and WV WV MA. CAMC and the Wointly in providing ation worked conference A physician ed the grant provided by the WVDHHR Bureau for Behavioral Health an Health Facilities and administered by the WVMPHP helped make this conference possible. at the Marriott at Waterfront Place in Morgantown, WV. 


\section{THANK YOU 2018 WVMPHP "Spirit of Wellness in Medicine" Contributors}

$\mathbf{O}$

behalf of the West Virginia Medical Professionals Health Program (WVMPHP), our participants, all of D18 WVMPHP "Spirit of Wellness in Medicine" Contributors.

The West Virginia Medical Professionals Health Program (WVMPHP) was established in 2007 by organized medicine as an independent non-profit 501(c)3. The WVMPHP promotes the health of West Virginians through improving the wellbeing of West Virginia physicians, podiatrists, physician assistants, medical students/residents, and other healthcare professionals. The WVMPHP remains the designated physician health program by both the allopathic and osteopathic licensure boards.

The WVMPHP has provided assistance and guidance to more than 270 ill healthcare professionals experiencing addiction and/or mental illness. Eighty-plus-percent of those individuals have achieved successful completion or pending completion of the program. In addition, the WVMPHP has provided more than 145 educational presentations, with more than 15,000 attendees, and continues to provide additional education at the annual Appalachian Addiction and Prescription Drug Abuse Conference - most recently hosting more than 350 professionals.

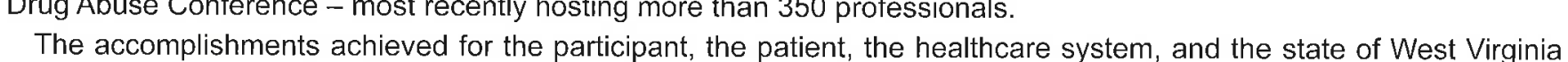
are only because of the ongoing support and recognition of organized medicine and specifically including our 2018 "Spirit" contributors.

The WVMPHP Board of Directors wishes to recognize our 2018 "Spirit of Wellness in Medicine" Funding Campaign Contributors:

\begin{tabular}{|c|c|c|}
\hline Friend $(\$ 1-\$ 499)$ & Lorenzo Pence, D.O. & Partner in Health $(\$ 10,000-\$ 24,999)$ \\
\hline Russell Biundo, M.D. & Sathyanarayan Reddy, M.D. & Charleston Area Medical Center \\
\hline Craig Boisvert, D.O. & Sherri Young, D.O. & Charleston Area Medical \\
\hline Davis Medical Center/Hospital & Advocate $(\$ 1,000-\$ 2,499)$ & Center-Medical Staff \\
\hline $\begin{array}{l}\text { Michael Brumage, M.D. } \\
\text { James Felsen }\end{array}$ & R. Curtis Arnold, DPM & Monongalia General Hospital \\
\hline $\begin{array}{l}\text { Marlene Hall } \\
\text { Randall Hawkins. M.D. }\end{array}$ & $\begin{array}{l}\text { Ahmed D. Faheem, M.D. } \\
\text { Scott Gilchrist, M.D. }\end{array}$ & Leader of Healing $(\$ 25,000-\$ 34,999)$ \\
\hline $\begin{array}{l}\text { Randall Hawkins, M.D. } \\
\text { David M. Hess, M.D. }\end{array}$ & Omar Hasan M.D. \& Irene & Cabell-Huntington Hospital \\
\hline Robert Knittle & Wasylyk, M.D. & Legacy of Wellness $(\$ 35,000+)$ \\
\hline William A. Merva, M.D. & Huntington Internal Medi & WVU Health System* \\
\hline $\begin{array}{l}\text { Charles McMullen, M.D. } \\
\text { Roots \& Harmony }\end{array}$ & Carl Overmiller, M.D. & $\begin{array}{l}\text { The WVUHS includes the } \\
\text { following hospitals: }\end{array}$ \\
\hline m Scott, PA & Riv & - Berkeley Medical Center \\
\hline $\begin{array}{l}\text { il Strobl, M.D. } \\
\text { ilip H. Strobl, M.D. }\end{array}$ & Stonewall Jackson Me & Clark Medical Center \\
\hline Elizabeth \& Peter Strobl, M.D. & Ally of Hope $(\$ 2,500-\$ 4,999)$ & $\begin{array}{l}\text { Jefferson Medical Center } \\
\text { Potomac Valley Hospital }\end{array}$ \\
\hline er $(\$ 5$ & & $x_{0}$ \\
\hline hyllis \& Sam Cann, & Pillar of Hope $(\$ 5,000-s$ & - St. Joseph's Hospital- Buckhannon \\
\hline Cheryl \& Creel Cornv & Princeton Community Hospital & - United Hospital Center \\
\hline -aura \& Owen Lander, M. & Roane General Hospital & West Virginia University Hospitals \\
\hline
\end{tabular}

Laura \& Owen Lander, M.D.

To date, your 2018 contributions have supported the WVMPHP which will assist us as we proceed forward in further establishment of a viable and successful Physicians Health Program.

On behalf of myself, the WVMPHP Board of Directors, our participants (current and future) and the public in which we serve, THANK YOU for your contributions and continued support of the West Virginia Medical Professionals Health Program.

\section{American Cancer Society holds inaugural Real Men Wear Pink Campaign reception}

In its inaugural year in West Virginia, men united to fight breast cancer with the American Cancer Society through participation in the Real Men Wear Pink campaign. Throughout October, Real Men Wear Pink participants encouraged community members to take action in the fight against breast cancer In addition to wearing pink and raising awareness about breast to help the American Cancer to help the American Cancer Society attack cancer from every breast cancer. Funds raised help us save lives from breast cancer through early detection and prevention, innovative breast cance research, and patient support Each Real Men Wear Pink participant accepted a fundraising challenge and competed to be the top fundraiser among his peers by the end of the campaign. A reception was held on October 16, 2018 at the West Virginia State Medical Association. Danny Scalise graciously offered for our and we had place at his facilly attendance. The candidates had time to network and be recognized for their efforts in our cause. Kathy Smith shared her personal story. We also would like to thank our in-kind donors: Estep's, In Stitches, the Homer Laughlin China Company, and photographer, George Brown

The 2018 Real Men Wear

Pink candidates are:

Clay Marsh, MD, West Virginia University, Vice President and Executive Dean Health Sciences

Richard Goldberg, MD, WVU Medicine/Director of Andrew Byrd, WV State Delegate,

Warner Law OMces,

Summersville, Mayor
David Mullins, MD, Surgeon, Princeton Community Hospital Allen McVey, West Virginia Insurance Commissioner Caleb Gibson, Edward Jones Financial Advisor Nicholas Oxley, Buckingham Strategic Wealth

Timothy Woodward, Hancock County Schools, Superintendent Bryan Hughes, WOW Danny Scalise II, West Virginia State Medical Association, Stare Medical Association Anthony Jenkins, West Virginia State University, President Kevin Fowler Cabell Huntington Hospital, Chief Executive Officer Mark Morgan, HIMG, Chief Executive Officer

Ryan Morgan, Steptoe \& Johnson, Attorney Rick Boothby, Bowles Rice, Attorney John Norman, FirstEnergy Corporation

Phillip Wright, AEP, Vice President of Distribution Operation Jeremy Hall, Beckley ARH Hospital, Assoclate Administrator

College, President Josh Baldwin, Havenbrook Media, President

Richard Eid, Woodlands Retirement Community Director of Technology Matthew Midkiff, Mardi Gras Casino and Resort, Database Specialist Dale Sparks, All Pro Photography

Greg Elkins, Lincoln Primary Care, Chief Medical Officer Benjamin Moosavi, St. Mary's Medical Center Mark Heitman, Movement Mortgage, Market Leader Austin Pollack, WDTV Anchor/Reporter Weore, MD, OB/GYN Scott Sincoff, WBOY, Meteorologist Larry Mazza, MVB Bank,

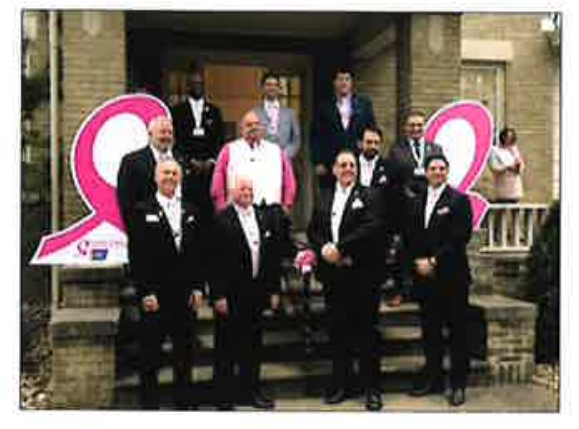

Rob Johnson, State Farm Insurance, Agent Gaston Caperton, Former Governor of West Virginia Dave Zimmerman, Graybar Electric Van Broughton, Mayor of Elkins According to the American Cancer Society Cancer Facts \& Figures 2018, an estimated 266,120 women in the United States will be dlagnosed with breast cancer, and dis 1,700 women will be diagnosed 1,700 women wil be diagnosed the disease. 280 will die from the disease. Breast cancer is the death in women, and it is the mos common cancer diagnosed in women other than skin cancer. "Our community can make a huge impact in the breast cancer cause," added Ellenwood. "We are grateful to our Real Men Wear Pink participants for lending their voices to this cause and fighting for everyone affected by breast cancer." For more information about breast cancer or the Real Men Wear Pink campaign in West Virginia call 1-800-227-2345 or visit www. realmenwearpinkacs.org/WV.

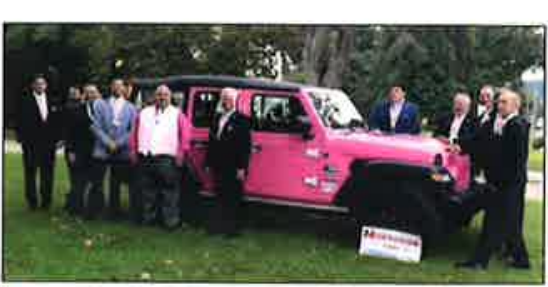




\section{Obituaries}

The WVSMA remembers our esteemed colleagues..

Elena H. Cendana, MD Dr. Elena H. Cendana, 82, of Kanawha City, admired and beloved wife of Jun Cendana for 59 years, passed away peacefully, surrounded by family, on November 10, 2018, at CAMC Memorial Hospital, Charleston, W.Va. Dr. Cendana was born on June 22, 1936, in Manila, Philippines, daughter of the late $\mathrm{Dr}$. Antonio and Salud Hernandez. Elena had numerous strengths, gifts and talents but devotion to family was her priority. Elena is survived was her priority. Elena is survived by hers, Jun Ced hus 59 yours, Juns, A. Brett , M.D., her four wife Trish, Ed.D.) Of Morgantown, W.Va., A. Jay Cendana (and wise Melissa) or Huntinglon, W.Va. A. Ray Cendana, M.D., (and husband Cory) of San Francisco, Call., A. Michael Cendana (and wife Toni) of Dallas, Texas; her brother, Amando Hernandez (and wife Edith) of Cross Lanes, W.Va. many grandchildren and great grandchildren. She was preceded in death by her parents and her younger brother, Freddie Hernandez. Dr. Cendana graduated Cum Laude from the University of St. Thomas in Manila with her Doctorate of Medicine. She completed postgraduate courses in Hematology at the University of Kansas Medical Center and Cancer Chemotherapy and Electrocardiography at New York University.

She was very passionate about her faith and devoted her
Iife to service. She graduated from Wheeling Jesuit University, of Arts in Applied Theology. Dr. Cendana was also involved in that included the American Medica Association, West Virginia State Pastoral Musician's Association. Pastoral My andich's Association. Elena was a foun he Tr-State Fi-AmAssocialion of West Virginia, Kentucky, and Ohio, Board Member of Kanaw Hospice, President and Board Member of Charleston Commun Music Association, Founding Member of West Virginia Real Estate Investor's Association, Director of she started a University approved program towards a Doctor of Ministy Degree), Co-Founder and Vice President of Charleston Montessor School, and served on the Parent Advisory Council for the Kanawha County Board of Education.

You may send condolences to the family at wubarlowbonsal com Lewis Nevin Fox, MD Lewis Nevin Fox, MD, 91, passed away on February 11, 2018. Born March 22, 1926, in Morgantown, West Virginia, and raised in Prenter, West Virginia, he was the son of Benson Earl Fox, who worked as a coal miner, and Marie Nicholson Fox, who Wheeling, W.Va., with a Master's many societies and organizations Medical Associa Vingia Slate Medical Society Philippina Association, and the Natio Community Pastoral Care (where
He graduated as salutatorian of Sherman High School where he played the clarinet in the marching band. He then enlisted in the United States Army and served as a Sergeant for the 76th Infantry in Europe during World War II. After the war he went on to graduate from bre bacts altended West Virghia Universily's medical school, and gradualed

from the Medical College of

Virginia. He interned at Charleston General Hospital (CAMC).

Lew began his medical practice as the physician for Slab Fork Coal Company and shortly after married Shirley Gray Walters in 1957. He then set up a private practice in Mabscott, West Virginia, where he practiced for over 30 years. He was an avid fisherman and lover of big band and jazz music. He is survived by his wife of 61 years, Shirloy: daughter, Evans, and hey, daughter, Lynn randchidren: Crist Ken grandchildren: Christopher Drescher and his wife Abigail, Molly Widney and her husband Evan, Ashley Evans, and Ethan Evans; great grandson, Fox Drescher; and son-in-law, Alan Drescher In addition to his parents, he was preceded in death by his younger sister, Frances Dolores Fox, and his oldest daughter, Nancy Drescher. In lieu of flowers, memorial donations may be made in Lew's memory to the Beckley Presbyterian Church.

\section{Turns out even when you're dying, there can be a lot of living to do.}

We're showing the world how hospice makes more meaningful moments possible for patients, caregivers and families.

See their stories at momentsoflife.org

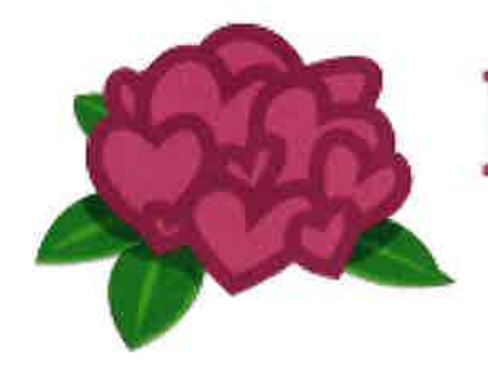
Hospice Council
ofWest Virginia
hospicecouncilofwv.org 
Manuscript Submission Guidelines ORIGINALITY: Articles submit- The criteria for specific article types, ted for publication become the sole i.e., case reports, review articles, property of the West Virginia Medi- and original research, please check cal Journal. Prior publication is un- the full manuscript guidelines on our acceptable. The Publications Com- website at www.wvsma.org. mittee reserves the right to edit any
material submitted Scientific articles material submitted. Scienticanicles ited to 3200 words and approximate are to be prepared in accordance the style adopted by the American with the "Untorm Requirements Medical Association as illustrated in for Submis "JAMA and detailed in the AMA's ManBiomedical Jounnas." Pease go to ual of Style. An abstract of 200 words or less should accompany each AUTHORS: A cover letter from the manuscript, stating the exact quescorresponding author, complete tion considered, the key points with physical malling address Please findings, and the and email submit address, $\left(\begin{array}{l|l}\text { articles to } & \text { conclusion } \\ \text { directly sup- }\end{array}\right.$ should wvmj.scholasticahq.com ported by the be sub- $\frac{\text { There is a one-time }}{\text { findings. }}$ the manuscript. $\$ 10$ fee. VISUALS: No Persons listed as authors more than 5 visuals (tashould have participated sufficiently bles and figures combined).

in the work to take public responsi- REFERENCES: References should bility for the concept No more tha be prepared in accordance to the billy for he concept. No more han be peran Medical Assocition six authors will be listed. Prease in

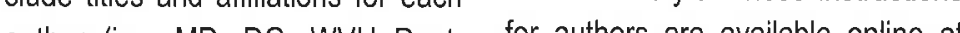
author (.e., MD, DO, WVU Depl. Lum a of Surgery, etc.). A corresponding ww.jama.com. Reterences are to ust be punctuation.

identified. Other contributors may be PHOTOGRAPHS/FIGURES: Submit recognized in an acknowledgement. digital files, which are at least large FORMAT: Submit articles in Micro- enough to fill a 2-3/8 inch space at soft Word and as a PDF. Both files $100 \%$ at 300 dots per inch (dpi). Use should include all elements of the arrows to point to areas of interest. article, in position. This includes RESUBMSSONS: Aultors ae authors with tittes and affliotions, quilod abstract, min atich firues with abstract, al alch to

ences. Additionally, all figures must Revised submissions missing this be allachesente document or response JOURNAL PLATFORMS: The documents which do not address all WVSMA publishes a printed, quar- comments from all reviewers will be terly WVMJ. We also publish case rejected without peer-review. reports online in an Open Access For additional information, contact platform-Scholastica. The purpose of publishing two journals is to enable publication of a larger volume of (304) $925-0342$ peer-reviewed case reports, review articles and original research.
ADD IDIIRRE:CTIOIRIY We Appreciate Your Support!

American Massage Therapy Association...

Bailey Glasser LLP..

CAMC Cancer Center.

Graphoom.

Highmark West Virginia

Hissam, Forman, Donovan, Ritchie

Hospice Council of West Virginia

Marshall University School of Medicine .................... IFC, Back Cover Scott Orthopedic - HELP Wanted

Suttle \& Stalnaker .

Tri-State Occupational Medicine, In

West Virginia Medical Health Professionals Program

West Virginia Mutual Insurance Company..

West Virginia Rx Card .

wvSMa Membership.

wVu School of Medicine .

Please let our advertisers know that you saw their ad in the West Virginia Medical Journal

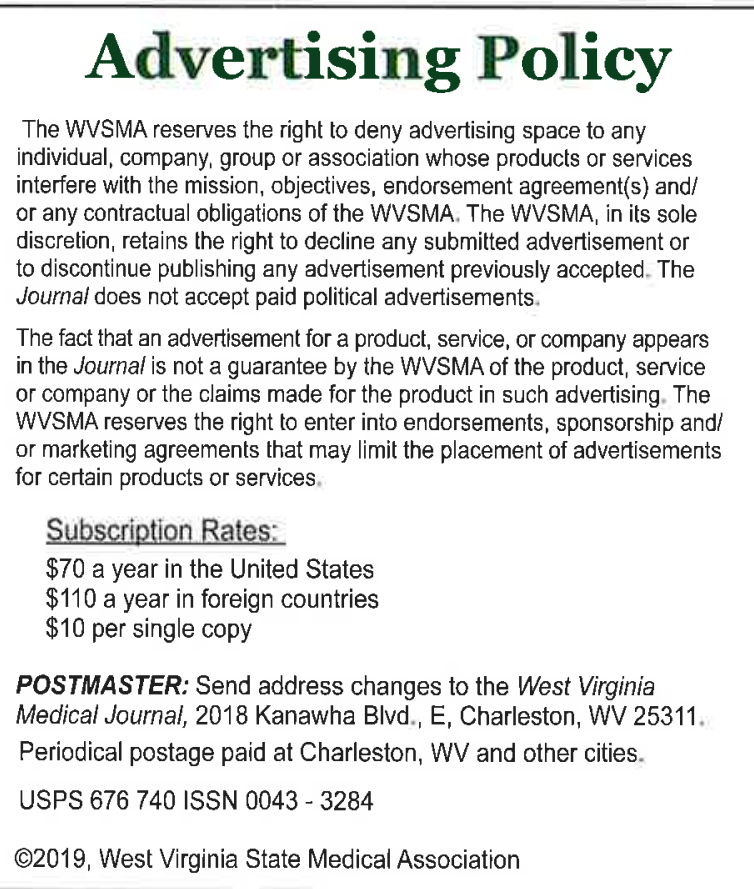

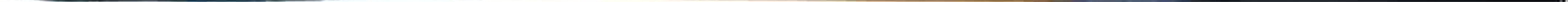


